University of Louisville

ThinkIR: The University of Louisville's Institutional Repository

Electronic Theses and Dissertations

$5-2004$

\title{
A study of technological literacy in writing programs.
}

Katherine V. Wills 1957-

University of Louisville

Follow this and additional works at: https://ir.library.louisville.edu/etd

\section{Recommended Citation}

Wills, Katherine V. 1957-, "A study of technological literacy in writing programs." (2004). Electronic Theses and Dissertations. Paper 1580.

https://doi.org/10.18297/etd/1580

This Master's Thesis is brought to you for free and open access by ThinkIR: The University of Louisville's Institutional Repository. It has been accepted for inclusion in Electronic Theses and Dissertations by an authorized administrator of ThinkIR: The University of Louisville's Institutional Repository. This title appears here courtesy of the author, who has retained all other copyrights. For more information, please contact thinkir@louisville.edu. 


\title{
A STUDY OF TECHNOLOGICAL LITERACY IN WRITING PROGRAMS
}

\author{
By \\ Katherine V. Wills \\ B.A, Washington University, St. Louis, MO, 1979 \\ M.A., Indiana University, Bloomington, IN, 1991
}

\author{
A Dissertation \\ Submitted to the Faculty of the \\ Graduate School of the University of Louisville \\ in Partial Fulfillment of the Requirements \\ for the Degree of
}

Doctor of Philosophy

Department of English

University of Louisville

Louisville, Kentucky

May 2004 
Copyright 2004 by Katherine V. Wills

All rights reserved 


\title{
By
}

\author{
Katherine V. Wills \\ B.A., Washington University, St. Louis, MO, 1979 \\ M.A., Indiana University, Bloomington, IN, 1991 \\ A Dissertation Approved on
}

\begin{tabular}{c}
$\frac{\text { April 12, 2004 }}{\text { (Date) }}$ \\
by the Following Reading Committee: \\
\hline Pamela Takayoshi \\
Dissertation Director \\
\hline Brian Huot \\
\hline Joanna Wolfe \\
\hline Beth Boehm \\
\hline Richard Selfe
\end{tabular}




\section{DEDICATION}

This dissertation is dedicated to my parents Vasilios and Kalliope who instilled in me a love of learning;

and to Howard, who encouraged me to be patient, have humor, and maintain a healthy perspective on the limitations of information. 


\section{ACKNOWLEDGMENTS}

This dissertation is a collaborative effort.

I would like to especially thank my dissertation director, Dr. Pamela Takayoshi, for her guidance and patience for offering thoughtful, extensive, and honest responses to my drafts. She insisted that I write this dissertation as book; her vision of the possibility of my work surpassed my own vision for a long time.

I would also like to thank the committee members Dr. Beth Boehm and Dr. Brian Huot for their contributions. Dr. Joanna Wolfe provided inestimable guidance with methodological framing; I hope to continue to work with her and learn from her in the future. Pam Takayoshi suggested I ask Dr. Richard Selfe as my fifth reader. His suggestions for online data collection significantly improved final product. I cannot forget to thank the consultants at the IUPUI Office of Professional Development: Heather Eaton, Jon Eynon, Tom Jenke, Nicole Johnson, and Kashy Valiyi.

Unqualified thanks goes to my husband, Howard, for his encouragement of my personal and scholarly growth. His support is nonpareil. 


\section{ABSTRACT \\ A STUDY OF TECHNOLOGICAL LITERACY IN WRITING PROGRAMS \\ Katherine V. Wills}

April 23, 2004

This dissertation empirically studies computer-assisted writing administration as a site of agency for social change by inquiring how writing program administrators (WPAs) use their agency and power when developing and maintaining computer-mediated spaces (CM) or computer-assisted instruction (CAI). This study asks, What are the results when individual agency meets technological literacy in the academic workplace? Numerous articles have examined WPAs as agents of social change (R. Miller, C. Selfe, M. Pemberton); few have used empirical data as their grounds. To date, no articles have examined the WPA's agency with technological literacy in computer-mediated environments. This study utilizes triangulated and multi-modal research methods including site observations as well as interviews and email surveys with WPAs, students, technicians, and non-departmental stakeholders. The study assumes that WPAs act as administrative agents who use their agency to move beyond the role of functionaries such as "boss compositionists" (Sledd in Harris, 2000) or 
academic bureaucrats (R. Miller, 1988). Special features of this dissertation include original primary data on WPA decision-making, education, compensation. Preliminary data show the following: WPAs report using their agency when managing technology use for departments and institutions; 70 percent of WPAs report that their technological literacy affords them power in their departments; 70 percent of WPAs state that their technological literacy has improved their relations with students; most WPAs receive little compensation for their technological skills other than salary; and search and screen committees increasingly require technology proficiency of their writing faculty. WPAs should take into consideration managerial trends: faculty who resist CAI professional development because they are in the "retirement track"; arguments that position CAI as a Technology vs. X false dilemma ("We can support either labor and people or technology"); assumptions that link technology with democracy and unexamined grand social narratives; and the conflation of technological literacy with critical technological literacy This data suggests that job skills and intellectual contributions of WPAs who work with CAI are not fully recognized and compensated in departments and contribute to a rise in invisible labor. The dissertation includes the following chapters: I. Introduction: Shoulders to Stand On and the Work Already Done in Computer-Mediated Writing; II. The Discourse on Technological Literacy: A Bakhtinian Reading of the National Infrastructure Initiative; III. What WPAs Say about Their Work as a Site of Agency; IV, Results from Online Survey of WPAs and Technological Literacy; and V, and Conclusion and Supplementary Materials. 
TABLE OF CONTENTS

DEDICATION

PAGE

ACKNOWLEDGMENTS

iv

$\mathrm{v}$

ABSTRACT

LIST OF FIGURES

vi-vii

$\mathrm{x}$

I. INTRODUCTION: SHOULDERS TO STAND ON AND THE WORK ALREADY DONE IN THE ADMINISTRATION OF COMPUTER-MEDIATED WRITING

CALL FOR EMPIRICAL STUDIES IN TECHNOLOGICAL LITERACY: CYNTHIA L. SELFE AND RICHARD SELFE

WRITING PROGRAM ADMINISTRATION AND AGENCY

II. THE DISCOURSE OF TECHNOLOGICAL LITERACY AND WPAS: A BAKHTINIAN READING OF THE NATIONAL INFRASTRUCTURE INITIATIVE

BACKGROUND ON THE AGENDA for ACTION:

NII AND GII INITIATIVES

HISTORICAL PRECEDENT FOR THE AGENDA

BAKHTIN, WRITING, AND TECHNOLOGY GRAND NARRATIVES

CONTEXTS FOR HETEROGLOSSIA

AUTHORITATIVE WORD AND THE PROMISE (INEVITABILITY OF TECHNOLOGY)

DEMOCRACY AND SELF-INTEREST

AUTHORITATIVE DISCOURSE

CENTRIPETAL/CENTRIFUGAL FORCES AND

TEXT ANALYSIS 
III. SITE INTERVIEW RESULTS: WHAT WPAS SAY ABOUT THEIR WORK AS A SITE OF AGENCY

METHODS

UNIVERSITY OF MIDDLE EARTH

71

UNIVERSITY OF NORTHWOODS

78

SOUTHERN HARBOR UNIVERSITY

85

GREEN VALLEY UNIVERSITY (GVU)

95

IV. ONLINE SURVEY OF WPAS WHO USE TECHNOLOGY 100 ONLINE SURVEY METHODS 100 BENCHMARKS AND NATIONAL TRENDS 103

TURF, POWER, AND SOCIALITY IN CAI 104

DISCOURSIVE ISSUES: USE OF "POWER" 110

$\begin{array}{ll}\text { SECTION TRENDS } & 118\end{array}$

V. SUMMARY AND RECOMMENDATIONS 124

SUMMARY 124

RECOMMENDATIONS 132

$\begin{array}{ll}\text { REFERENCES } & 139\end{array}$

APPENDICES

A. HUMAN SUBJECTS- INFORMED CONSENT 155

B. WPA PROPOSAL $2001 \quad 157$

C. SAMPLE OF THE SITE SURVEY TRANSCRIPTION 163

D. AGENDA FOR ACTION 166

E. FLASHLIGHT $®$ ONLINE SURVEY SAMPLE 181

$\begin{array}{ll}\text { CURRICULUM VITAE } & 187\end{array}$ 


\section{LIST OF FIGURES}

FIGURE

PAGE

1. How WPAs Have Challenged Hierarchies

20-21

2.

A Bakhtinian Frame to the Research Data

3.

Technology vs. People

74

4. Survey Question "I have difficulty..."

106

5.

Survey Question "My department ..."

6. Survey Question "In my department..."

7. Survey Question "People outside my department"

8. Survey Question "I have had conflicts..."

9. Survey Question “...[W]e have had issues...”

10.

Survey Question "Using Technology-social ..."

11. Survey Question "Using technology-personal..."

12. Survey Question "I plan to increase..."

13. Survey Question "Participating in business...

14. Effort Put Into Technology-Related Initiatives

15.

Social Effects of Teaching with Technology

16.

Academic Labor and Technology

17. Students and Writing with Technology

18. Romance and Reality of Technology 


\section{CHAPTER I \\ SHOULDERS TO STAND ON: \\ THE WORK ALREADY DONE IN THE ADMINISTRATION OF COMPUTER-MEDIATED WRITING}

Since the late 1980s, scholars of computers and writing instruction have published articles focusing on the administration of computer-mediated (CM) or computer-assisted instruction (CAI) for students, faculty, and staff in their production of student writing. Many of these articles have focused on start-up considerations such as selecting hardware, software and determining program objectives (C. Selfe, 1989; Harris et al.1989; Harralson, 1992; Hawisher, 1994; Taylor, 1996).

Cynthia L. Selfe and Gail Hawisher together and separately call for the field to pay attention to critical technological literacy and more empirical research, concerning the administration of computer-supported writing environments. Selfe calls for a critical technological literacy in Technology and Literacy in the Twenty-First Century (1999): "We have seen the twin strands of technology and literacy woven into the fabric of our lives... we need to reconsider this national 
project in relation to our own work as literacy educators and citizens and in relation to our hopes for America's future" (160-61). Hawisher calls for more empirical research into technology and writing at the 2001 Writing-Across-theCurriculum Conference (Bloomington, Indiana) and in the article she co-authored with Janet Eldred in Written Communication (1995). Richard Selfe concurs: "There are few enough of us interested in this topic [research on the WPAs' agency and administration of CAI spaces], unfortunately" (personal communication on January 3, 2002). Richard Selfe is correct in his assessment of the field given the dearth of published scholarship on the administration of computer-mediated classes.

The lack of empirical research in issues of administration can limit growth and adaptation to better modes of writing with technology. Hawisher and Ericsson note that composition programs, in general, have neglected to respond to visual and multimodal approaches to composition. Rather, writing programs perpetuate historical methods of writing instruction by privileging former methods that situate the study of literature and the academic "paper" at the center of pedagogy (“Stasis" 269).

Cynthia Selfe's call for empirical research specifically addresses examining issues of critical technological literacy: a study of socio-economic factors that influence computers and composition ( $\underline{C C C C}, 1998)$. She defines technological literacy as a "complex set of socially and culturally situated values, practices, and skills involved in operating linguistically within the context of electronic environments including reading, writing, and communicating. The term refers to 
the linking of technology and literacy at fundamental levels of both conception and social practice" (Technology and Literacy 11). She notes four cultural forces that contribute to technological literacy: government, business, education, and parents (Technology and Literacy xxii). Selfe situates her discussion, in part, in the social power and administrative action of the National Infrastructure Initiative (NII) and the Global Infrastructure Initiative (GII) for technological literacy, which the Clinton-Gore administration formally launched in 1996. The NII and GII herald the technologizing of the American populace through the educational system.

The responsibility for implementing technology and writing in higher education falls (in part) on writing program administrators (WPAs) and the computer-mediated classroom. Depending on the institution, the responsibility sometimes falls to departments or areas outside of college English such as Integrated Technology (IT) departments or the students themselves. Where implementing technological initiatives is the responsibility of WPAs, they often find they are complicit—consciously or unconsciously-in what Selfe sees as the objectives of unreflective technoligization, or using technology for technology's sake without concern for the human and social impact. In some cases, the use of technology reflects a genuine interest of the WPAs; in other cases, the push for technology is a reflexive action of uncritical technological application. C. Selfe's concept of technological literacy relies upon the goals and aims of the national infrastructure project to expand technology use (Technology and Literacy 10). 
Selfe's concept of critical technological literacy entails a refinement of technological literacy that took into account not only "paying attention" but also actively pursuing change in technological environments. Attention should not be drawn away from the reality that a technology agenda supports "social divisions along race, class, and gender and keeps us from fully understanding the complexities of literacy values and practices and from defining literacy instruction in ways that could help address some of these problems" (xxi).

The concepts of technological literacy and critical technological literacy play a significant role in this study and need to be further refined. Depending on the speaker or reader, the concept of technological literacy can mean anything from booting up a computer to coding programs. Selfe's critical technological literacy as she expands it in Technology and Literacy in the $21^{\text {st }}$ Century carries an assumption that technology should be examined for the effects it has on society, its economic roots, and its consequences to people. Additionally, critical technological literacy implies moving beyond academic or theoretical discussion to activism. This study seeks to document what WPAs do concretely as technology administrators, as well as learning about their feelings and thoughts.

The term "technological literacy" has a broad range of meanings. To some it might mean that they use email and can surf the web. The term critical technological literacy as introduced by Selfe, however, has distinctly social and economic overtones that direct theory and practice. Technological literacy can be a set of tasks. Critical technological literacy entails values. These values provoke inquiry. Users question the ultimate benefit or good of technology in society. In 
this study, technological literacy means the mechanical skills or training to use computers at a basic level. Critical technological literacy means the examination of technological applications as they relate to social contexts and consequences. In other words, those who possess technological literacy might only know how many computers are in a room; those who apply critical technological literacy seek to know who has access to available computers. Furthermore, those with critical technological literacy might take action to remedy inequities in access, if they exist. Those with technological literacy ask what the most efficient software for a given task is; those using critical technological literacy want to know what the inherent biases of one software program over another are. Those who approach technology with a critical perspective pay attention to social, political and economic contexts.

C. Selfe notes these possible sites of critical attention: computer-supported writing (149), professional organization, scholarship and research (151), and coalitions (159). Specifically, she asks that critical technology users and managers heed these considerations:

- Pay attention to local and specific knowledge as they inform the technology-literacy link (149).

- Reflective on and be aware of cultural and social phenomena that operate within the context of electronic environments.

- Pay attention to the political in applications of technology (148).

- Consider computer-supported writing facilities as sites of critical praxis (154). 
Like C. Selfe, Edward M. White recognizes that WPAs should no longer wear blinders regarding the confluence of technology with their administrative work. White raised concerns about the social repercussions in writing programs when WPAs are not cognizant of their agency: “... power and the various uses of power are centrally important to most WPAs—but most of them are not only unaware of the fact, but resistant to it because of its too close association with Administration with the capital "A"” (108). White concludes that WPAs "... cannot afford the luxury of powerlessness" (113). White and C. Selfe question the nature and uses of power and literacy. At the social level, how do WPAs (mis)use power?

In recent dissertation work at the University of Louisville (2000), Morgan Gresham examines the administration of computer-mediated technology from a feminist "snapshot." Gresham questions "how and why technology is incorporated" by WPAs while redrawing the boundaries of power relations and student learning (6). She surmises: "Administration is central in understanding and navigating this new computerized landscape because administration provides the systemic approach to theories and practices across systems" (6). Gresham then states, "It is important that we remember that technology is a catalyst that has the potential for agency: it changes the way we work and the power relations inherent in our work" (148). Gresham argues that a greater awareness of decision-making and power, or the application of power in the form of agency, by WPAs and directors of technology programs would alert them to unexamined administrative or pedagogical assumptions. 


\section{New Work of this Study}

Much of the research in this dissertation centers on the agency in writing programs that use technology by examining the contact zone between information technologies and power in social organizations. How does incorporating and managing computer technology in writing programs influence the social practices of writing departments and vice versa? This research study will achieve a more nuanced understanding of the roles of WPAs by collecting and analyzing data on the intellectual, labor, and activist contributions WPAs make to the field of computers and writing. The audience for this study includes WPAs, participants in tenure and promotion committees, graduate students considering administrative positions, IT support staff, technology purveyors, trustees, and university and community stakeholders.

I investigate and research these three these claims:

- WPAs often act as administrative agents as they apply theory and practice to influence the material conditions of writing technologies and labor.

- WPAs can determine the content and conditions of the teaching of writing.

- WPAs may contribute new knowledge as administrators and not necessarily replicate extant hegemonic bureaucracies.

The following research questions build upon the claims above. The questions seek to identify the processes by which WPAs function as administrative agents and create new knowledge when administering CAI writing spaces: 
- When can WPAs say they felt they were agents of change and power within their institutions? What is the evidence? What were the costs and outcomes?

- What concrete accomplishments can WPAs point to that illuminate their theoretical beliefs with their CAI practices?

- By what means and methods do WPAs express their agency?

- What external and internal factors influence WPAs' decision-making processes?

- What historical forces have influenced the administration of the composition classroom?

While researching these questions, I simultaneously fill in the gaps in this under-researched area of computer-mediated writing program administration as a site for agency and social change. How have individual WPAs used their agency when managing computer-supported spaces?

The central objective of this study is to examine the hypothesis that WPAs act as administrative agents, or administrators who have individual agency to act on their own beliefs and not as appendages to higher administration. I want to find out if WPAs implement technology with an eye towards Selfe's desire for social change through technology. Also, I would like to know how WPAs put their agency into action. Agency may take on various meanings depending on how a WPA defines and actualizes his/her power. Agency may be asserted by passive resistance to technology, as well as by active participation with technology. I seek to diminish the notion prevalent in some composition literature that WPAs have 
difficulty actualizing their agency beyond their roles as functionaries such as "boss compositionists" (Sledd as qtd. in Harris 2000) or academic bureaucrats (R. Miller 1998). To summarize Sledd, "Boss compositionists" react to the managerial needs rather than act out of personal vision or agency toward goals. They do not create new knowledge, but only reproduce existing academic hierarchies. "Boss compositionists" primarily align themselves with the managerial class of the academy, not with their students, disciplines, or colleagues. The notion of agency for a "boss compositionist" hinges on efficient implementation of rule-governed behavior in the management of labor before attempting the critical examination of power.

What is an administrative agent in the context of this study? Administrative agency is a condition in which an individual is in a position, more or less, of authority and power to influence student learning, curriculum, hiring decisions, workload decisions, workplace conditions, promotion and tenure, and related administrative obligations of a department. Administrators who manage CAI sites along with their routine writing program duties arrive at these positions both by happenstance and planning. In either case, they exert their own agendas when managing CAI sites; they act as administrative agents towards change. They do not see themselves as a rubber stamp for administration. WPAs act as liaisons between the community, their institutions, and their departments, teachers and, students; however, they bring to their administrative positions personal visions that are often unrecognized by their colleagues. 
For example, my pilot research surveys and interviews (see Appendix C) suggest that WPAs and directors of CAI are influenced by their personal prioritization of technology use combined with writing - they act as agents for change and they can point to specific changes in their institutions or departments to support their use of power. The following incidents gathered in my research point to the idea that administrative agency is persistently at work within writing programs. One WPA lobbied her dean of Arts and Sciences for years before receiving funds for more computers in the writing program. Another WPA produced unsolicited annual reports of CAI needs for higher administration in order to garner funding. Yet, another WPA heeded graduate student requests for more computer resources. Admittedly, WPA agency is often constrained by local conditions. Different institutions exert more or less control over these areas. An administrator or WPA may or may not use his/her agency, or may have limited authority. In any case, the power to influence or make decisions in an administrative capacity is a function of administrative agency.

The dissertation includes the following chapters. Chapter I. "Shoulders to Stand On and The Work Already Done in the Administration of ComputerMediated Writing," orients the readers to the research questions on technological literacy and the organization of the dissertation. I introduce the arguments for the importance of empirical study on writing program administration and technology, so that WPAs can have a snapshot of how WPAs exercise their agency in order to teach writing better with technology. I introduce readers to key texts and concepts from the overlapping literatures of Computers and Writing and Writing Program 
Administration. I also include articles that track the evolution of digital technology from its historical roots in Cold War technologies and Arpanet. This section is relevant because it analyzes the rhetoric of technology as it has evolved to serve the needs of those in power at given moments. I use this historical perspective as a comparative example for how teacher and administrator agency has been previously influenced in the classroom. The role of the WPA is situated within a historical continuum. Chapter II, "The Discourse of Technological Literacy and WPAs: A Bakhtinian Reading of the National Infrastructure Initiative's (NII)" makes a unique rhetorical move by framing empirical research data through a soviet social constructionist Baktinian framing of language. Using Bakhtin, I compare how the U.S. government built its case for technology use through the Agenda for Action in 1996 and how the government has built its case for public mandates historically. Even empirical data is, to a degree, a fiction created through discourse. I make my arguments by the examining the rhetorical power of the qualitative and quantitative data through a Bakhtinian frame. I rhetorically read both the qualitative and quantitative data with a Baktinian frame. Empirical data is used to create a "fiction" about technology in order to influence others. As in cultural studies perspectives of technical writing, data is not objective; it does not defacto speak for itself. It is as subjective as its selection and application process-it can be read as persuasive literary event. Chapter II shows how WPAs' work can be understood through Bakhtin's notions of language: passive and resistant language, centrifugal/centripetal forces, unitary and divisive discourse, heteroglossia, and other analytical tools. Bakhtin brings to light how 
power and agency surrounding administration and technology have been constructed in the study of technology and writing program administration. The Bakhtinian frame of Chapter II contextualizes the data from the site visits described in Chapter III and the survey of Chapter IV as WPAs appropriate the language and ethos of socially constructed notions of technology.

Chapter III, "What WPAs Say about Their Work as a Site of Agency," reports on the results of the four site visits. This data is examined through the Baktinian framing of Chapter II. Readers are informed about the rationale and methods used to collect data from four writing programs that use technology. Chapter IV. "Online Survey Results of WPAs Who Use Technology" reviews quantitative data gathered from a national survey of WPAs regarding their experiences with technology and writing. Chapter V, "Conclusions and Recommendations in Technology and Literacy" summarizes the data of the previous chapters. It then provides closing arguments that CAI needs more research in order to make and practices visible. With this visibility, the WPAs' goals and outcomes for student writing with computers and critical technological literacy are better served than if WPAs manage programs with untheorized and unreflexive practice. WPAs' agentive practices significantly affect student learning and the direction of Writing Program Administration inside and outside academia. The References and Appendices are included after Chapter Five. 


\section{The Call for Empirical Studies in Technological Literacy}

Cynthia Selfe calls not only for a critical technological literacy as mentioned earlier, but also for more empirical research into technology (Selfe and Eldred 1995\}. At the 2001 Writing-Across-the-Curriculum Conference (Bloomington, Indiana), Gail Hawisher urges the attendees to apply more empirical methods in their work. As early as 1989, Harris, George, Hult, and Killingsworth express concern for the need to correlate administration and technology in Writing Program Administration. The authors state, "The computer is most useful when it is part of a sophisticated, comprehensive program of instruction that is designed by writing program administrators who know how to put sound writing theory into practice" (42). Harris et al. further observes, “. . . one constant factor in dealing with computers is change. As writing program administrators, we must try to keep informed of the changes and to react appropriately to them" (41). Yet, seven years later, Todd Taylor reaffirms that, even with the introduction of the Internet into the composition class and additional responsibilities, WPAs' technological work is under-analyzed in the field. Ed White gave a nod to the difficulty of collecting information from writing programs: "It is not easy to discover what is going on, or why, in any college writing program. The research describing these programs is surprisingly constricted" (E.M. White as quoted in Gale 42).

In 1996, Todd Taylor notes this gap in Writing Program Administration ("Update" 7) by observing that the journal published zero articles about administrative developments in computers and writing between 1990 and 1996. 
During the same time period, the other journal in which we might expect consideration of CAI administrative development was Computers and Composition. A hand search reveals no articles specifically focusing on the administration of computer-mediated environments.

A review of Writing Program Administration: Journal of the Council of Writing Program Administrators provides only articles that might focus on writing technologies at the intersection of writing program administration Herzberg 1983; Harris et al.1989; Taylor 1996; and Himley 2003). The 1983 Herzberg article is intriguing simply because it introduces Writing Program Administration readers to word processing as a "powerful writer's tool" and alternative to handwriting. By 1989 , Harris et al. forewarns writing administrators that computers and computer facilities must be informed by sound pedagogical theories. Many of the scholars who focused on start-up issues have within the last ten years focused on the administration of computer-supported writing environments as sites of technological literacy and Writing Program Administrator's (WPA) agency (Taylor, 2002; C. Selfe, 1999; D. Selfe, 1997; Hult, 1995).

Richard Miller suggests that WPAs and their work should not be understood narrowly in context of the materiality of their work or as being limited to the margins of the academy. Instead, WPAs should be at the center of administrative consciousness and action. They should seek positions of agency in higher education. Yet, so much of what WPAs do, especially those who work with technology, is to manage the materials and the material conditions intrinsically 
linked to student writing and labor. Miller and Strickland (2001) argue that composition curriculum, computer-mediated or otherwise, is an outgrowth of the nature of the workforce of graduate students and itinerant workers. Composition's strength as a discipline and a political force comes from its institutional position as "the place where first-year students....are collected together" ("Wasteland" $35)$.

In additional to labor issues in administration, Miller describes the social implications to students, administrators, and teachers when using information technologies? According to Miller, thinking like an administrator can lead WPAs to the following:

- An awakened sense of what role composition might play in the evolving university allowing the discipline to change effectively

- Preservation of what is valued about the composition classroom

- Recognition of the local and national, institutional, and pedagogical expectations of workers and students

- Enhancement and understanding of WPAs' image of themselves and their work in the field

Miller argues that administrators should be comfortable with their roles as "bureaucrats" as they examine both the local narratives of individual teachers and the extant master narratives that guide the field of the (Wasteland 29). Composition has spawned its narratives in the form of "veteran stories on the porch" (Faigley 28), North's lore, and adjuncts tales of freeway flyers. This dissertation examines the technology narratives viewed through a Bakhtinian lens 
of grand narratives. WPAs perpetuate familiar generalizations (narratives) that technology encourages democracy and that technology levels the playing field regarding gender and race issues.

In Terms of Work for Composition, Bruce Horner argues that pedagogies of student writing function as "material social practice in which structure and agency meet" (244). He cogently argues for the need to think about composition as a set of intellectual and material practices in which materiality and socioeconomic conditions contribute to writing instruction (xviii). Like Cynthia and Richard Selfe, White, and Miller, Horner traces material practices to class interests (xvi). Horner posits that in order to reveal the reproduction of "unjust social relations," those arguing for adopting particular academic institutional forms must document their official purposes, origins, features, or effects. However, in so doing, all these arguments ignore the contingencies of material history (121). What is "official" for WPAs, then, often does not spring from WPAs' agency; rather, it is, to a degree, a purpose or feature of institutional bureaucracy. This directly relates to Selfe's plea for more critical literacy that does not stand primarily on what is "official." Instead, the WPAs with an interest in the social consequences of their labor (especially with technology in this case) should keep an eye towards the social. Similar to Horner, Selfe's address (1998) insistently asks that we question the uses of administrative decision-making regarding technology use and its socio-economic ramifications. According to Selfe's reading of the National Infrastructure Initiative (NII), the impetus for CAI began in K-12, extended to higher education and beyond, and arose from the ideological assumptions that the 
"fruits of scientific effort (technology) will yield a better world for the human species (progress)" (Technology and Literacy 115). The assumption that technology will yield a "better world" underpins educational objectives and outcomes to which most WPAs are bound; however,

Richard Selfe, too, examines the intersection of technological literacy and administration in his dissertation, "Critical Technical Practices in and Around Technology-Rich Communication Facilities" (1997). He brings to light the WPAs agency-power. In his dissertation, R. Selfe argues that WPAs and those in power (WPAs?) who use technology must see its critical applications for students and learning. Technology should not just used for distance education, games, and organizing data. Technology must be used for broad social projects: "If we retain our traditional, narrow focus on the technology itself or even the instructional possibilities associated with the technology, it does not bode well for the development of a citizenry capable of the critical, humanistic assessment of technological ..."(6).

Similar to R. Selfe's concern for the motives and outcomes of technology use, the WPAs in a thread on the composition listserv, WPA-L, had concern for critical understanding of their own relation to technology. In this listserv discussion during December 2000, list members focused on the comparative demographics of lab administration: class size, room styles, technology uses, and other material uses.

More important, the listserv discussion reveals the interest of a cohort of scholar-researchers seeking answers to social and critical issues. Sean Williams of 
Clemson University posted a research study in order to gain a more comprehensive understanding of technology management and teaching of writing (2001). Anthony Atkins of the Ball State University is conducting research on the role of graduate students in the administration process (2003). Studies of ergonomics, software applications, and information-driven studies will take their place next to more research on the human ramifications of technology in writing program administration, thus, producing more information about the consequences of technology and writing.

In "Envisioning Literacy: Establishing E-Mail in a First-Year Program," Beth Daniell emphasizes the importance of narratives from WPAs about their experiences with technology at Clemson. Her narrative can also be seen as a type of thick description from the field:

One day on the WPA listserv, someone wrote that there is no evidence demonstrating that computers make people better writers. But in order to write at all in the future, this WPA said, the students we are teaching today are going to have to be able to use electronic technology... This comment helped me see the computer as a part of the always-changing-over-time definition of literacy. (160).

In preliminary, informal investigations about technology and writing program administration, composition scholarship found that teaching writing with technology is increasingly common (Faigley; Hawisher and Selfe; Hawisher, LeBlanc, Moran, and Selfe). Simultaneously, WPAs increasingly face mandates from administration and others (students, boards of regents, accrediting agencies) 
that they use more CAI in writing classes (Selfe, Takayoshi). These mandates and initiatives from higher administration often directly affect the degree and nature of the work that WPAs do. Specifically, WPAs are expected to produce results without access to methods or data about how to proceed while lacking a picture of the broader context of writing instruction and writing technologies. They are expected to increase student retention and recruitment by offering online course delivery systems. The ability of distance education to retain students is still scant. WPAs are expected to meet the diverse pedagogical and material needs of teachers: writing and literature, full-time and part-time, tenured and adjunct. With that may not be the best more research into writing programs and technology, WPAs can have more information on how to best teach writing while being actively and reflectively aware of their own agency and how it is used.

\section{Writing Program Administration and Agency}

During the past ten years, a plethora of investigations and theorizations on WPA subjectivity and writing program administration has increasingly filled the intellectual coffers of composition and rhetoric journals (WPA, JAC, $\underline{\mathrm{CCC}}$, Composition Studies) and collections (Anson et al. 2003; Rose and Weiser, 1999 and 2002; Brown and Enos, 2002; Ward et al. 2002; Crowley, 1998; Cambridge and McClelland, 1995; Jananjelo and Hansen, 1995). Additionally, journals in technology and writing, institutional critique, theory, labor (Computers and

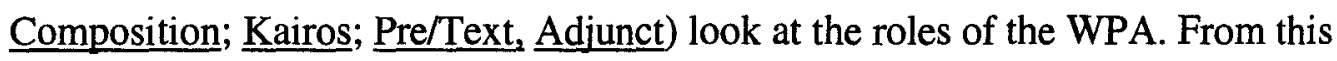
interest, some scholars have imagined theories and practices to aid WPAs 
(Popham et al.; Burnham). Some point to the essentially ideologically and politically embroiled WPA (Gunner). Others call for more research or exploration of the WPAs subject position (Gale; Cain and Kalamaras). This section culls articles and chapters that, to varying degrees, discuss the WPA as agent. No text denies WPAs' close relations to management; however, some authors see tacit complicity, others see progressive actualization, and others see resistance.

In "Breaking Hierarchies: Using Reflective Practice to Re-Construct the Role of the Writing Program Administrator," Popham, Neal, Schendel, and Huot describe their use of reflective practice and encourage WPAs to “...break traditionally concretized hierarchies in their programs" (20). The authors base their practices, in part, on Donald Schön's theories of reflective practice. Figure 1. shows how the authors' administrative practices utilize reflective practice.

Figure 1. How WPAs Have Challenged Hierarchies in Popham et al.

\begin{tabular}{|l|l|}
\hline $\begin{array}{l}\text { Curricula and course } \\
\text { development }\end{array}$ & $\begin{array}{l}\text { Experienced teachers may design } \\
\text { own courses or select textbooks (24) }\end{array}$ \\
\hline Social interaction with & $\begin{array}{l}\text { Spontaneous, ongoing conversations } \\
\text { in the academic workplace and out } \\
\text { colleagues }\end{array}$ \\
\hline concerning are encouraged (22) \\
\hline Professional & Teachers free to "enact' disciplinary \\
& knowledge in the writing program \\
& (23) \\
\hline
\end{tabular}




\begin{tabular}{|l|l|}
\hline $\begin{array}{l}\text { Professional } \\
\text { development: Student }\end{array}$ & $\begin{array}{l}\text { Integrate reflective practice theories } \\
\text { into graduate student instruction (25) }\end{array}$ \\
\hline Pedagogy & Teachers free to reformulate styles \\
& $(26)$ \\
\hline
\end{tabular}

Many WPAs express their desire for democratic departments operating from egalitarian and progressive missions; however, the same WPAs will cite the need for a standardized student experience as a core reason for common readers, common syllabi, common assignments, and common grading dates, leaving few avenues for the changes that reflection might bring.

Christopher Burnham situates his agency most directly in the uses of assessment: "To me, assessment means more than determining what ought to be listed in a strategic plan...[rather] whether students are learning what we claim to be teaching... whether what we are teaching is worth teaching... [what is] the best approach to helping students becomes learners and writers..." (Burnham in Brown and Enos 304). Burnham shares administrative stories and strategies of colleagues who applied their agency on the job trying ways in which WPAs' agency can be actualized in assessment:

- Accept power; use it or lose it.

- Practice reflective thinking.

- View self as a professional.

- Use rhetorical power to influence stakeholders.

- Engage various audiences (304). 
Jeanne Gunner's "Ideology, Theory, and the Genre of Writing Programs" describes writing programs as an essentially "formalist" genre constrained by its managerial roots (Gunner as qtd., in Rose and Weiser Theorist 15). Gunner posits from a postcolonial subjectivity that the WPAs must negotiate their agency from the "converging discourse of the two spheres of critique and administration. And, thus, is the agentive power of the individual WPA contained. However messianic, the individual voice cannot speak outside the terms of exchange..." (163). In other words, Gunner is saying that WPAs should transcend staid hierarchical imperatives by practicing "altering practices," not merely theorizing in the abstract.

Gunner hopes for WPAs to increasingly act as "agents of change" at the local level. Gunner concedes that her "agency" as a WPA in Silicon Valley remains intrinsically linked to the discourses of "entrepreneurialism and vocationalism." Then, again, Gunner also concedes that she has a possibility for agency:

We know that we must design means of resisting a vocationalizing of the program by tying rhetorical theory to the flexibility required in contemporary workplaces, for example, establishing a functional claim for the curricular elements that are most at risk if challenged by a discourse of functional preparation in the 'real world. (17).

In Journal of Advanced Composition a few years earlier, Gunner cites the WPA-sponsored Portland Resolution (1992) as a type of job description that negated the political role of the WPA, while concentrating on "vocationlism," especially in the context of basic writing. Gunner notes that the resolution focused 
on duties of WPAs such as the selection of textbooks, scheduling, and placement of mailboxes (158). Gunner seems to draw on ideas from Dewey's time on the role of higher education in the "public interest." By implication, the WPA has a social or critical responsibility. Yet, WPAs' agency is fettered, Gunner argues, by at least these disciplinary archetypes:

- Subservient to a literature hierarchy

- Identified with remedial and service education

- Invisible in the discourse of power, though informed by it

- Considered atheoretical by many outside the field

Irene Gale argues (like Selfe and Hawisher) for more research into the work of the WPA. More research would assist WPAs to understand the intra- and interinstitutional contexts from which they operate. Gale summarizes several studies in which administrators possessed only a "tacit" understanding of the writing and teaching paradigms in their departments. More scrutiny by WPAs into institutional practices would bring to light possible ambiguity in administration direction that undermines effective student leaming.

For example, Gale cites the Polin and White California study that found that students "write better" when a writing program has one WPA rather than multiple co-coordinators (45). Such findings offer rich opportunities to examine causes, contexts, warrants, claims, and methodologies that produce such results.

Cain and Kalamaras uses two WPA narratives as research "evidence" (Geneva and Steve) as heuristic tools to discover the complexities of professional identity and agency. Geneva moves into a full-time lectureship but is conflicted 
by her appreciation for the taste of this "privilege" versus the pressure to compete and "talk about her teaching in authoritative and reflective ways" (47). Steve feels conflicted by his director's treatment of him "as an apprentice requiring special training and supervision" (50). How can the WPA instill agency when much of the ongoing professionalization of staff in the discipline seems to instantiate composition and rhetoric as less than a full-fledge discipline?

Cain and Kalamaras offer no tested strategies or future efforts for contextualizing the WPA and her work. They give a passing nod to the importance of reflection and preparation for WPAs relative to Popham et al. (57). Ultimately, they conclude, "The problems these stories illustrate inscribe the site where the work of all WPAs begins, specifically in the improvisatory and conditional nature of their decision-making and action" [emphasis mine]. They hint at the destabilized identity of WPAs in academic power grids.

Sharon Crowley and Eileen Schell situate the WPA squarely in a labor discourse in Brown and Enos' collection, The Writing Program Administrator's Resources. Like Crowley and Schell, many of the WPAs I interviewed at the writing program sites define their job requirements and personal agentive interests as focusing on labor issues: "getting more money for lecturers," "writing a book on labor," and "helping my teachers." Crowley offers her total sympathy for the "freeway flyers" who must "feed their families" (225); however, she make the distinction between respecting the people and respecting the conditions of their employment: 
I simply cannot accept the argument that first year comp must remain required in order to employ everyone who has a teaching position in the university...[F]ulltime faculty in creative writing and literary studies create the pool of unemployed teachers whose thwarted expectations are exploited by universities. I refuse to endorse a scam that benefits full-time faculty as it oppresses graduate students, marginally-employed teachers of composition, and millions of freshman (225).

Crowley's longstanding solution to labor inequity in freshman composition is to eliminate the requirement for first-year composition, thus minimizing WPA's power.

Eileen Schell examines how WPAs have "taken action" or used their agency to redress labor's working conditions in composition. She unequivocally states, "Though WPAs can serve as change agents, we also face a number of structural and political challenges that affect our ability to initiate changes in labor practices" (183). She listed deficits as follows: lack of control over budget; lack of control over hiring; staffing problems that affect curricular quality; a disenfranchised position in the power base of the department and university; and finally a lack of collectivization. Schell outlines WPAs and the WPA discourse on labor as follows:

- Conversionist: Converts part-time to full time positions.

- Reformist: Improves working conditions by adding benefits.

- Unionist: Form collectives.

- Abolitionist: Abolishes the first-year writing requirement. 
Schell envisions many possible modes of agency for WPAs. Her caveat to WPAs is that neither innovative strategies for the teaching of writing (professional development, curricula, assignments, syllabi) nor creative occupational configurations for teachers (more tenure-track, more $\mathrm{PhDs}$ from rhetoric and composition programs) will improve the teaching or learning of writing until "the working conditions of the majority of the field's practitioners are a priority; we are short changing quality literacy instruction for our students" (198).

From another labor perspective, the possibility of WPAs possessing agency has been questioned and described as the "rhetoric of pleasing the prince" (Bousquet 494). In Bousquet's argument, WPAs forego collective organization and critique in favor of catering to the needs of upper administration-the prince or princess. Only a "labor theory of agency," not a "management theory of agency," can liberate composition from overdependence on adjunct labor. WPAs are labor and management. It is highly unlikely that WPAs answered the question, "What do you want to be when you grow up?" with "I want to be an administrator."

Rather than viewing the historically inveterate labor problems of composition as indicative of a lack of agency, it is possible to frame composition as a site of agency in action for more than one hundred years. In this dissertation, the definition of "agent" or "WPA" is not fixed as a lone and heroic individual (agent as WPA) constructed within the grand narratives of the Enlightenment. The empirical nature of this dissertation emphasizes that WPAs have acted and continue to act as one of the most collectivized disciplines in the academy. WPAs 
need not be "encouraged to believe in their own agency as regards institutional transformations" (507). The data from the site surveys, the national survey, and the interviews confirm uses of power both individually and collectively in a myriad of issues: labor, curriculum, technology, and socialization, to name a few.

One WPA I interviewed for the dissertation lobbied her dean of Arts and Sciences for years before receiving funds for incorporating technology into writing classes. She received no material or fiscal support until her dean read outside materials (extra-institutional) on the urgency for incorporating technology in writing instruction. At that point, he mandated that the WPA begin computermediated writing instruction forthwith and with a sense of urgency. Over time, the interdisciplinary activity systems of the dean and the WPA blend resources. This WPA persists and eventually gains access to funds to accomplish her goal of incorporating technology in her writing program for her students.

Porter et al. recognize the role of WPAs as agents in institutional change: "Many forms of institutional action have been prominent in our field, especially in the work of writing program administrators...we have a strong track record for enacting change [my emphasis]. ...Those of us who are WPAs contend on a daily basis with our academic institutions for material resources, control over processes, and disciplinary validity" (614). For Porter et al. Sullivan, Blythe, Grabill, and Miles, examining questions about WPA agency and labor can promote administrative action that reshapes the roles of those associated with institutional structures (615) in order to improve working conditions in institutions for writers, students, part- and full-time teachers, and both academic and non-academic 
community. Porter et al. suggest institutional critique needs to examine similar bureaucratic structures such as lines of authority, personnel interactions, and intraand inter-institutional communication (Grabell's study in Porter et al. 626). Scholars in the field have called for more empirical research in technological literacy and begun to examine WPAs' agency in order to provide improve better pedagogy and student learning. These scholars suggest using strategies such as reflective practice, labor analysis, institutional critique, and a variety of theoretical frames to elucidate power and agency in writing programs.

The literature review in Chapter I notes the ongoing interest in WPAs, their labor and administrative possibilities. Yet, at the intersection of technology and writing programs, there is precious little research that documents what WPAs do, what means they use to complete their objectives, how they discuss their labor, and how they imagine and actualize their agency. This remainder of this study attempts to provide insight to these questions: As we examine the answers to these questions, I hope the answers to these questions and others presented in this study will provide stepping-stones to more informed decision-making for WPAs, teachers, graduate students, and all stakeholders. Just as composition has its stories (Faigley, North, freeway flyers), those WPAs who promote and/or teach with technology, construct their techno-rhetorical narratives. These are some of their stories. Chapter II, "The Discourse of Technological Literacy and WPAs: a Bakhtinian Reading of the National Infrastructure Initiative" provides a socialconstructionist frame of discursive analysis for understanding administrative agency and the work of the WPA. 


\section{CHAPTER II}

\section{THE DISCOURSE OF TECHNOLOGICAL LITERACY AND WPAS:}

\section{A BAKHTINIAN READING OF THE NATIONAL INFRASTRUCTURE INITIATIVE}

Cynthia Selfe calls for scholars to practice a critical technological literacy, specifically noting the National and Global Infrastructure Initiatives in

Technology and Literacy in the Twenty-first Century as documents that pave the way for the use of technology in K-12, higher-education, and society. The Agenda for Action, or Agenda, summarizes the central tenets of the Initiatives. While I doubt that many WPAs have read or are even familiar with the Agenda, or have any reason to be, unless they have read Selfe's work, or should be, I argue that examining its assumptions can assist WPAs in understanding their power to serve students and themselves better. This understanding is relevant to WPAs because it influences the material conditions of their daily work: what they are told to value by higher administration, what students expect from writing programs, and what WPAs assume they must value. For WPAs, using Bakhtin can illuminate how the public imagination and technology narratives of legislators, stakeholders, and some scholars affect WPAs' own work. Bakhtin helps elucidate how, at the 
discursive level, technology narratives shape process and product. Bakhtinian concepts include, but are not limited to passive and resistant language, centrifugal/centripetal forces, unitary and divisive discourse, and heteroglossia, inevitability acceptance/passive resistance to technology. I read the Agenda through a Bakhtinian frame to show how the discourse of technological literacy in the Agenda instantiates a technological vision for students and citizens.

My rhetorical reading heeds Selfe's call for a critical literacy by analyzing the socio-economic and political mandates of the NII Agenda for Action. Based on this analysis, I then hypothesize that these mandates influence WPAs daily work for WPAs' work with technology. I bring this critical attention to the data collected in my research by positioning the public NII Agenda as a socially and politically motivated discourse that is meant to influence legislative members, community stakeholders, educators, and instructors and students in the composition classroom towards more knowledgeable and conscious decisionmaking.

In this chapter, I show how the discourse of technology influences (and has influenced) conceptualizations of technological literacy. Figure 2 encapsulates recurring themes in the data.

Figure 2. A Bakhtinian frame to the research data.

\begin{tabular}{|l|l|}
\hline $\begin{array}{l}\text { Democracy and the } \\
\text { WPA's Heteroglossic }\end{array}$ & $\begin{array}{l}\text { Self-interest and the } \\
\text { WPA's } \\
\text { Discourse }\end{array}$ \\
\hline Promise of & Heteroglossic discourse \\
\hline
\end{tabular}




\begin{tabular}{|l|l|}
\hline technology & technology \\
\hline WPA as a resistant & WPA as a passive \\
agent to technology & agent to technology \\
\hline
\end{tabular}

I frame my research findings with four tensions from the Bakhtinian rhetorical reading: democracy and self-interest in the heteroglossic WPA, the promise and inevitability of technology, passivity and resistance, and centripetal/centrifugal technology because these concepts seem to be recurring assumptions central to arguments, lore, and narratives regarding technology.

One tension arises between notions of the WPAs' work being in the service of democracy or self-interest. Using heteroglossic rhetoric—or the speaking of two tongues or languages expressing both altruistic democracy and self-interested motivation-WPAs position their labor as sometimes appealing to the greater democratic good of society and, at other times, as a choice of individual often difficult and eccentric - agency toward administrative and labor goals. This bifurcated vision of motivation can be problematic for WPAs as they try to assert their agency within administrative constraints. Another tension arises between technological literacy as presenting an open-ended "promise" for the future or as an externally imposed inevitability from multiple stakeholders. Interviewees describe technological literacy in writing programs as an inexorable force mandated from both students and administration. A third tension stems from notions of passivity or resistance to technological and technological literacy in writing programs. Finally, I contextualize WPAs' views of technology as a 
Bakhtinian struggle between centripetal/centrifugal forces that unite or divide all parties involved.

Background on the Agenda and the National Infrastructure Initiative

The Agenda (http://www/ibiblio.org/nii/NII-Agenda-for-Action.html), as of October 2003), serves as a distillation of the imperatives for technological literacy of the much longer NII and GII initiative (<http://www.ibiblio.-org/nii/toc.html $>)$. The Initiatives and the Agenda were written by a taskforce, advisory team, and staff that included the (then) Secretary of Commerce, Secretary of Communication, and Director of the National Institute of Standards and Technology.

In order to understand the evolution of the Agenda, I provide a synopsis of the history of computing infrastructure from Selfe's comprehensive history leading to the initiative (Technology and Literacy 47). In 1969, the United States Department of Defense sought to improve computer communication and share resources between research universities and the military. These networks grew exponentially as personal computers entered commercial markets. President Bill Clinton saw the potential of technology as an engine indivisible from political and economic growth nationally and globally. On February 22, 1993, the Clinton administration announced Initiatives and their purposes (51):

- Revitalize the slumping domestic computer industry.

- Improve technological literacy in the workforce.

- Expand computer networks in support of education. 
- Exhibit the social and cultural benefits of a national information infrastructure.

- Increase global demands for and access to American products.

- Spread ideas of free-market capitalism and democracy.

About a year later, Gore outlined the goals of the GII in Buenos Aries, Argentina, at the International Telecommunication Union. In 1996, government policy-makers committed even more funds toward American technological literacy for constituents in $\mathrm{K}-12$, higher education, the workforce, and the general citizenry. By 1997, economic analysts concluded that "policies aimed at increased support for science and technology" contributed to the "nation's economic revitalization and acceleration of its productivity and the growth of Gross Domestic Product" (55). Much of the ensuing success was attributed to the Clinton administration's national and international technological initiatives (60).

The Clinton administration signaled to the world the importance of implementing technological infrastructure (the physical facilities to transmit, store, process, and display voice, data, and images through items such as televisions, computers, switches and disks.) In order to implement his goals, Clinton, through the Initiatives sought to motivate legislature, community stakeholders, and citizens to build and maintain a national information infrastructure (see Appendix D).

The Clinton-Gore administration and its technological planners sought to promulgate technological literacy by teaching about computers, software, and the information superhighway. K-12 teachers and higher education teachers would 
spearhead digital project in their classrooms. According to Selfe, the purpose of this project was to encourage a technologically literate populace that “... would also develop an increased appetite for powerful and sophisticated technology produced by the American computing industry," thus, revitalizing the economy retooling the workforce (52). An early report of the NII Agenda stated that another key objective was to "...create, manipulate, manage, and use information" (53).

The NII is worth probing for the fiscal, intellectual, motivational, and occupational imprint it has had upon teachers and students since the early 1990s. Much of the lore, hype, marketing, and direction of both K-12 and secondary education, teacher training, and job requirements can be seen in light of the implicit or explicit effects of the NII. WPAs must contend and plan for student expectations and appetites for technology as they enter college and writing programs, just as instructors and administrators have had to modify their curriculum and pedagogy in response to other national projects throughout history.

Historical Precedent for the Agenda

I compare the Agenda to the historical effects of the GI Bill and the Morrill Land Grant Act on education in order to better understand how the NII and its Agenda operates within the longstanding genre of public documents. These documents have historically forwarded a variety of imperatives: economic, social, and political. The GI Bill of Rights anticipated the negative economic 
consequences returning veterans at the end of World War One and World War

Two. The American GI Bill of Rights was modeled on the World War One British format created to address the effects of demobilization and economic fluctuations.

Theodore R. Mosch in The GI Bill: A Breakthrough in Educational and Social

Policy concluded that economic stability was best served by the educational focus of the GI Bills: "Of all the provisions of the GI Bills, those concerning education were, according to many, the most significant" (3). Just as the Morrill Land Grant and GI Bills linked educational directives to democracy, the NII and the Agenda also link educational (and other) current technology directives to democracy.

Historically, teaching trends implemented in the composition classroom often correlate to public policy directives initiated by mobilizations and demobilizations of demographically significant numbers of displaced or returning armed service people. Such was the case, in part, with Harvard's implementation of English A, for what was at the time non-traditional students. Also, the Second World War and the GI Bill influenced the content and topics on English and writing classes as the upheavals of war shaped public policy in anticipation of negative economic consequences.

Policy responses to shifting demographics in the form of the Morrill Land Grant Act, the GI Bills, and the NII and GII exerted and continue to exert pressure in the composition classroom. Students are increasingly required to learn or come prepared with computer skills in their composition classes. Administrators in order to achieve institutional accreditation while fulfilling policies of public preparedness implement these expectations. Richard Ohmann speaks to this view 
when he historically positions “... the university as a response to the vagaries of competitive capitalism, the recurrent cycles of boom and bust that characterized the nineteenth-century economy. The university was an important part of the strategy to control this economic instability" (as quoted in Berlin 480).

In Composition Rhetoric: Backgrounds, Theory, and Pedagogy, Robert Connors traces the history of demographic shifts as they relate to war and composition. He states, "I am a historian, and social history teaches us to watch the demographics, because they under gird many other things. Our disciplinary demographics are shifting, and it may be those changes will have a more profound impact on where we go from here than any theoretical shifts." It is important to note here that Connors seems to imply that it is the effects of war on the economy that cause the shifts in populations. Connors observes that the mobilization of populations of service people lead to postwar composition rhetoric: "After 1865 American college culture changed radically, and composition-rhetoric shifted with it. The Morrill Act of 1862, which established the Agricultural and Mechanical Colleges brought a large new population of students to American colleges and helped found the major state universities, which would become important sites for composition teaching over the next five decades" (9). Sharon Crowley also connects the practices of the classroom to results of economically motivated demographic shifts. She notes that process pedagogy was developed as a "means to alleviate difficulties associated with mass instruction...student attitudes and their writing improves as well," even if elite schools first sensed the need for writing instruction (Composition 193). 
Similar to Connors and Crowley, Betty Pytlik says economic imperatives affect writing classrooms. In her 1993 presentation at the Conference on College and Communication, she lists three concrete examples of how WPAs' agency in composition classrooms was affected because of demographic shifts:

- Course content related to war related topics such as "Poetry and the War," "the Shape of Postwar Literature," and American Letters Between Wars" was introduced as curricula in English classes (4).

- "To accommodate draft-age students and returning veterans...entrance exams were liberalized. ..." (4).

- "During the war some high schools and colleges dropped freshman composition to make room for more courses in defense-related skills...offered correspondence courses, and extension programs were expanded" (4).

Along these lines, John Heyda in "Fighting over Freshman English: CCCC's Early Years and the Turf Wars of the 1950's" documents that demographics shifts influenced classroom instruction. To meet the demand of veterans, universities were forced to hire "...new faculty to do teaching for which their English $\mathrm{PhDs}$ had not prepared them" and they continue to do so (663). In order to confront student demands, communications studies evolved as an alternative to English studies.

Like the reification of technology literacy under NII and GII, the coding practices of communication studies and communication proficiency links students 
and teachers to democratic ideals. Students had to learn new coded ways to communicate to fight the Cold War. Communication studies was the discipline for innovative and burgeoning language alternatives. The term "democracy" is bandied about as an immutable good that we all understand; rarely do we have an analysis of what "democracy" is and how it plays out for differing audiences in language and technology education. This pattern is similar to the messages in the

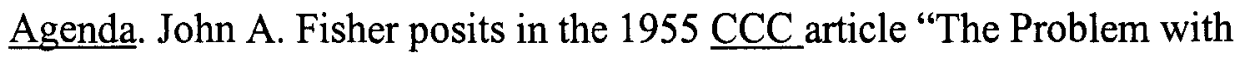
Freshman English: What Are Its Dimensions?" that "The broadening view of the function of language has led away from this literary orientation to the point where the English Language Arts finds the 'main objective' of the English teacher to help his students become proficient enough in the use of verbal skills 'to enable them to be effective defenders and preservers of the democratic tradition"' (77). Are we speaking of the same democracy that the classical Greeks and the American founders had in mind when "democracy" meant only certain citizens, not women and not slaves? What do statements, mandates, curricula that assert language and technology instruction support democracy look like in practice for each generation?

Textual Carnivals, Susan Miller's socio-Marxist-constructionist view of writing instruction situates writing in the service of the hegemonic and hierarchical powers of capital. Her views echo current discourse on technological literacy as expressed in the Agenda; however, the Agenda depicts technology's close relation to capital as positive, democratic, and utopian. Decades later, Jeff Grabill observes, “...literacy tends to be constructed in relation to the mandates of 
funding and policy interests (largely from government and industry)" (Grabill as quoted in Porter 626). The influence of public acts, bills, and initiatives shape curricula in the composition classroom long before technology partnered composition.

In retrospect, it becomes easier to see the effects of national initiatives on composition curriculum today when noting the historical documented effects of public policy such as Morrill Act and the GI Bills in the composition classroom. What is more difficult, however, is to discern how current public initiatives relating to technology shape the work WPAs do today in the computer-mediated classroom. Previous public acts (Morrill Land Grant), bills (GI Bills), and initiatives have been found to shape curricula in the composition field (Heyda, Kitzhaber, Levitan, Mosch, Moss, Connors, Faigley). Little attention has been paid to how current and less visible public initiatives shape the daily work of compositionists (WPAs) when incorporating new communication technologies.

When reading the words of WPAs from the site interviews of this study, it may first appear that, contrary to the preceding arguments, WPAs are not influenced by public initiatives, mission statements, and bills to re-imagine technology and the teaching of writing. WPAs in our study, on one hand, speak of their resistance to such mandates. They seem to follow their own agency-and in many instance they do; however, a close reading of the WPAs reveals ambiguity and tension among multiple factors influencing WPAs' decision-making processes. I use Bakhtin to tease out more subtle and socially constructed assumptions will prove helpful to WPAs as they negotiate their power or 
perceptions of power and agency for the best educational product for their students.

\section{Bakhtin, Writing, and Technology Grand Narratives}

Admittedly, the study of bureaucratese, or the jargon of bureaucrats, seems to be an onerous task, which is probably one reason why the genre has been neglected. The documents do not seem to have the nuance of literary works, or the immediacy of workplace documents. Yet, this genre ideologically and practically influences technology use, funding, and public perception. Through a Bakhtinian frame, readers can re-interpret public policy documents as more ideologically complex and socially powerful than bureaucratic text might initially appear. Michael Holquist suggests in his Introduction to The Dialogic Imagination that Bakhtin understood that novels couldn't be studied with the same frame of ideas about language or style as other genres (xxix). As Carol Berkenkotter and Thomas Huckin surmised, "Genres are the intellectual scaffolds on which communitybased knowledge is constructed" (501). To read the bureaucratic Agenda as a literary text might be problematic. Holquist conceded that Bakhtin names the "novel" as "whatever force is at work within a given literary system to reveal the limits, the artificial constraints of that system" (xxxi). Genre is both generative and limiting.

If we reposition public policy, however, as a fictionalized narrative of what society should look like, then the public policy morphs into a utopian fiction - a story in search of a place in history. Democracy, prosperity, and 
security will follow technology. Public policy is not yet history; it exists digitally or on paper as much (or as little) as a novel. By minimizing the effects of public policy, readers might neglect to see it as sub rosa socio-political force or inspiration predictive fiction that shapes public and educational material conditions and imagination. Yet, these policies are written precisely to become history and fact. Additionally, these fictions expand beyond novels to epics that shape cultural history and the daily lives of millions. We can look again at the impact of other public documents - i.e., the GI Bill of Rights and the Morrill Land Grant Act, which channeled the energy of mass mobilizations of postwar families into education and a vision of nationhood. At this point, though, I merely point out that those policies instantiate the ideological grand narrative of the good life vis a vis upward mobility through education.

My rationale for equating this public document with a novel is that both can function as a type of moral propaganda. In the same way, we can question the boundaries and uses of genres and situate public policy initiatives as fictions. The effects of a piece of writing in one genre often interact and have effects beyond narrow genre-based definitions. For example, the Declaration of Independence, although written as a political mission statement, has ignited the literary imaginations of generations and spawns derivative works across a spectrum of non-discrete genres.

Like literary writing, the Agenda develops on the "boundary between two consciousnesses, two subjects" (Speech Genres 106). The Agenda is complex in its intentions to influence readers and to make itself a material reality. Robert 
Scholes comments on the bureaucratese genre's textual imperative in The Rise and Fall of English. Texts offer audiences/readers a role to play. Bureaucratic forms want "a person who can follow directions" (Scholes 131). In the case of the Agenda, the audience should embrace technology and its purported ideology of democracy. In this language system, the text, the Agenda is an utterance, as Bakhtin wrote, because it possesses two characteristics: a plan or intention and an expected realization (Speech Genres 104). The Agenda and its call for the incorporation of technology speak from many voices to multiple audiences: community stakeholders, politicians, business people, students, and the general public. Bakhtin isolates a quality of the novel: "Authorial speech, the speeches of narrators, inserted genres, the speech of characters are merely those fundamental compositional unities with whose help heteroglossia [raznorecie] can enter the novel" (263). Public policy and the ideas expressed in the Agenda permeate our teacherly lives by affecting public motivation and perceptions. In the minds of community stakeholders, these perceptions are now reinforced by texts and translate into actions that affect the material conditions of the technologies with which we teach. For example, according to C. Selfe, "Pressure from governmental agencies to support technological literacy continued through educational funding initiatives and opportunities.... In such language, the direct ties between government funding and state educational efforts to increase technological literacy became clear" (78).

Readers can view any text with both macro and micro lenses. The micro lens of unitary language focuses on lexical details of connotations and denotations. 
The macro lens of external persuasion focuses on the socio-ideological nature of language. Through the process of reading, Bakhtin argues that readers are part of the "ideological becoming of a human being, in this view is the process of selectively assimilating the words of other," (Imagination 341).

The United States government is the nation's largest producer of text (http://lib.mansfield.edu/mudocs.html). Nevertheless, scholars rarely examine governmental texts' rhetorical functions. Genre studies emphasize the socially constructed nature of genre (Bazerman and Paradis, 1991; Van Nostrand, 1997; C.R. Miller, 1984; Booth, 1982). The genre of the government policy statements constructs meaning and exerts agency in the same way as educational institutions, families, neighborhoods, businesses, and the media. And in turn heteroglossic government documents at once produce new powerful discourse, such as legal and public policy (Brown v. Board of Education) while replicating the dominant hegemonic culture in the name of democracy. Yet, the government's textual practices and functions remain invisible to stakeholders who implement the mandate-like objective.

To look at technology critically is to remain focused on the underlying social and political realities that impede or encourage literacy. For those of us who teach, or are told to teach computer technology, along with the writing technology, these documents might shape our daily intellectual lives.The Agenda is simultaneously protean and fixed. The incorporation of technology in the writing classroom is constructed in part by public initiatives such as NII, and not solely as a result of decision-making at the post-secondary level by local 


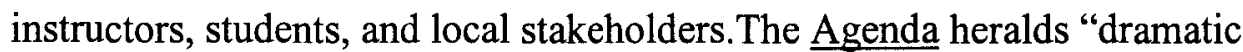
changes." According to the Agenda, readers' lives will be enhanced by technology that directly involves education: "schools," "teachers," "courses," "literature," "science," and "libraries" (Agenda 1). We are told, "these changes promise substantial benefits for the American people" (Agenda 4). Implicit in the Agenda is the correlative notion that resisting change is undemocratic. Also implicit is a call for all good citizens, teachers, and students to jump on the technology bandwagon. Selfe's critical technological literacy targets the conflation of technology with social advancement.

The Agenda calls for action to “...help educate and train our people [Americans] so that they are prepared not only to contribute to the further growth of the NII, but also to understand and enjoy fully the services and capabilities that it will make available" (Agenda 3). Inherent in the call is the assumption that the public is unprepared to contribute to or fully enjoy technology. The Agenda asks readers to assume that the public needs technology and that personal needs will inexorably expand (3). Given that the Agenda functions both persuasively and authoritatively, readers can extract heteroglossic elements of the Agenda. Bakhtin argues that language in this and any other moment in history is heteroglot, representing the co-existence of socio-ideological contradictions of both present and past (Dialogic 290).

By combining the use of first, second, and third person, the Agenda blurs authority. The first person plural calls many together: "We are committed to working with business, labor, academia, and public interest groups" (2) "We will 
help build a partnership of business, labor, academia, and the government that is committed to deployment of an advanced, rapid, powerful infrastructure accessible and accountable to all Americans" (4). The third person reinforces the distance and objectivity of the Agenda: "The private sector will lead the deployment of the NII" (3). "The Task Force currently is undertaking a wideranging examination of all issues..." and that "The administration will work with Congress..." (5). The Agenda hails readers in its opening by using the second person: "Imagine you have a device...Imagine further..." (1). The Agenda thus uses first, second, and third persons to speak to many readers in varying levels of linguistic subjectivity. The reader is spoken to, spoken of, and spoken for.

\section{Contexts for Heteroglossia}

In addition to uses of multiple persons, the Agenda speaks to multiple audiences by using a Bakhtinian heteroglossia. These heteroglossic "utterances" allow for multiple interpretations. They have the ambiguity expected of literature, thus potentially speak to diverse audiences with diverse understandings. Here Holoquist explains this ability of heteroglossia:

Heteroglossia is Bakhtin's way of referring, in any utterance of any kind, to the peculiar interaction between the two fundamentals of all communication. On the one hand, a mode of transcription must, in order to do its work of separating out texts, be more or less a fixed system. But these repeatable features, on the other hand, are in the power of the particular context in which the utterance is made; this context can refract, 
add to, or, in some cases, even subtract from the amount and kind of meaning the utterance may be said to have when it is conceived only as a systematic manifestation independent of context. (Holquist in Dialogic xix).

Bakhtin informs us that language is never unitary. Even in the Agenda, with its bureaucratic basis, we can see complex and dispersed meanings and readings. Bakhtin states,

It goes without saying that these languages differ from each other not only in their vocabularies; they involve specific forms for manifesting intentions, forms for making conceptualizations and evaluation concrete. And even the very language of the writer (the poet or the novelist) can be taken as professional jargon on a par with professional jargons. (Dialogic 289).

The authors of the Agenda accentuate key concepts for readers. The term "deploy" from militaristic rhetoric suggests that application of technology is a battle for democracy and against ignorance (to spread out troops or ships as for battle). The phrase "promise of NII" invokes a social pledge within the Agenda. The Agenda's promise presupposes it can provide the following in the future without recognizing or mentioning the complexity of social change: "best" schools, resources to art and culture, health care, occupational flexibility by technology, improved manufacturing technologies, and access to government resources. These are the "promises" of the technological utopia. The reader is 
rewritten as a consumer who desires these technologies without being asked his/her opinion of what access is preferred or needed.

\section{Authoritative Word and the Promise (Inevitability) of Technology}

The Agenda links the abstract "promises" of democracy and global economic proliferation to the concrete cables, wires, computers, disks, television, and switches. The hardware of technology correlates with the goals of global ideology. Readers are told "The NII will integrate and interconnect these physical components in a technologically neutral manner so that one industry will not be favored over another" (2); hence, we have the promise of democracy, faimess, and equal access. This will be the "promise of the information age" (2). This easy correlation distances readers from both complexities of infrastructure technicality and abstract generality. Correlation serves to create a new community and knowledge on a "conversational continuum," thus simultaneously shaping the bureaucratic genre to meet institutional needs. In this continuum, information is called a "most critical resource" (1).

What are the possible socio-political outcomes of the NII and GII on ideas about property? The presence of computers and televisions and all peripherals in homes across the country enter the realm of the public domain. Individual capital (property) of citizens has now come under the governmental umbrellas of the need to support the systems that produce all these items. Computers and peripherals in private homes become capital of the national infrastructure. The call to action thus transfers, conceptually for now, privately held capital to the 
public domain. The privately owned commodity part of the public realm as described in the Agenda imperceptibly slips into the public sphere, while the public infrastructure moves toward private corporations. These mass transfers of property and wealth are visible to the trained eye as stadiums and other resources built with public funds are turned over to corporations by government. Less visible is the ongoing slippage of property and wealth in the virtual realm. The government calls for action to upgrade the American and international technological infrastructures. People, students, teachers, businesses WPAs write the curricula, pay the taxes, buy the software/hardware to make the new American dream of the good life via technology. However, this technology is increasingly under the scrutiny, if not control of the government and big business. It is not a family farm or a mom and pop store as public ownership turns into private capital for national use. So, an outcome of the NII and the GII is to bring under the corporate umbrella previously publicly and individually created and held capital.

\section{Democracy and Self-Interest}

The ideals vested in the Agenda beckon us to use technology so that we can participate in democratic values, best schools, health care, and social mobility. The Agenda tells readers that they must seize the opportunity to use technology toward a cyber-dream of social fulfillment: "The potential benefits for our nation are immense...firms will compete and win in the global economy, generating good jobs...ameliorat[ing] constraints of geography and economic status, and giv[ing] all Americans a fair opportunity to go as far as their talents and ambitions 
take them" (13). These are familiar terms to which the reader wants to connect to the best within himself/herself. Readers find the Agenda internally persuasive, even though the Agenda emanates from an external authority.

What is absent in the Agenda is the understanding that the ideological assumptions about abstractions such as democracy, mobility, and so on existed prior to digital technologies and will continue when the next technology arrives. The wording of the Agenda (in all its bureaucratic display) should not be ignored because it helps readers come to grips with WPAs' contemporaneous life's work by examining embedded cultural ideals. Internally persuasive discourse maximizes the word (Agenda) and the context (encouraging the incorporation of technology) (Imagination 346). Bakhtin observes that internally persuasive discourse can be infused with images that reinforce the internalization. For instance, according to Bakhtin, the internally persuasive text presents a "special conception of its listeners, readers, perceivers. ..." (346). In the case of the Agenda, this special conception is in the assumed agency of the listener/reader/perceiver. Because the reader wants to believe himself/herself as having agency to buy/use/know technology, the text is internally persuasive.

This ethos of reader agency is omnipresent in the Agenda, as it is with other documents in the bureaucratic genre seeking action from the readers. The specter of the executive leaders Clinton-Gore floats above the Agenda, adding to power. The mere transmission of the forms or genres is not as important, but the "embryonic beginnings of what is required for an artistic representation of another's discourse" (Imagination 347). The Agenda has elements of internally 
persuasive discourse, even as it seems to operate as a genre of external authority. Its artistic quality comes in its artifice to be double-voiced: harkens to the internally persuasive and operating from the power of the externally authoritative. Like creative literature, the internal and external linguistic and ideological forces create multiple meanings in the Agenda.

Bakhtin questions whether texts precede from the internally persuasive speech (341) or the authoritative language. In looking at genres, do we assimilate our consciousness to their ideological world? "The authoritative word demands that we acknowledge it, that we make it our own; it binds us, quite independent of any power it might have to persuade us internally," observes Bakhtin (342). Located in the distanced zone and perceived to be hierarchically higher and historically more authentic, the authoritative word demands our acceptance. Internally persuasive ideological discourse stimulates possibilities in our consciousness. Bakhtin continues, "Internally persuasive discourse-as opposed to one that is externally authoritative - is, as it is affirmed through assimilation, tightly interwoven with 'one's own word" (345). The Agenda operates simultaneously from both positions because the government taps into cultural power and each life.

\section{Authoritative Discourse}

The Agenda functions as externally authoritative discourse because it adheres to numerous factors of authority. First, the content is from the "official line" (344). In this case, the official line links to the executive office, the president and 
the vice-president of the United States. The document also gains credibility because it is couched in the ethos of "democracy" and the future of all people. The trustworthiness and security of communication channels and networks are essential to the success of NII (8). Readers can become part of the Agenda's master narrative of the future or be left behind. Moving beyond just an initiative of an official line, the text becomes a venue for global objectives to unite the world in a communication network never before imagined, or so we must believe.

Second, authoritative discourse often organizes itself around and with many other discourses. The Agenda calls on tradition and cites previous public acts and initiatives, such as the Communications Act of 1934, which articulated a "universal service" for telephones (5). The Administration behind the Agenda is described as working with Congress to manage the Omnibus Budget and Reconciliation Act of 1993. The Agenda unites itself with the needs of educators, minorities, manufacturers, artists, and leisure-seekers. In the Agenda, we see the struggle to overcome the official line with an inclination to distance itself from the difficulties of the contact zone (Imagination 345). Utopian scenarios like these are provided:

- “...to create more powerful computers...more sophisticated hardware...providing engineers and scientists with the tools and training they need to solve 'Grand Challenges. ..."' (6);

- to sign into law “...tax incentives for private sector investment in the NII... R\&D, and new business formations. ..." (5); 
- "to share information about how government can effectively use the NII. ..."(7);

- “...to gather information... and hear from public interest groups. ..." (6);

- “...to ensure individual privacy. ..." through better encryption (9).

An analysis of these expected actions reveals that the NII is more focused on replicating its own survival. Services provided to the readers fall primarily in the categories of entertainment, alternative purchasing methods (not economic access), and purchasing security. It could be argued that the Agenda is speaking to itself as much as to readers. By combining its inherent authority and its rhetorical persuasiveness, the Agenda constructs the importance of its own existence for the readers and the nation.

Third, Bakhtin argues that the authoritative word merges with other discourses, yet remains a genre in and of itself: “...authoritative discourse...remains sharply demarcated, compact and inert; it demands, so to speak, not only quotation marks but a demarcation even more magisterial, a special script, for instance..." (Imagination 343). Public policy seems to unite stakeholders toward a common social goal; however, in order to accomplish this, it must simultaneously disrupt existing socially defined goals that are already in place.

In a Bakhtinian light, public policy assumes agency and the authoritative voice and succeeds unquestioned in its own implementation. For example, the Agenda lists and describes in the first twelve pages what should be important to readers. Then, after presuming to answer these questions through its authority, the 
Agenda asks of readers, "What information does the public want? By what means can it be distributed? How can all Americans have access to it?" (12). These questions at this point are moot because they were answered in the first twelve pages.

Fourth, the language of the Agenda aligns itself with political power, institutions, and masses of people. It stands indivisible, and we cannot individually affect its integrity; we can join in its promulgation or ignore the future. After posing the answers and then suggesting the appropriate questions to be asked, the Agenda notifies readers in boldface “America's Destiny is Linked to Our Information Infrastructure" (13).

The Agenda functions as internally persuasive because its themes and language are so familiar-they seem to be half ours and half someone else's. Americans are acclimated to the rhetorical background patter that calls for change as a road to progress and democracy—a road that must be repaved every generation with new technologies or economic imperatives found in public directives. Instead of just being told that education is the road to economic health, the education should now also entail digital technology.

\section{Centripetal/Centrifugal Forces and Text Analysis}

In the best Bakhtinian fashion, the Agenda operates both centrifugally and centripetally. In order to embrace technology of the future, according to the Agenda, we must leave behind some of the old technologies. We should come together as a nation, we are told, in order for the technology to come to fruition: 
“America's Destiny is Linked to Our Information Infrastructure" (13). The

Agenda hails readers together toward centripetal behavior; however, within the calls for unity and a "blueprint for action" is the unspoken centrifugal force that disperses readers from old technologies. Readers must embrace and follow a divergent path. While the document suggested it can “...ameliorate the constraints of geography and economic status, and give all Americans a fair opportunity to go as far as their talents and ambitions take them" (13). The American frontier is now boundless, if everyone at home and abroad would just agree to cooperate. Little attention is given to where the American people say they want to go. Readers are asked to unite under the historicized bandwagon call: "Thomas Jefferson said that information is the currency of democracy" (11). Readers are asked to unite history and the future. Readers must also separate themselves from the current technological limitations as expressed by the Agenda.

Bakhtin states that we couldn't know anything without dialogue between two subjectivities. Monologic discourse is false. Yet, the genre of the public policy does seem to engage readers in discourse; it is incorporated and applied without discussion or, often, without reflection. The public policy document enters the public imagination without many intertextual referents. The Agenda, as a bureaucratic document, wields power in the imaginations of readers and decisionmakers by its use of externally authoritative and internally persuasive rhetoric, heteroglossia, appearance of unitary language, and dialogism. When considering the agency (or lack thereof) WPAs have in designing curriculum and using 
various technologies, we can see how meaning is constructed in unexplored genres that influence many of the decisions and funding of our pedagogy.

The visions and objectives of decision-makers (administrators, community leaders, politicians, and educators) are often one of the intended audiences of these documents. These analyses can be correlated in part with funding and mandates that motivate educators and scholars to incorporate digital technology with writing technologies. Applying a Bakhtinian frame to the discourse of technological literacy can assist WPAs in their reflective practice and decisionmaking. WPAs can gain insight into the nature and degree of their socially constructed agency. In the following chapter, I apply these Bakhtinian concepts to the interview data collected for this study: centrifugal and centripetal social consequences of technology; passivity and the inevitability of technology; promise of technology, heteroglossia and authoritative words in the discourse of technology, grand narratives promulgated about technology and resistance to technology. 


\title{
CHAPTER III
}

\author{
WHAT WPAS SAY ABOUT THEIR WORK AS A SITE OF AGENCY \\ "The first rule of method is that we shall have no rule about what \\ constitutes knowledge." Bruno Latour
}

Review of Methods: Rationales, Benchmarks, and Invisible WPAs

\section{Introduction}

As administrators of our English Department's computer writing program, Pamela Takayoshi (Director if CAI) and I (graduate CAI Assistant Director) have learned that local and national knowledge are necessary for writing program directors in shaping, running, and assessing a program incorporating technology as well as in articulating to the administration the need for resources. In order to gather this information, we applied for and were granted a Writing Program Administration Research Grant. We gathered data on how our institution compared to our benchmarks so that we could argue for more resources for CAI in our department. 
We wanted to use the data to prove to upper administration at our institution that our CAI program needed increased CAI funding to compare favorably with our benchmark institutions in regards to technology support (see Appendix B). Instead, to our surprise, we found that within our benchmarks, our institution was already practicing and funding CAI at a higher rate than our benchmarks.

Benchmark institutions are commonly defined as institutions that share similar missions and demographics. In our study, we focus on benchmark institutions as a way of giving WPAs a method for examining their implementation of technology into writing courses relative to peer institutions that share similar missions and resources. Additionally, focusing on benchmark institutions lessens the number of variables that might conflict with making accurate comparisons about a writing program's uses of technology. The benchmark concept is explained in more detail in this chapter.

Even though our data did not make a strong argument for increasing funding at our institution, we accumulated a significant pool of information about CAI writing program. This information raised further various questions: How do WPAs meet the demands of diverse educational stakeholders? How are different universities incorporating technology into their curriculum? How are classrooms configured? How are instructors prepared? Are program directors allocated reasonable funds and support for successful integration of technology in the classroom? Are WPAs provided a context of success? Are stakeholders' expectations in line with benchmark institutions? Answers to questions such as these provide heuristics and comparative information for individual programs and 
for the field, contributing to a snapshot of the current status of technology instruction across the country. The need for information about how other institutions handle the demands of computer-oriented instruction often permeates formal and informal discussions among WPAs. We found that discussing one's program with colleagues from other institutions can have limited comparative value if the institutions differ in mission and resources.

This research from the WPA Research Grant that Takayoshi and I were awarded became the basis of my dissertation. Because we had collaborated as coresearchers and co-writers on the WPA grant, we agreed that using first person most accurately reflected our research process. I used first person plural (we) to describe those parts of the data collection that were collaborative: conceptual framing of the WPA Research Grant and the e-mail survey. I used first person singular to describe all the remaining parts of the dissertation, including my analysis of the site survey data and the online survey in Chapter IV.

Our method begins with contacting the WPA at each of our university's fifteen benchmark institutions by query e-mails (Appendix B) and interviewing her about the uses of technology in first year writing. Our interview questions (Appendix B) ranged from the pragmatic (how many sections of first year writing are taught each semester? who are the instructors? what do the computer facilities look like?) to the programmatic (what training do teachers receive? who manages the computer facilities?) to the theoretical (what are the beliefs and assumptions that inform writing program administrators decisions?). By focusing on benchmark institutions and questions that get at information that can be compared 
by institution, we have limited the scope and focus of the study to ensure an efficient way to collect valuable information.

Once the interviews were transcribed and reviewed, we conducted on-site visits and follow-up interviews at four programs selected as representative or exemplar models of technology and writing instruction. These on-site observations gave us a different kind of data to develop our understanding of the institution's integration of technology. By observing the everyday life of these institutions' uses of technology, we gathered valuable information that the interviewees and the researchers might not have considered significant during the initial interviews. We then had a rich body of data (interview transcripts, observation notes, follow-up interview transcripts) for three different constituencies: 1) a comparative assessment of our institution's approach to integrating technology into writing instruction for our local needs; 2) a picture of the daily lives and practices of a cross-section of the nation's writing programs addressing an increasingly ubiquitous trend for composition scholars and theorists; and 3) an examination of WPAs agency relevant to their own programs. Because the methodology focused on programmatic change and concerns, we sought to create a mode of inquiry that was amenable to the needs of each institution. This methodology could be used by WPAs to collect data about issues such as teacher training, program review, and assessment to enact informed material and theoretical change in their programs. 


\section{Rationale for Methods}

We design a multi-modal study to gather and compare empirical data on how WPAs use their agency employing three forms of data: query emails of all 15 benchmark institutions, four on-site visits and observations at selected benchmark institutions, and an online survey to WPA-L and Tech-Rhet-L listservs. We employe multi-modal methods because of the following characteristics: an attempt toward objectivity and objective methods, reliability of results, triangulation of sources and methods, and validity. Currently, practice favors the multi-modal approach that utilizes triangulated methods with multiple data points.

As we design the study, we keep in mind at least these three considerations. First, research is not simply for the sake of collecting information or knowledge, but for making a contribution to the community that it serves. Researchers seek to fill a gap in knowledge that society or the field needs to address. If a gap or problem is presented, a researcher, as differentiated from a theorist or a rhetorical reader, should be prepared to suggest a solution.

Second, Kurt Spellmeyer warns researchers to be cognizant of the many intended uses and consequences of research the professional managerial class forwards its interests. Research in and of itself is neither positive nor negative. Spellmeyer would have us consider the motives of research. Third, a researcher needs to question the degree to which he or she is influenced by a tendency for scientism or Hairston's "physics envy." Hairston's phrase "physics envy" humorously plays with the scientism's appeal. Because of scientism's association with objectivity, validity, and reliability, the results of a "scientific" study may 
seem more significant than a more qualitative study. Every method implies a loss or a gain. The methods we choose ultimately determine the kind of knowledge we produce. Instead of negating the validity of one method over another, we invest in selecting methods appropriate to the outcomes and the audiences.

In "Types of Empirical Research," Julian L. Simon offers four types of research formats: description, classification, measurement, and comparison. Descriptive research serves as a jumping-off point that avoids rigid rules of scientific evidence for study in new areas. "When one does not know anything at all about a problem, he must understand it in a general way before beginning to make specific inquiries about specific aspects of the subject" (58). In Composition Research Empirical Designs, Lauer and Asher examine the similarities between rhetorical and empirical research relying on problem formulation while creating new insights: "Rhetorical inquiry suggests behaviors, environments, or populations for empirical study" (6). The authors affirm the advantages of applying at least two types of inquiry because multimodality helps prevent the "nearsightedness that causes some other fields to overlook major problems because they fall outside the domain of a particular mode of inquiry" (6). Descriptive research can entail complex statistical analysis in which the researchers do not deliberately structure of control the research field of study. The information collected is sorted into categories thereby allowing for the interpretation of patterns and relationships (15). Lauer and Asher find that descriptive sampling and survey studies have several advantages. 


\section{Benchmarks as Moving Targets}

Based on the initial e-mail survey responses to the benchmark institutions, we abandoned notions of any significant similarities that could be drawn under the heading of "benchmark" institutions. In some institutions, computer-instruction across all disciplines had been mandated or relegated to university wide control. Neither teaching with technology nor teaching technology was part of these departments' curricula at the time of this e-mail survey. The term "benchmark," then, described similarities at the institutional and demographic level, but not at the technological or pedagogical level. Our benchmark institutions are urban and diversely populated campuses with similar missions and enrollment in the range of 20,000 to 30,000 students. Benchmark did not signify programmatic similarities. Two institutions we decided to interview had been part of the

\section{Annenberg Epiphany Project.}

\section{Invisible WPAs and the E-mail Survey}

We initially sent out an e-mail survey to our 15 benchmark campuses in order to decide which four of 15 campuses to visit. The e-mail survey was meant to serve only as a tool for selection. The e-mail survey provided interesting data about the 11 benchmark campuses that we did not visit. Five of the 15 WPAs at the benchmarks responded to our e-mail query about technology and writing in their programs. Five provided no information and five supplied partial or enough information that we could determine whether to exclude them as a site visit option. The WPAs and programs that we excluded as site visits are not invisible 
in this study and are discussed briefly here, though this process could be an article in its own right.

Generally, the WPAs at benchmark campuses report wide variation regarding the use of technology in writing programs. For example, at one campus, our questions are irrelevant because decisions about technology and technology facilities are determined outside the English department writing program. The English department teaches writing with a focus on Literature.

Specifically, we found two levels of information that deserve further investigation. The first level concerns the broad spectrum of writing with technology at benchmark campuses. The second level of information--and more surprising--was the nature and degree of responses by WPAs to our e-mail query. WPAs report the following on technology use:

- No sections of composition taught in computer classrooms.

- Program has little computer orientation and no computer facilities. Students use the University Writing Center.

- Students use Writing Center facilities and online writing tutoring.

- Program has one computer classroom with 25 stations. The decision to provide computer-mediated composition is a "self-fashioned" decision by individual instructors.

- Program has two computer classrooms with 25 stations. All other classes are "smart rooms" with an online teacher's station; two computer classrooms. 
- Program has two computer classrooms with writing course taught half time in computer room and half time in regular room. Computer rooms may be used at the instructor's discretion. Interested faculty self-select to teach in computer classroom. Program has two computer labs with writing courses taught in computer classrooms by interested graduate students and teachers.

- Program has a close link between the computer classrooms in the Classroom Building and the writing program, though minimal technology support is available to writing faculty interested in teaching with technology. Individual instructors make most decisions about technology, but graduate student students are expected to be computer literate.

- The University Information and Technology Services center supports CAI and any computer-mediated technology for students across all disciplines at this campus. The English department did not foster computer-mediated writing instruction. Of the roughly 180 sections of composition taught per year in the English department, computer-mediated writing instruction was primarily the interest of "of a few individuals who have become interested in CAI. There is no system to study here."

- One WPA responded in a phone follow-up stated that she did not want to participate in the survey, saw no reason to participate, if she wanted to know about technology she would ask her colleagues, and that furthermore and she was on her way of the country for travel. 
This last response hints at the diverse attitudes that WPAs at our benchmarks hold toward technology, as does the lack of response by a third of our benchmarks. No single model of writing with technology describes the technology with writing configurations (or lack thereof) in the benchmark writing programs. This fact alone can be open to many interpretations. We hypothesize that perhaps WPAs are so inundated by administrative duties that few of them can get their head above water to reflect on academic issues in their work-a-day lives. Several WPAs had difficulty directing me to the person in charge of technology in their writing programs. We were referred to various people across several departments as WPAs people sought to put me contact with someone who handles questions about technology in their program. Without more concrete data into the circumstances of these departments, we can only guess as the multitude of reasons for this information lapse. The program offerings may signal that institutions respond to local and regional, student and faculty, missions and mandates for technology and/or writing.

The lackluster responses by almost half of the benchmark WPAs caught me off guard. One WPA said he sent an e-mail and we must have lost it; he did not resend the errant e-mail. Two programs and I failed to have closure after numerous continued attempts at e-mails and follow-up phone calls We have no record at all of receiving any e-mail or phone feedback from two other programs. While researcher error or poor demeanor might be a deterrent when gathering data, in this case, these results seem to point to other answers for the low response rate. 
One possible reason for one third (5) of the 15 benchmarks failing to respond might that the WPA did not wish to participate in a dialogue about her program (or technology with writing) with me. She states that she sees not reason to contribute to any discourse with those outside her program. Also, she did not carefully read or clearly understand the nature of the e-mail survey. She says that if she wants to know about technology, "I would ask my colleagues." The e-mail survey offered her not advice. Rather, we requested advice from her. She saw no benefit to contributing to a research study on CAI and chose to rely on local collegial networks.

\section{Background on Site Surveys}

WPAs focus on several areas of agency or activism related to the teaching of writing: curriculum development, labor management, faculty development, and technology. In the most technologically rich and well-funded department, technology was seen increasingly to be taking a backseat to issues of retention. Future technology efforts consist of maintaining existing student computer classrooms, trimming redundant technology services promoting course management software, and planning a curriculum for those few (faculty and students) who wish to pursue a major in writing and technology. In those departments where technology is less well funded and the WPAs have a limited personal interest in technology, prospects for growth in the area of computers and writing seem at a standstill. For example, at the site visits, the University of Middle Earth (pseudonym) mentioned few new concrete plans on the horizon for the writing program. At Green Valley University (pseudonym), the departmental 
curiosity and camaraderie about technology that was initially stimulated by the Annenberg grant and Epiphany Project has not been sustained at previous levels. At Southern Harbor, funding flow serves to channel enthusiasm and productivity.

Significantly, all four of the universities at which we conducted site visits had multi-million dollar building projects underway, while the English departments and writing programs remained in older buildings with broken equipment and run-down classrooms. These campus facilities projects include substantive student centers, science buildings, dormitories, libraries, tech centers, and other facilities. English department renovations were limited to converting one or two classrooms for CAI, or less.

At all four institutions we visited, WPAs unequivocally agree that they feel strongly encourage to implement course management programs and online courses. Administration assumes that online courses will lead to greater cost savings and student retention in writing classes. The success or failure of online education for retention is still in the research stages, even though this study shows an overwhelming push at all four institutions that we visited to incorporate more online courses across all genres.

WPAs must contend with antiquated notions about technology from upper administration and disciplinary peers. In one example from the site surveys, administration in charge of implementing technology "bragged" that the English department has the oldest server on campus. WPAs must contend with misunderstandings about what constitutes effective technology even as they try to determine what is best for their programs. 
In another example, WPAs' disciplinary peers resist technology because they associate technology with pedagogical issues. Colleagues see plagiarism as stemming from the computer technology itself, rather than from social or pedagogical circumstances. Plagiarism has taken center stage in academic discussions and it is quite often directly linked to technology. Faculty describe technology as "making students lazy" because they go online to access library sources instead of going through the stacks. Using technology in this research capacity is not seen as an increase in technological efficiency. These unexamined assumptions make the work of the WPA more difficult. The impetus is to use technology primarily as a tool for hierarchical automation, homogenization, and efficiency as described by in the 1960s (385). Technological literacy equates with efficient and standardized experience rather than heuristic or creative productivity. WPAs' choices for technology with writing produce homogenized experiences and products.

At three sites, the data reveal that WPAs in CAI programs are often implicitly responsible for teaching students technology skills in CAI programs, yet, many departmental faculty resist computer literacy. WPAs state in the survey that they are waiting for retirement. In a similar vein, WPAs say that many of their colleagues see no need to upgrade their skills because they will be retiring within a decade so student exposure to new writing technologies must take a back seat. Finally, WPAs who work with technology say their extra skills have labeled them as "techies" or technicians when they possess technical expertise in addition to their scholarly achievements. 
Viewed amid these conflicting perspectives, WPA interviewees ponder for a moment when we questioned the WPAs about their agency with computers and writing. They pause and carefully reposition the ways in which they had exercised whatever definition of agency they had. The term "agency" in the context of this study is similar to Greg Wilson's definition in the article "Technical Communication and Late Capitalism": agency is the ability to act in one's own interest (73). Wilson's stated goal is to encourage students to "critique their relationships as communicators and social actors to technology and authority...to instill a sense of agency as communicators and workers in order to improve the profession of technical communication and the product of companies that employ technical communicators" (74). The WPAs express many of the same objectives. These conclusions conform to Gary Rhoades' observation of material conditions in writing administration: "Decisions on whether or how to use specific instructional technology have largely been made by administrators, not faculty, including decisions to use such technology to eliminate faculty $(189,194)$ " (Rhoades in Horner 24). Often WPAs" agency might not be transparent. Agency takes the form of benign neglect in the implementation mandates. For example, interviewees at three sites state that some of their co-workers have no interest in learning new technologies because they are close to retirement. If upper administration wants technology and writing, then the WPA makes available two CAI labs for interested faculty: that is all. Agency-in-action is a not as transparent or identifiable as one might first imagine. 
Agency can be compared to the term "activism." WPAs often plan, delegate, and guide their programs to the best of their understanding toward CAI that assist students and colleagues. WPAs' activism is in line with C. Selfe's "professional activism," which takes into consideration uses of power (1999 $\underline{\mathrm{CCC}})$; LeBlanc's "teacher activism" (LeBlanc in Hawisher and LeBlanc 95) argues for theorized software development; or with Ellen Cushman's politically aware researcher/activist who insinuates her administration with a civic duty "to empower people with our positions" (14 "Rhetorician"). WPA activism/agency manifests and participates in similar discourse that focuses on labor, retention, and curriculum and other issues. Computer-mediated writing, to the degree it is funded institutionally in the English department, seems to flourish or stagnate. However, the force of personality of an enthusiastic WPA or CAI community has attracted funding and interest in CAI.

WPA's heightened awareness of power issues in the academic bureaucracy may lie in other factors: the labor conditions of writing programs that have traditionally relied on heavy use of adjunct labor and WPAs are sensitized to power issues. As Horner observes regarding labor, composition has a perceived "greater organic significance to socio-economic production" (24 Critique). The focus on pedagogy can be seen as both a bane and a boom. Composition still fights perceptions of being a "contentless" non-discipline and stepchild to literature; yet composition's protean identity has helped it attach itself into so many areas of multi-disciplinary content: business, technical, informatics, humanities, professional, writing centers, WAC, WID, sciences, and workplace. 


\section{University of Middle Earth Site Visit}

"We used to run our own server in this department. It was a very old server. In

fact, management before us like to say that it is the oldest server on campus-like it was a good thing." --Graduate Technical Assistant

\section{Inevitability and Resisitance}

Like most the other benchmark institutions, University of Middle Earth (pseudonym), is a public, urban, and multiculturally diverse university of approximately 25 thousand students. It is located in the Midwest. The Middle Earth English department teaches approximately 90 sections of introductory composition in the first fall quarter. Faculty interested in teaching or students interested in accessing computer-mediated labs have available two departmental computer labs, a 24-hour building computer lab, and the library computers. The department employs 50 full-time faculty members mostly in literature. About 55 adjuncts, graduate students, and full-time, non-tenure track faculty teach composition. Cathryn Appleton (pseudonym), Director of Composition, seems comfortably resigned to the inevitability of technology and its role in the English department writing program. Appleton arranged interviews with herself, two lecturers, and a graduate student who had some administrative responsibilities (2001).

Appleteon asserts her agency as a WPA by agreeing to the larger administrative goals for which she was hired, while limiting personal commitment to CAI. On close reading, her "narrative" about technology in her department 
reveals undertones of resistance. In her interview she talks about what she accomplished for CAI in the past and now she has moved onto to managing the more pressing needs of her teachers and students. She exercises her agency not by overt, bold, or public action, but by what will become a common tactic of resistant WPAs' and most English department faculty in this study: passive resistance. If we read Appleton's interview through a Bakhtinian frame, we can hear in her words the sense of the inevitability of technology. When asked what her role as a WPA has been since she came to University of Middle Earth, she replies, "I can say that when I came it was clear to me that they wanted to hire someone open to develop that part [technology] of our work here." As part of her preparation to develop CAI, Appleton says she sat in on one composition class that was taught in one of the departmental computer labs to see what it was like. That experience helped her formulate her stance on technology in her writing program. More recently, she has assisted faculty to become fluent in Blackboard $\mathbb{B}$ and e-mail.

Even though Appleton admits that upper administration at the University of Middle Earth strongly encourages technology use, she feels she has left her own imprint on the curriculum and faculty organization: "I worked pretty hard when I first came here to find out how things were done...but I am a very different administrator than say, Janet Fletcher (pseudonym) was.” Appleton does not envision a greater role for technology in writing under her tenure as a WPA: "I don't know in 20 years what I would do, but I won't be here that long anyway...so just more availability and resources to train support people. I think 
that would be the best way to go." Appleton states that is planning to retire in the next few years. A pervasive theme at three of four site visits is the notion of the changing of the guard by those who I describe as being on the "retirement track" At three of the four sites we visited, WPAs allude to faculty who were hired about 15,20 , or more years ago and will be retiring soon. These people show a reluctance to commit more effort to technology development beyond e-mail. WPAs report that many Literature faculty day they will be retiring soon and prefer not to commit to professional development in technology.

Similarly, Appleton says prefers to focus her energies with staff development and strategies to retain students. Appleton describes her primary concerns as follows:

- Securing pay increases for faculty

- Introducing more critical thinking in the writing curriculum

- Improving ESL and minority student retention in writing classes.

A significant part of Appleton's interview centered on the development handbook for the first-year 101 Introductory Writing Course. With colleagues, she implemented a departmental Composition Handbook that is updated and republished annually for students and faculty. Most important, Appleton emphasizes that the handbook answers student and faculty concerns. Students buy the 101 handbooks for under $\$ 15$ and the course expectations are predictable across instructors and composition sections. Appleton closely connects technology use with the agenda of upper administrators (See Figure 3). She prefers the more altruistic managerial work that focuses on "people" and 
"students." For Appleton, technology is not aligned with the needs of students and people; technology detracts from labor issues and student writing.

Figure 3. Technology vs. People

\begin{tabular}{|c|c|}
\hline Technology & People \\
\hline CAI & Labor and Students \\
\hline Administrator-driven & People-driven \\
\hline Finite Projects & Ongoing work \\
\hline
\end{tabular}

In this program, the use of computers has been left to the individual initiative of technology-friendly instructors and students. Furthermore, she blames computers for an increase in plagiarized writing cases with students who use the Internet to procure essays for writing assignments. She also hints that a lack of writing rigor in the second quarter research-writing course is due to the advent of computer technology. In the research course, teachers routinely instruct students in the use of the library and computers as research tools. Appleton notes that "in some ways technology has made them [students] lazy" because they do not even know how to find a book in the library or what a call number is. Paradoxically, she adds that the more computer labs the department has, the better off the program would be. She concedes that technology does not attract or benefit everyone equally: “I don't think everyone is meant to teach in one [computer classroom]". 
In her role as WPA, Appleton has judiciously enhanced technological niche areas such as course management programs, e-mail, and writing classroom access for technophiles and upper administrators. "Critical thinking" remains located in the composition classes as a rhetorical tool of the few instructors (mentioned in the next section) who like to teach with technology. Appleton does not foresee incorporating a critical technological literacy in the near future at this department.

\section{Force of Personality:}

The CAI classrooms were in place shortly before Appleton came to Middle Earth. Tony Baccio and Chris Diaz (pseudonyms) teach first year courses (101 Composition, 102 Research, and 103 Literature) in computer-mediated classrooms. Baccio and Diaz are two of the department's ten non-tenure track lecturers called Adjunct Assistant Professors. They are represented by a union and negotiate a three-year renewable contract, are salaried, receive full benefits, are expected to do some service, and present pedagogical work at conferences. According to Baccio, high rates of instructor turnover prompted these positions: "Jane[former department WPA] and Cathryn said we needed some continuity [in the part-time faculty] so I became a member of the freshman English committee."

A central concern at three of the four site visits was continuity and consistency within departments. WPAs sought to standardized curriculum, staffing, faculty development, and instruction. Technology was valued to the degree that it served as a tool that could homogenize the work of the WPA. CAI does not yet seem to be utilized as a tool for creativity, discovery, sociality, or agency, albeit the laudable efforts of a handful of classroom instructors such as 
Baccio, Diaz, and graduate students. These cadres of teachers, WPAs, and students often act at the periphery of departments. Many WPAs gravitate toward technology applications that standardize educational experience rather than use it as a critical heuristic. Technology appeals to many WPAs for its potential to recreate a modern grand narrative of efficiency.

When Diaz began teaching in computer-mediate spaces, he received almost no technical or pedagogical training, as is the case with many composition teachers; still, he firmly believes that students learn better with CAI. He believes that students "could see and hear me and that was better than if they read it in Hacker, at least I thought so...I started using more author sites.” Baccio concurs, “Books just don't have it anymore and I can see it even in myself. I don't read as much as I used to read." The lecturers were aware that the English department in general does not currently share their philosophy because "everybody is still pretty much book oriented, language oriented." Selfe, Hawisher and Ericsson echo Baccio and Diaz's observations that schisms in conceptualization of CAI pedagogy exist. Selfe et al. note that composition programs in general, have neglected to respond to visual and multimodal approaches to composition. Rather, writing programs perpetuate historical methods of writing instruction. This might take of the form of the primacy of the study of literature and the academic "paper" (“Stasis" 269).

When asked if his vision of technology and writing was institutionally supported, Diaz offers, "I think we've gotten fair support. The university has been kind of nudging everybody in this direction. But it wasn't until fairly recently that 
our department got the kind of equipment that we really want people getting interested in." However, I saw that the phrase "using technology" might signify very different processes and outcomes when said by administrators or by teachers such as the Baccio, Diaz, Selfe et al. Upper administrators herald "using technology" as an organizational equalizer that regulates and standardizes experience and generates new student markets. The teachers herald "using technology" as a way to access more diverse modes of experience. These modes might take the forms of hypertext argumentation, graphics, and global access through blogs, MOOS and so on. Baccio and Diaz note that Provost Richard Larsson (pseudonym), a professor in English and an associate dean promotes technology: "He [Provost] is also pushing for learning communities and...online work on the computer." These lecturers look forward to more classrooms being at least a smart classroom with a projector and Internet connection.

\section{Becoming the Authoritative Word: Graduate Student as Techno-Authority}

Frank (pseudonym), a master's student became interested in technology because no other position was available in the department for him at the time of his matriculation into the graduate program: "I requested to teach. They didn't have a position for me. They offered this [technology position] to me and I took it." According to the lecturers, teaching or administration of computer-mediated spaces at Middle Earth has most often evolved along two paths: someone was "really into" or "got hooked." Frank "got hooked" on technology because his departmental needed technological support staff. The conversion or "got hooked" 
narrative is very common when talking about how academic laborers came to technology. Frank exemplifies the graduate student, who because of his affiliation with and for technology, is transformed into an authority figure of technology in the composition and the writing program. He notes antiquated ideas about digital technology in the department: "We used to run our own server in this department. It was a very old server. In fact, management before us likes to say that it is the oldest server on campus-like it was a good thing." As a young WPA, Frank already sees that administrators have varying degrees of technological sophistication. Interviewees at all four sites indicate strong undergraduate and graduate student support of computer-mediate instruction. Frank agrees that that undergraduates seem to be increasingly computer-literate with each semester. Students interviewed in the site surveys did not question the place of technology in writing instruction.

\section{University of Northwoods Site Visit}

"I really wanted to create a space for instructors to come in where they'll feel comfortable and welcome....I actually had to fight a little to get a coffee pot that I've got." --Graduate Technical Assistant

\section{Centrifugal Forces: Technology vs. X}

Anita Jackson (pseudonym) had been the writing program director for seven years at the time of the University of Northwoods (pseudonym) site visit. 
Northwoods is a Midwestern university with demographics similar to University of Middle Earth. Jackson has worked at Northwoods for 22 years as a scholar and the writing center director. During her tenure as a WPA, technology issues in her program focus on how to buy computers, not issues of literacy and technology, pedagogy or sustainability. She candidly reveals, "I have to say I was embarrassed when I looked at the list of survey questions [i.e. the e-mail survey questions sent to all 15 benchmark institutions]. We are no way near; it is nowhere on the horizon." CAI has not and will probably not be a priority in her tenure as a WPA at Northwoods.

She admits her technological concerns have focused primarily on how to secure money to buy 30 computers, not on sustainable infrastructure, critical technological literacy, or long-term sustainability. More than Appleton at Middle Earth, Jackson reports that she receives explicit direction from upper administration on how to incorporate computer-mediated instruction, or how not to incorporate it. She feels pressure from the new chairperson Henry Foster (pseudonym), to focus on issues of grammar. Neither Jackson nor Foster has used technology to assist with grammar instruction. Her agency is tempered by his vision for writing instruction. " $[\mathrm{H}] \mathrm{e}$ is desperately working to get more sentence-level focused instruction in our classrooms. I am working with him. Henry is going to train eight lecturers to add grammar to their classes so that they can be part of his clusters program and have more sentence-level work."

Repeatedly in the interviews, technology was described as competing for resources. For Appleton and Jackson technology was in competition for their time 
to work with labor. For Foster, technology stands in the way of the real work or writing, which he assesses as grammar instruction. For literature faculty, technology competes with the content of Literature. This formulaic binary-Technology vs. X--coerces technology into an oppositional role. It strains departmental resources: time, people, funds, space, materials instead of best utilizing resources. The language of many WPAs toward technology, even those who favor it, emphasizes technology's intrusion into writing and instruction. Some faculty hold an "and this too shall pass" attitude.

These binaries fail to take into consideration alternative perspectives of technology. Technology funding has contributed to English departmental facilities and writing, if not literature studies. Technology funding does not necessarily take resources from departments by the funds that support hardware, software, and professional development. Rather than seeing technology in competition with labor, technology can be seen as an ally to historically unbearable workload of writing classes. Workload can be ameliorated with innovations such as paperless classrooms, editing software, and some distance education features. Part-time lecturers often lead the way in technology use because of the flexibility it offers. Time spent on technology need not decrease time spent communicating with people. Once users overcome learning curves for new applications, technology increases opportunities to communicate with people in a variety of formats, times, and venues.

The Technology vs. X language is often used by WPAs in our study to describe technology (and CAI by association). A well-meaning provost at 
Northwoods, a computer engineer, asked if technology could help Jackson with her labor crunch. Jackson clarified the slippage between meaning and language: "When the Provost asked this question--isn't there some way technology can help--he is speaking very carefully." She suggests that the Provost thought the writing program could (should) use technology to streamline the writing program and make it more efficient. Jackson adds, "I do not think he comes to it with an understanding of the basics of writing instruction and practice."

For Jackson, incorporating more technological options for critical technological literacy in the writing program that looks at the social consequences of technology will only come after satisfying administrative wishes for distance education. "We do have a strong push for online instruction...from central administration for online instruction," Jackson explains. Upper administration views technology as a means to decrease costs during this time of budget crisis. Northwoods stakeholders were battling a 50 percent retention rate of freshman class with a six- to seven-year graduation rate.

One area related to technology and writing that Jackson sees expanding is the area and scope of the Student Computer Aided Instruction Lab (STUDLAB: psuedonym) facilities. The lab is co-funded by tuition from foreign students for English language study. The English department and the University Writing Center plan to establish a MOO for campus-wide online writing tutoring to support the connection between composition and other undergraduate content courses. Much of the computer-mediated instruction has been designated to 
graduate assistantships and STUDLAB personnel. Jackson says only one faculty member is active in technology and writing at a theoretical and critical level.

WPAs must deal with technology in the writing program daily, yet Appleton and Jackson see their agency as centered elsewhere. Their language implies that they are pushed and pulled by conflicting perspectives on technological literacy. They must negotiate varied meanings and intentions in their communication about technology use in their programs.

\section{WPAs in Training: Technophobes and the Retirement Track}

WPAs and graduate students from the site visits report that English faculty (especially in Literature) reluctantly consider implementing computer-mediated writing and technological literacy, if at all. Suma Mandalay, a second-year graduate technology assistant in Langauge, Literacy, and Rhetoric at Northwoods describes pervasive departmental avoidance of technology and writing. Most professors are disinclined to use technology according to Mandalay who did not anticipate that "proselytizing for the use of technology in the classroom."

Mandalay crated an artsy coffee house mood to her STUDLAB office space to sooth technophobes. She replaces the harsh fluorescent lighting with incandescent bulbs. She covers the walls with warm rouge and earth-tone tapestries and littersthe floor with pillows and beanbags. The decidedly eclectic office exudes a low-tech feel even though the office supports several computer stations for faculty and graduate students. Mandalay muses on how hard she had to fight for her vision of accessible, friendly, and visible technological support: "I 
really wanted to create a space for instructors to come in where they'll feel comfortable and welcome.... I actually had to fight a little to get a coffee pot that I've got....I really feel like people are perhaps a bit more techno phobic in this department."

Mandalay observes that it took two years of aggressive marketing to get even a few tenured faculty to come down to the STUDLAB. Generally, faculty seem unprepared to re-imagine syllabi in terms of using a computer and technology in the classroom though a few instructors use computers in classrooms for the following: discussion, online tutoring, class chats, small group conferences, textual discussions, and accessing research, and surfing websites. Mandalay sees a core of a dozen people who are dedicated to integrating technology into their classroom. A dozen more teachers, mostly non-tenured, make regular trips to STUDLAB during the semester. As with University of Middle Earth, faculty at Northwoods who has secured tenure see little need to learn anything new about technology. During casual conversation Mandalay discusses which faculty will be retiring.

Unlike Frank, the graduate student at the University of Middle Earth who was a converted technophile by happenstance, Mandalay admits to being a technophile since authoring her first Web page in 1995. Mandalay prepares the teaching schedule for the computer classrooms and presents a one-day technology seminar at the beginning of each semester. Her position carries a one-class equivalency as a teaching assistantship plus being 15 hours per week for one-on-one consultations and training sessions in software use, such as PowerPoint. 
Composition graduate students, junior faculty, one Literature teacher, and a few part-timers are the most enthusiastic technology adopters in the department. Mandalay hypothesizes that perhaps these groups embrace technology and writing more readily because of their age, familiarity with the medium, or seeing technology as a way to distinguish them from the pack. Her hypothesis corroborates other interviewees from this study who have commented on Literature faculty's aversion to writing or teaching with technology and reconceptualizing technology as having a critical or theoretical component. This appears to be a rich area for future research.

In "Conflict, Collaboration, and Authority: Graduate Students and Writing Program Administration", Suellynn Duffey et al. ask, "How, then might we prepare graduate students to understand and work for change in the material constraints of our local bureaucracies?" (80). She answers this question with the following: collaboration, critical self-reflection, and communities of teachers who "develop their roles as agents of change when they become faculty members" (80).

Mandalay attempts to use her agency to change the ethos of her department toward technology. At this department as in others, many faculty seem tolerant of CAI, but were resistant to its incursion into their established scholarly interpretations or what constitutes writing and pedagogy. Even though her program provides reasonable support for her technological activism--graduate student assistantship, computers, classrooms, offices, access, time, visibility, she nonetheless, expresses frustration at the general lack of enthusiasm she feels for 
CAI. Duffey et al. argue, "A significant part of one's initiation into the profession is developing a sense of oneself as a teacher and/or administrator" (84). For the graduate student who desires a technology-based position (Suma at Northwoods) or the student who is placed into a technology-based position (Frank from Middle Earth), this transition is enriched by the experience of CAI administration.

\section{$\underline{\text { Southern HarborUniversity Site Visit }}$}

"This I think is the real problem for technology-identified people in English departments because as soon as you are identified, even if your line has nothing to do with technology, you are the one that people will grab in the hall." --Lecturer and WPA.

\section{Promise of Technology: Sustaining Labor}

Southern Harbor is a midwestern university of very similar demographics to Middle Earth and Northwoods. The Southern Harbor University English department (pseudonym) originally hired Sara Smith to run placement tests because of her assessment experience, unlike Appleton and Jackson who were hired in part to develop technology and writing in their departments. Smith's computer experience was a bonus to the department. Smith's interest in technology started in college when she struggled with computer programming and decided to take a course in BASIC, which she then found engaging. Since 1993, she served as a WPA in varying capacities. In 1998, she became Director of 
Writing. Several non-tenure track lecturer lines were rewritten to include administrative duties on 3-3 teaching loads in order to assist in administration. Smith's program was at one time funded by a national Annenberg Epiphany grant for technology, which she credits for positioning technology in a positive light in her department and institution.

The department's non-tenure track WPAs Jackie Cross, Lisbeth Witherspoon, and Kit Capshaw (pseudonyms) have shared in collaborative management of the writing program for over ten years. The curriculum is constructed so that all first year students have the opportunity to have half of their class time in a CAI classroom. Democratic and consistent teaching with technology is attempted in most writing courses. A strong institutional support exists for students and for faculty development. The writing program has remained unified in its goals with Literature operating in its own sphere. WPAs state a high sense of agency in their work

Smith states in the interview that she does not feel pressure from the higher administration to incorporate technology in the writing program: "Not really. We have always had computer labs." Yet, applying computer technology to writing has been an institutional priority even before her arrival in 1993. Smith concedes that "We definitely feel pressure to incorporate EZCourse [pseudonym for a university-based course management system] into our teaching, but that comes from the students as much as the faculty." Also, as the interview progresses Smith describes in more detail the budgetary constraints that have indeed, do pressure 
her to curtail her plans to pursue critical technological literacy in deference to pressure for online courses and course management programs.

As with our other sites, the WPAs at Southern Harbor are expected to implement course management systems. Technological literacy is an objective in the university-wide guidelines for undergraduate learning, which highlight key outcomes for undergraduate learning. Smith elaborates, "Our campus is just so technologically sophisticated that any pressure in skills that would incorporate technology in the curriculum here simply comes from the fact that we are a technology-rich campus."

Smith notes that technology has always been an important feature of the Southern Harbor writing program. At the insistence of upper administration, the

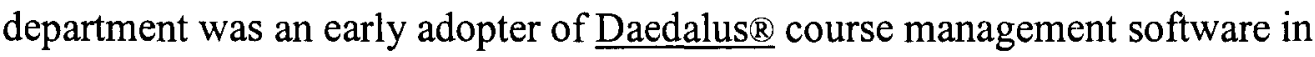
the mid-1980s before they switched to EZCourse. Additionally, Smith lists the institutional support provided for technology use in several support departments. The Center for Teaching and Learning provides a full-time staff to assist faculty on all technology needs related to teaching. Various cross-disciplinary programs provide ongoing workshops. Weekly e-mails inform faculty of local and national workshops on technology use. Funds are available for professional development.

Smith and her cadre of lecturer-administrators decided want a consistently delivered curriculum so that all writing students have at least half their classes taught in CAI classrooms. Smith adds, "We were reluctant to start exploring those things in our composition curriculum for some students and not others." 
All writing faculty are expected to teach with technology. Southern Harbor continues to provide student assistants in each computer classroom during writing classes and technology workshops throughout the year and at the beginning of each semester.

Smith states that her writing program has achieved consistent delivery of technology and writing with a stable faculty. Smith pensively comments on the irony that just as her program has the stability to develop courses with critical components such as highlighting technology within the English major and teaching more courses that focus on literacy and technology, educational funding shortfalls have "squeezed out" critical opportunities. The one-course release for each Cross, Witherspoon, and Capshaw might be eliminated in a few years. The elimination of the WPA course support for writing courses is rationalized because as students enter college with improved computer use skills, administration seeks to diminish departmental support for one-course release per semester to complete administrative work They will face an increase in workload with less time to explore critical curriculum. Funding initiatives such as student retention and faculty development take more precedence. Her administrative priorities are directed away from technology proficiency of faculty and students to labor reorganization and use of the EZCourse course management system.

Smith states that she prefers to concentrate on “...f]aculty development, notions of literacy that you find embedded in the curriculum, notions of access...the roots of technology are taking hold and things are sprouting up." However, Smith's 
agency is tethered to budgetary and labor constraints. In any case, Smith's need to deal with budget restrictions is standard in academia.

The WPAs describe a recurring scenario found in our site visits. Budget problems seem to swell just as programs seem on the brink of innovation. The relative stability of Smith's department provides a window of opportunity to add critical components now that the objectives or administration have been met. However, now er funding is being redirected to other objectives of higher administration. This effect can be seen in the next section that listens to the words of three WPAs and instructors whose workload will be most affected (curtailed) by this next shift in institutional mission by upper administration.

\section{Grand Narratives: Rhetoric of Agency, Reality of Budgets}

I suggest that Southern Harbor is entering the next phase of technology and writing. Specifically, now that Southern Harbor administration can assume that graduating students have consistent writing-with-technology skills upon graduation, instructors have been provided the measured requisite dose of professional development, and the management of the writing program is well oiled, CAI fiscal support can be shifted by upper to online instruction.

As virtual space expands to meet institutional and student needs, meeting physical space needs continues to plague the English departments. Lecturers receive a computer and a cubicle in a common area in the English department or are moved across campus to the theatre building. Cross, Witherspoon, and Capshaw concur that teaching space is "really maxed out in our building." 
Cross, Witherspoon, and Capshaw, who have have been collaborators and coworkers at southern Harbor for over 40 cumulative years, initially approached CAI from opposite perspectives. Witherspoon embraced technology in 1989 while Capshaw resisted technology until the late 1990s. Cross is the Director of CAI. All three are now active technology users. In 2002, Capshaw, the onetime selfproclaimed Luddite, designed and taught an online introductory composition class. A significant part of their occupational and personal self-image--and daily workload-- is linked to their growth as technology users.

Cross, Witherspoon, and Capshaw clearly define the borders between the technologically literate and the language literate. Cross, Witherspoon, and Capshaw comment that the "techies" or assistants and institutional support staff know very little about composition and might not be able to "pass English." They express concern that the supervisor of the lab and her staff can contribute no pedagogical, English, or writing assistance: "She [technical support supervisor for Liberal Arts] doesn't even have a degree to coordinate those two rooms." The student work-study technology assistants act as "security blankets" for instructors when the printers don't work. Also, the WPA instructors are concerned that instructors unprepared in using technology and writing effectively are "just giving students typing time. They are not using the computer technology in the way that would really help them achieve course goals."

Technology assistants at Southern Harbor maintain hardware and technical support from funds from the School of Arts and Sciences. A group of seven to ten work-study students (mostly Technology majors) and a supervisor oversees the 
English computer classrooms, foreign language labs, 24-hour general labs, and the social science labs. A technology fee of $\$ 120$ per semester funds this technical support group. Techies provide support and installation of new computers for faculty every three years. The technical support personnel at Southern Harbor are proud of their contributions in support of technology at Southern Harbor: "I've always been interested in computers" and "They [some faculty] hated computers until we helped them." Clearly both technical support and instructors eagerly promote technology for their co-workers.

To summarize the site visit at Southern Harbor, Smith sees her close relations to the instructors as a site of administrative activism. Her curricular curriculum allows for the integration of technology and writing. She connects her research and administrative interests in labor issues to her experiences as an administrator. Smith links agency, as Appleton and Jackson, to her labor practices and to writing a book about labor: "I am more likely to participate in that [the writing of a chapter on labor issues in the composition programs] than if I even were a fulltime lecturer who didn't have administrative responsibilities simply because I know so much more [about labor issue]." Additionally, Smith emphasizes that she uses her agency to in the following ways:

- to be public about notions of literacy

- to change people's perception about what it means to be writing.

- to marshal resources to address issues salient to our students and faculty

- to be vigilant for signs of pockets of excitement

- and, to look for pockets of discontent. 
Smith's denies that she senses pressure from upper administration about the uses of technology in her writing program. However, later in her interview, she reveals numerous mandates and budget changes that will directly affect her freedom to incorporate critical literacy, such as new courses with social, cultural, and critical emphasis. She fears these exigencies may get in the way of her plans for a more critical curriculum and course development. Her conflicting observations about the pressures she feels to use technology are significant. Even though she manages a stabile and longstanding CAI program with much support and many resources, she is under the mutable expectations of upper administration. Of the benchmark writing programs we studied, Southern Harbor receives the most institutional support. Institutional support, however, may come at the price of personal agency and goals.

\section{Promise of Technology: Labor and Division for Non-tenure WPAs}

Eileen Schell documents "psychic income" or the personal, social, and cultural personal worth that a job brings above and beyond monetary compensation, especially regarding adjunct teachers, though any teacher can work for the psychic benefits of an academic position (41). Cross, Witherspoon, and Capshaw, though full-time non-tenure track with over 40 years of combined teaching time among them fit Schell's definition of academic laborers who produce above and beyond the service or teaching requirement. Technically, they cannot be paid for research according to their contracts. CAI in their department offers an abundance of opportunities to provide uncompensated labor. When the 
objectives of upper administration have been met regarding technology and writing, administration easily cuts funding, this leaving Cross, Witherspoon, and Capshaw to "retool" for the next objective. They have agency within the scope of their occupational description, that is, their teaching to the degree it conforms to curricula. Smith, on the other hand, as a program director, has more power to the degree that she has funding.

Southern Harbor WPAs wear many hats as administrators, researchers, innovators, and teachers. Some of these administrative releases take the form of titled positions: Coordinator of W131, Coordinator of W132, and Coordinator of Composition by Computer. Most of these workers are women with master's degrees who have worked in the English department for more than ten years. Many of their concerns center implicitly and explicitly on the material conditions of their labor: time and space.

They are generally proud of the fact that they receive some credit on their annual evaluations for attending conferences, publishing articles or books, and generating intellectual product similar to the tenured faculty. However, $70-80$ percent of their workload resides in teaching and the rest in service. Their research efforts cannot be compensated. Nonetheless, they are prolific workers in the department and very proud to be positively associated with technology and visible to upper administration: "Once you become known for something, then you suddenly start getting all these e-mails and calls. The Associate Dean in the School of Liberal Arts e-mailed me and asked me if I would do a presentation to the whole school; it would be a Brown Bag on Just-In-Time Teaching" She then 
describes her presentation on just-in-time teaching that integrated technology so that students can have "little assignments at a certain deadline." Using technology this way, she feels, seems to avoid the "canned" lecture. Cross, Witherspoon, and Capshaw observe the double bind of being appreciated for their non-teaching achievements and being swamped by the workload not related to technology:

Okay, you get a course release for being the coordinator of a course; which means not just that you deal with that course...it also means you are part of the administrative structure, the writing program...the decisionmaking, everything that is part of running a writing program. But nobody gets a course release for being on the writing coordinating committee... more of your work comes from being on the committee than it does doing these specific things.

Once in the administrative structure, the instructors/WPAs found their workload had expanded to include the following: coordinating EZCourse teaching circles; attending strategic planning committee; attending Writing Coordinating committees; justifying annual reviews for teaching when much of their work is service; writing grants to implement an online program; training English faculty to work with EZCourse; and negotiating the tension between the Office of Campus Writing and other constituencies that deals with faculty and WAC. For Cross, Witherspoon, and Capshaw, technology increases their workload. In the interviews, the workload was compensated by factors such as collegial camaraderie, professional support, and institutional recognition for work with technology. 
WPAs at Southern Harbor and Green Valley University (GVU) in the next section appreciate their supportive CAI community. Notably, both these programs an WPAs participated in the Annenberg Epiphany Project. In additional to internal institutional support, external support such as the Epiphany Project lays the groundwork for sustainable technology.

Green Valley University Site Visit

"I have influenced a number of things for the positive, but it was as if I was speaking in another language." --Lecturer and WPA

\section{The Public Face of Technology}

Green Valley University is also an urban, public, and ethnically diverse campus of approximately 18 thousand students. It is located in the southeastern Untied States about one hundred miles from the Atlantic shore. Like Southern Harbor, the Green Valley University (GVU) writing program participated in the Annenberg grant-funded Epiphany project beginning in 1986. Such large and public initiatives carry the message to participating faculty and institutions that technology deserves attention, if nothing else. William Rodgers, Technology Director, came to GVU as a graduate student in 1986 with almost no experience in computers. In his second year as a teaching assistant, he asked to teach in a computer classroom. By his third year, he was managing the English department labs for ten hours a week. He applied for and received a non-tenure track instructorship with administrative duties for Blackboard ${ }^{\circledR}$. At GVU, Blackboard ${ }^{\circledR}$ 
rose to importance a few years ago when parents complained that students could not write. Parents and others wanted to know what was going on in the classrooms. Instructors could post their syllabus for all to see: "It was part of putting a public face out there in the midst of this reorganization and debate" summarizes Rodgers.

Constructing the "public face" of technology was central to Rodgers' agency. He became the not only a technology facilitator, but a technology advocate both inside and outside as his department. Locally, in the GVU writing program, affiliation with the Epiphany project highlighted CAI. Rodgers directly correlates the mainstreaming of faculty into technology and the addition of technology to the classrooms to departmental participation in the Epiphany project. Because of the Epiphany project's national reputation, Rodgers believes that overall departmental participation and attention was greater. A lesser technology initiative or a colleague's work would not have attracted so much attention. Regular Friday meetings brought together faculty on technology issues: "We had a core of individuals who would come to those meetings, including some older faculty, faculty who were a little shy of using technology" Rodgers says in his interview. Rodgers describes reluctant faculty as "shy" rather than technophobic or resistant. Rodgers laments the fact that they had not planned on problems of sustainability after the project concluded: "If there is any regret I have about it [Epiphany project], it is how difficult it was to sustain the energy that was generated by Epiphany meeting group once the grant was over and the follow-up grant was not funded." 
Now that the Epiphany project has ended, Rodgers is expected to maintain departmental technology and enthusiasm. For instance, he has to impress on upper-level administration that institutional technology support has to be reliable. He has to deal with power outages that the administration sees as unavoidable inconveniences. Rodgers summarizes his concerns: "So, again, here you are saying this is the way that we do business but then the whole systems can just crap out. All they say is oh, we are sorry. This is beyond an inconvenience; this might be stopping instruction." When administrators decided the cost of printing was too high, "One administrator's answer was to make printing available from only one terminal. So they were trying to do cost savings through inconvenience. I argued against it," Rodgers comments. When asked how he feels about himself in an administrative role, he answers, "There are administrative functions I have. But I guess that I try to think of myself more as a teacher, even in support roles and situations. When you call me to your office because you need help with Blackboard $^{\circledast}$, I am in a teaching role."

GVU does have a computer initiative that requires freshman students to come to college owning a computer. A relatively small percentage of writing courses are taught with technology. Rodgers sees improving pedagogy as his role as administrator. He wants to move beyond using his time implementing Blackboard $^{\circledR}$ course management system, to forwarding one of his personal initiatives, a paperless editing component.

Rodgers expresses his frustration with trying to integrate technological skills and literacy in his department even after previous exposure to technology and 
writing in the Epiphany project: "I am troubleshooting not only at the network, computing and pedagogy, but I feel like sometimes I am trouble shooting larger systemic issues and having a hard time getting anyone to hear. I feel like I have influenced a number of things for the positive; it was as if I was speaking in another language." The idea that those who work closely with technological literacy often feel as they are speaking a foreign language to colleagues or students came up repeatedly in the interviews. Often underlying this communication block are often feelings of isolation and marginalization.

\section{GVU Technical Support Staff: Inevitability of Technology}

Rodgers does not question the inevitability of technology in the academic workplace; however, he does question the inevitability of professional resistance by faculty to technology. Rodgers supervises four full-time workers and one student field worker who assist with the hardware and software on Dell computers, as well as one staff member who answers phone queries. Rodgers relies on Bill Wang (pseudonym), director of Technologies for Humanities and Sciences, for ongoing and supportive collaboration. They have internalized each other's needs and synthesized that understanding into their working relation ship for the benefit of student learning.

Wang manages the Novell Network, supplies hardware for faculty, computer labs, and maintains backups. From a technical perspective, Wang ranks the English department at the cutting edge for using technology in interactive ways and for creative ways of teaching. Students seem to put more time into classes 
with a technology component: "They don't get as bored with it as easily." When asked where Wang sees technology and writing use going, he says he expects more self-paced learning applications. He adds that courses such as introductory math and English might still require more time with teachers face to face than other courses.

Wang notes the discrepancy between what is expected of students and what is expected of faculty regarding computer literacy skills. He states, "We require students to have computers and require them to have knowledge of computers and have a certain level of understanding in order to graduate. Maybe we ought to require faculty to have computers and to have certain knowledge. Maybe they should take the computer proficiency. There is a layer of faculty that are just kind of waiting to retire and not have to deal with it; but all incoming people and students are very active."

Chapter IV shifts the focus from the e-mail survey, site visits, and interview data to the results of a broad national survey that targets WPAs and technology. I examine the similarities, differences, and surprises I find between the two data samplings. How do the local benchmark findings compare to a general observation of computers and writing WPAs? 


\section{CHAPTER IV}

SURVEY RESULTS OF WPAS AND TECHNOLOGICAL LITERACY

"Teaching with technology seems to be widely perceived by students, some

faculty, and many administrators as inherently virtuous, as a panacea for any

number of teaching and learning problems."

-Respondent's comment from online survey

\section{Online Survey Methods}

The purpose for collecting the online survey data was to descriptively compare the site visit results to broad trends reported by WPAs working with technology. I hope that the two forms of data collection will point me and other technology and writing researchers towards new avenues of research. Given these expectations for the online survey, the claims and topics of the online survey were identical to the claims and topics of the site visits.

The survey tool used was the CTLsilhouette Flashlight ${ }^{\circledR}$ Online survey hosted at Washington State University (see Appendix E). The survey format consists of 68 customized questions in multiple forms as follows: radio buttons on 
4- and 5-way scales; check boxes that allow single or multiple responses; and text boxes with open-ended questions at the end of each section. The survey content consists of eight sections: Demographic Questions (1-7); Compensation (9-12); WPA Effort (14-23); WPA Technology Preparation (25-29); Social Effects (3138); Labor and CAI (40-47); Students and Technology (49-54); Material Conditions (56-63); and text-boxes $(8,13,24,30,39,48,55,64)$.

The survey was posted to the WPA-listserv and the Tech-Rhet listserv on September 30, 2003 and closed on October 19, 2003. In that time, 61 discrete respondents provided answers for an $\underline{n}$ value of $61(n=61)$. In some cases, a respondent may not have responded to all questions, so the $\underline{n}$ value may be listed as less than 61 (e.g. 60, 59, and 58). The two listservs support over 2000 members.

"In Electronic Surveys: Ethical Issues for Researchers", Goree and Marszalek cite the advantages and disadvantages of using online surveys. These factors came into play in the developmental process of the survey. Ultimately, the types of conclusions I can claim comfortably about the data is limited by the method of collection. Researchers post online surveys because they are less expensive than other forms of surveys, they have a quick response time, and they also reach respondents who might not be reachable by other methods: "Online surveys avoid outdated mailing lists, stuffed and banded envelopes, paid for postage, and waiting weeks" state Goree and Marszalek (76). I posted the survey online because the target audience--WPAs in technology--seemed like a good fit for an electronic medium. 
The disadvantages of online surveys appear when trying to generalize from the online data. It is impossible to know who the survey reached exactly. Also, I cannot guarantee the size and accuracy of the two listserv subscriber pools: WPA-L and Tech-Rhet-L. How representative is the sample of 61? Is the subject pool inclusive regarding race, gender, ethnicity, and region (Goree 77)? Given that I lack this information, I find it difficult to use "inferential statistical analysis for electronic surveys" (Goree 78). The results of the study are descriptive statistics because some factors could not be controlled. Nonetheless, the quantitative findings confirm trends from the site visits, as does the qualitative data.

As mentioned above, I provide text boxes at the end of each section of the survey. The qualitative information in the text-boxes proved to be extremely useful. The respondents contributed over 15 single-spaced pages of comments ranging in topic from clarifications of their Lickert answers to questions about the survey itself. Some respondents sent personal greetings. All respondents were anonymous unless they identified themselves in the text-boxes.

Needless to say, not all the data can be covered in the dissertation at this time and will require more time to analyze. This dissertation will examine only four sections and a few individual questions. The four categories that relate most closely to agency of WPAs in CAI programs are Effort, Social Effects, Labor, and Students.

One significant difference appeared between the WPAs I visited on site and the online survey respondents. Survey respondents were much more pro- 
technology than the WPAs at the site visits. I credit this to the nature of the survey itself. The survey format selected for WPAs who would be highly technologically proficient and active. The survey-takers were inclined to use technology (listservs, computers). Some of the face-to-face interviewees candidly admit that they are not very proficient or even technophilic. They are WPAs who have to deal with technology in their writing programs. I hypothesize that the general pool of WPAs who use CAI or technology fall in the latter category. On this assumption, I can think of several methodological alternatives for future study on WPAs.

\section{Benchmark Campuses Reflect National Trends}

The empirical sampling of WPAs in the online survey shows similar trends to those in the e-mail surveys and the qualitative site visits of Chapter III: WPAs overwhelmingly state that they will continue to incorporate technology with writing as prescribed, though not necessarily as critical technological literacy as explained by Selfe. The previous finding supports the surprising response that fewer than 20 percent of WPAs surveyed report combining technology in partnership with business, industry, community or in service learning projects. WPAs predominately approach CAI as something constrained by the classroom experience even if technology can access the WWW and global audiences.

WPAs participating in the online survey generally show more eagerness to use technology in future courses than in the interviews. WPAs who are most at ease answering the survey online may be generally more proficient and comfortable with technology than a random cross-section of all WPAs. 
Respondents of the survey and site visit interviews unequivocally say that they encourage their staff to incorporate course management and online education. Likewise, WPAs feel pressure by supervisors to implement course management and online education.

\section{Turf, Power and Sociality in CAI}

The WPAs responding to the survey recognize their administrative charge to implement institutional objectives. The WPAs' agency seems to be split between resigned acceptance of the institutional and occupational mandates for efficiency and an unexamined application of a watered-down "technological literacy" that translates to not much more than word-processing and management formats. One WPA states that his entire FYC program is online and that it is "more cost efficient" [compared to what?] and "pedagogically sound" but there is "considerable resistance."

Three other WPAs bluntly state the following about their control over technology use in their departments:

- "Promotion of technology often gets corrupted into pressure to put courses online. Courseware often shows its source among programmers rather than among academics"

- "The use of technology is a given here; a part of our agreement with the university is to provide computer and Internet literacy in exchange for the use of computer labs." 
- "When I arrived, the first-year writing courses already included a required technology component."

For these WPAs, technology is a transparent and contractual relation to incorporate course management and online education. Technological literacy in the form of course managements and online course delivery forward the goals efficiency and standardization of curriculum and experience. Just as many of our site survey WPAs report technological literacy as management tools, so did many of the online respondents. Efforts on the part of WPAs to develop critical applications in addition to extant workloads can seriously impinge on the time needed to keep up with advances in technology, not to mention the other writing components of a course. Selfe's vision of critical technological literacy is not an additive experience tacked onto literacy. Critical technological literacy needs to operate integrally within a network of pedagogy, practice, theory, and activism. Regrettably, respondents report they barely have time to keep up with technological innovations. A combined 64 percent of the WPAs polled in Figure 4 agree that they have difficulty keeping up with technological advances in their current positions. 
Figure 4. I have difficulty keeping up with and applying technological advances

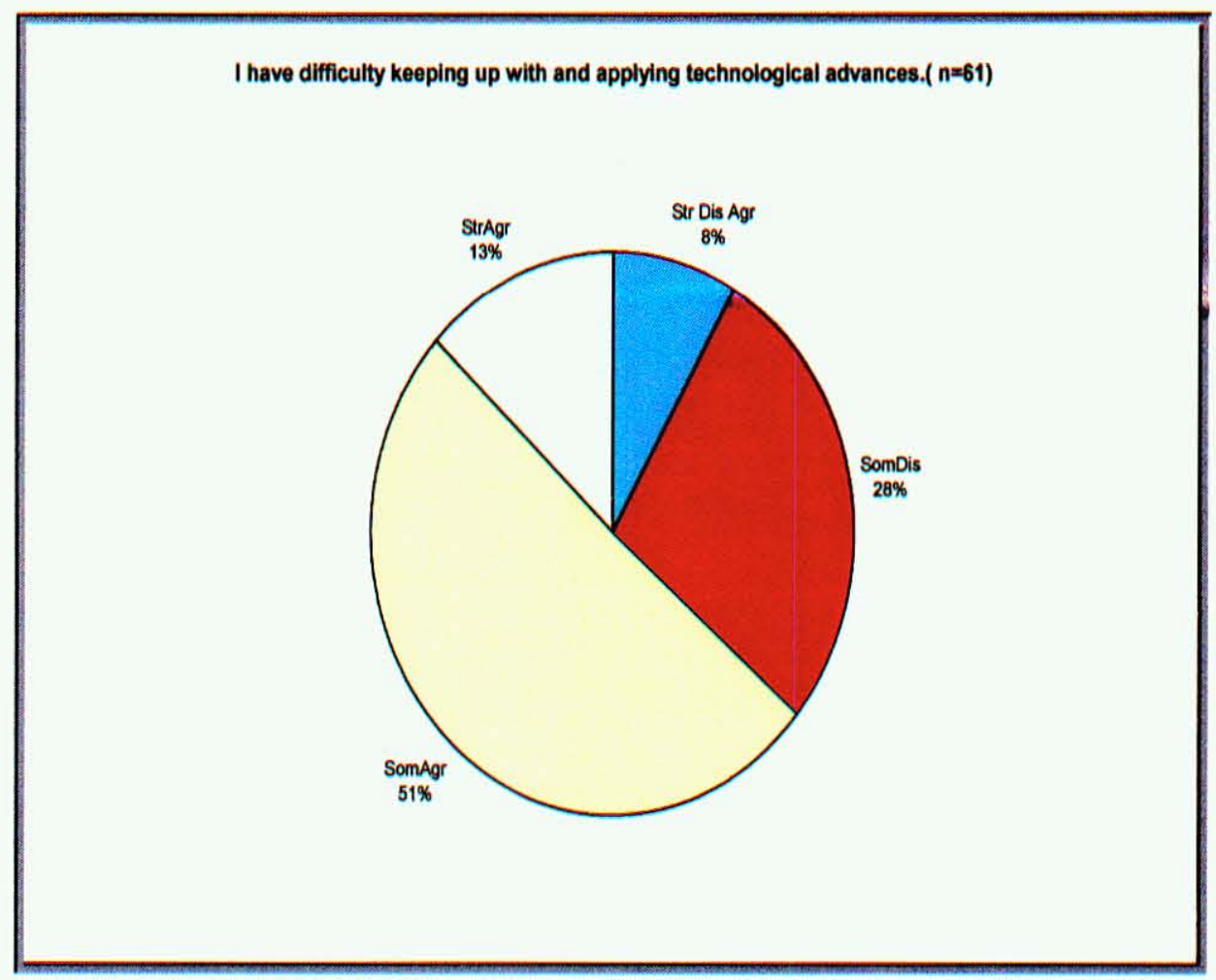


In Figure 5, we see that WPAs are almost evenly divided about being compensated fairly for their labor, with only 8 percent $\underline{\text { Strongly Agreeing that }}$ they are well compensated for their technology skills with 34 percent that $\underline{\text { Strongly Agree, }} 30$ percent that $\underline{\text { Somewhat Disagree, and } 28 \text { percent that } \underline{\text { Strongly }}}$ Disagree.

Figure 5. My department compensates me well for the technology skills I bring to writing classes

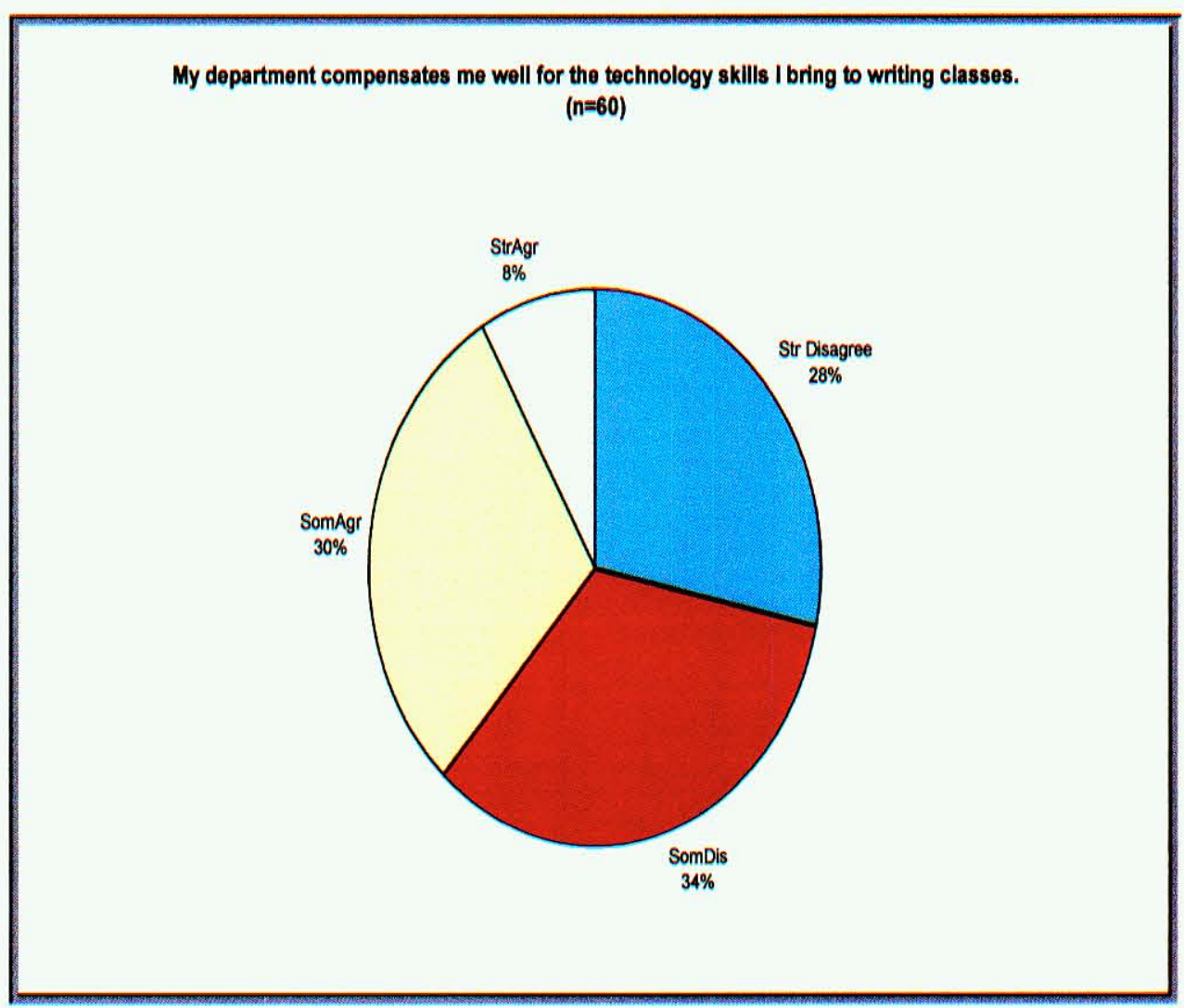

As with the site visit data, survey respondents state that adjunct faculty seem more inclined to incorporate technology than Literature or full-time writing faculty: One respondent stated in text-box question 39 that "Our part-time 
lecturers are quite competent with technology. Our full-time faculty is not." ("Any comments on teaching with technology or incorporating technology in writing programs?) Adjuncts may use CAI because technology helps adjunct instructors communicate with students outside of class time. In general, Literature faculty do not teach the lower division composition classes and they often see no need to pursue technology. Adjuncts might find technology an ally because they need to be more time-efficient and flexible. The same respondent confirmed the onsite interview evidence that technology use in writing classes was primarily the domain of non-literature faculty: "My department is very based in Literature, and there is no real interest in incorporating technology at all by the ranked faculty."

The online survey reveals a spectrum of WPA positions regarding the use of technology with writing. At one end is the view of technology as an intrusive tool in the writing process that should be used for lower-order concerns. At the other end, WPAs are attempting to use technology as an interpretive and critical tool for rethinking institutional and social power inequities. As with the some of the site visit data in Chapter III, some respondents still see technological literacy as a nonessential element in the writing process. Real writing it seems is only the alphabetic notation and verbal rhetorical moves writers make. Many WPAs and respondents do not concede that technological elements, such as graphics and hypertext, can contribute to rhetorical and persuasive writing. One respondent saw technology as discrete from real writing:

I'm very hesitant to agree that using writing classes to provide technology instruction is a good idea... I think it is a good idea to provide SOME tech 
instruction, as it relates to student writing \& editing, but perceive it as an extra, non-essential aspect to a writing course. And I feel it shouldn't ever overshadow the writing aspect (Q55: "Any comments on students and writing with technology?").

Another WPA expresses the familiar frustration of having to take class time to explain basic technology formatting in a writing course. In the following quotation, the speaker defines technology as word-processing. There is no understanding of technology as a complex rhetorical tool capable of social impact:

To be boldly honest, I wish the students would take a computers 101 class *before* taking composition, so that I could assume that they know basic things, such as file management, Microsoft applications (word, PowerPoint, explorer, etc), common file extension types, how to use (and how NOT to use) spell check and grammar checkers, and so on. Every time I have to explain how to save a file to a zip or floppy disk, I feel I'm wasting valuable time. (Q55).

I empathize with the respondent above. I, too, have wished that some of my students were better users of writing tools. Technology also has persuasive power. While some responses define the borders of writing and technology in the classroom as above, other responses define the term "power" in the survey questions. 


\section{Discursive Issues of Power}

Several respondents question the use of the word "power" in survey question number 38: "In my department, knowledge of and proficiency with technology affords power to those who have it." In Figure 6, 58 percent of the respondents $\underline{\text { Agree }}$ or Strongly Agree that in their department, knowledge and proficiency with technology affords power. Some respondents, however, put the term "power" in quotation marks ("power"). The respondents attempt to qualify and contain the term "power". "Power" is the tip of an iceberg for invisible and highly personalized interpretations:

- "These answers reflect two different workplaces since I recently changed institutions. The 'power' questions, for example, apply to my former but not current situation."

- "I disagree with the use of the word "power." Those who use technology heavily are equally respected and equally powerful compared to those who choose other teaching strategies.”

- "37 and 38 are interesting. Knowledge and proficiency afford a certain kind of power, but sometimes (often?) such facility w/technology has less 
academic cachet than other talents. So it can be negative rather than positive. Difficult balance."

The fact that some respondents felt uncomfortable with my use of the term "power" points to issues of authority and agency that this study seeks to explore. Why is does "power" in the context of writing programs, technology, and writing cause dis-ease? Future studies might focus just on terminology of agency power.

Figure 6. In my department, knowledge and proficiency with technology affords power to those who have it

In my department, knowledge of and proficiency with technology affords power to those who have it. $(n=61)$

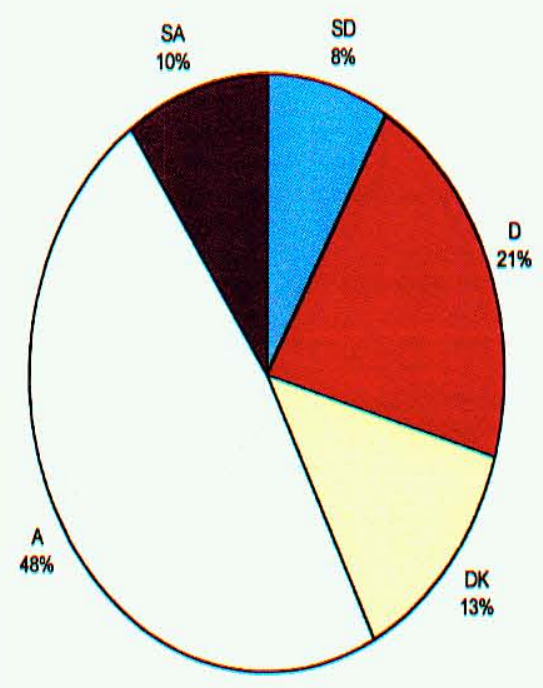

In Figure 7 and Figure 8, however, WPAs mention technology as a more predictable locus of strife within their English department. WPAs note a positive 
regard for their work with technology, as shown in Figure 7, by people outside the academic community.

Figure 7. People outside my academic workplace show me respect and admiration for the work I do

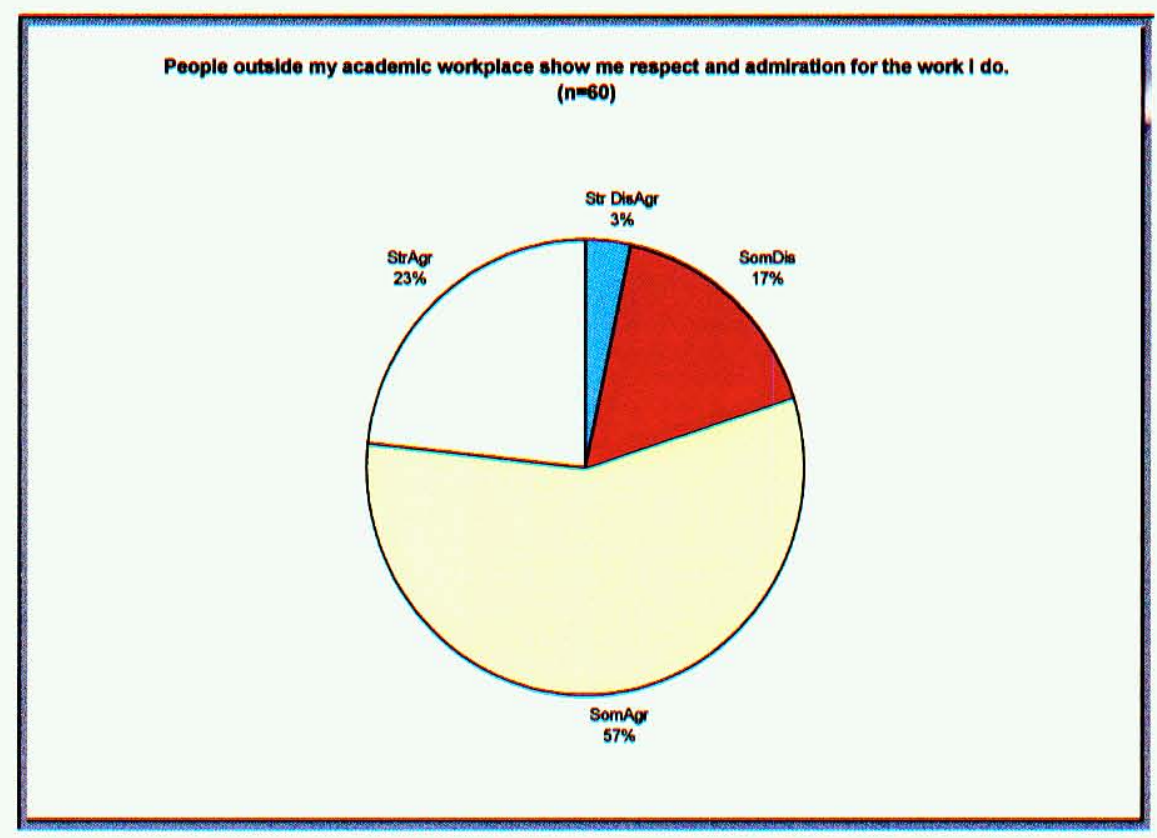

If WPAs seek recognition and respect for their work with technology, which can be a kind of power or agency, they report strong appreciation for their technological expertise. I am reminded of William Rodgers from Green Valley University whose technology work created GVU's "public face" of technology and writing for the parents and community. Public and student perceptions of technology work remain positive, for the most part. Within departments and writing programs, combining technology with writing has been found to cause conflicts. Here a much closer examination of faculty perceptions of technology and writing might be useful. 
Figure 8. I have had conflicts with co-workers because of technology-related concerns

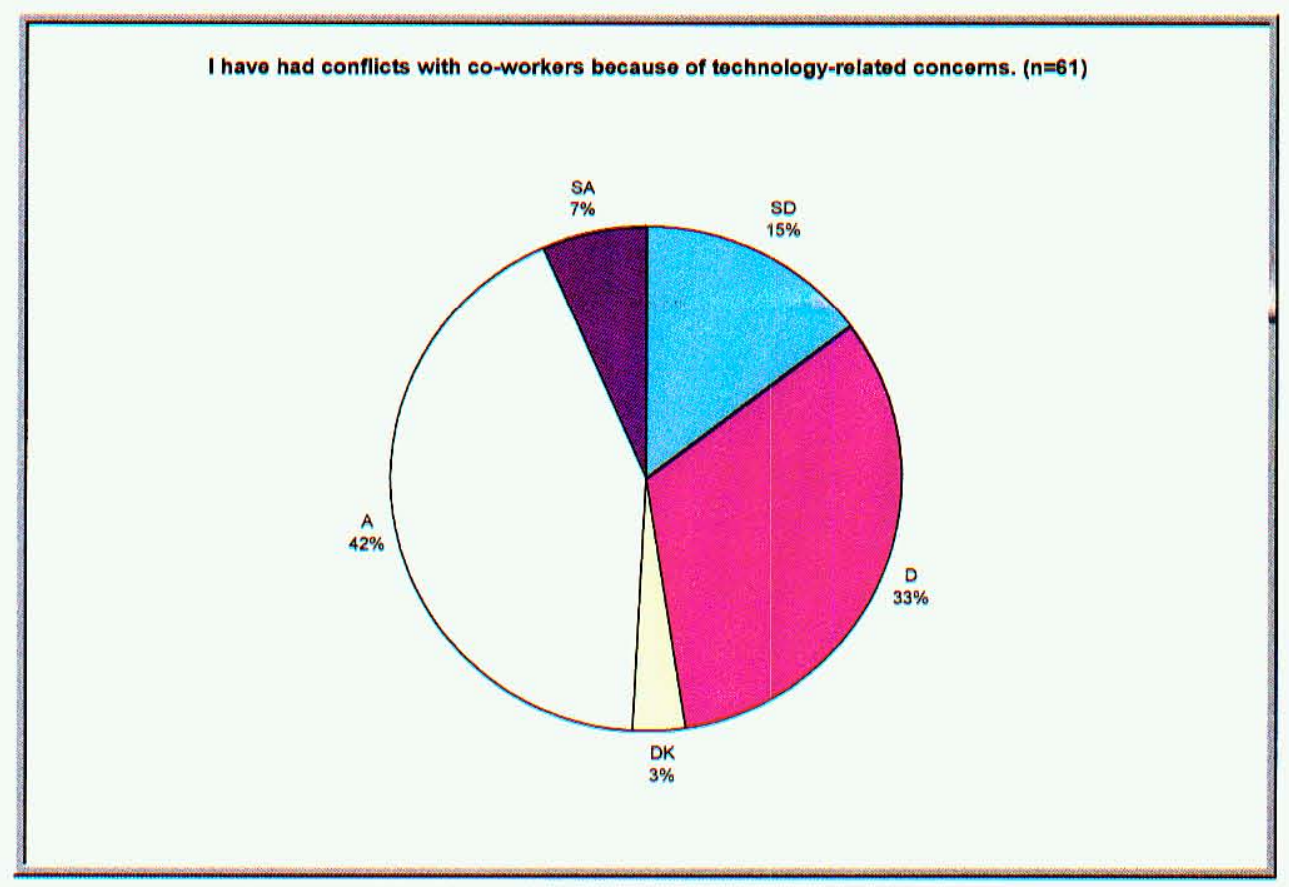

Forty-nine percent of WPAs agree that they had conflicts with their coworkers because of technology-related concerns, while almost one-third saw technology having no effect at all. Conflict in this case may be interpreted as a sign of routine intra-disciplinary boundary exploration. That is, as faculty try out new ideas and pedagogies, curricula, and materials, departments experience pangs of growth and upheaval. What exactly is a desirable or healthy ratio of conflict to growth? What can or should a department or institution tolerate for the sake of growth?

In Figure 9, only 33 percent of the respondents $\underline{\text { Agree }}$ or Strongly Agree that technology is seen as proprietary or "turf," while 48 percent $\underline{\text { Disagree or } \underline{\text { Strongly }}}$ Disagree that technology is seen as proprietary. Respondents report that technology causes conflicts, but those problems are not related to control or 
ownership. The precise nature of the conflict in departments as it relates to technology would be an area for future study.

Figure 9. In my department, we have had issues where technology was seen as proprietary or "turf"

In my department, we have had issues where technology was seen as proprietary or "turf". $(n=61)$

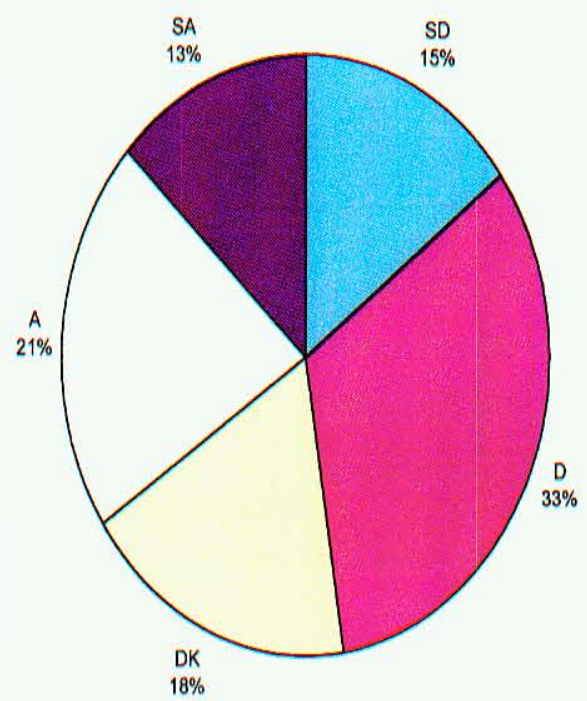

In Figure 10, however, regardless of the difficulties stated previously in the survey responses previously, when asked if using technology had improved social relations, 54 percent $\underline{\text { Agree }}$ or Strongly Agree that using technology had improved social relations. 
Figure 10. Using Technology has improved my social relations in the academic workplace

Using technology has improved my social relations in the academic workplace. $(n=61)$

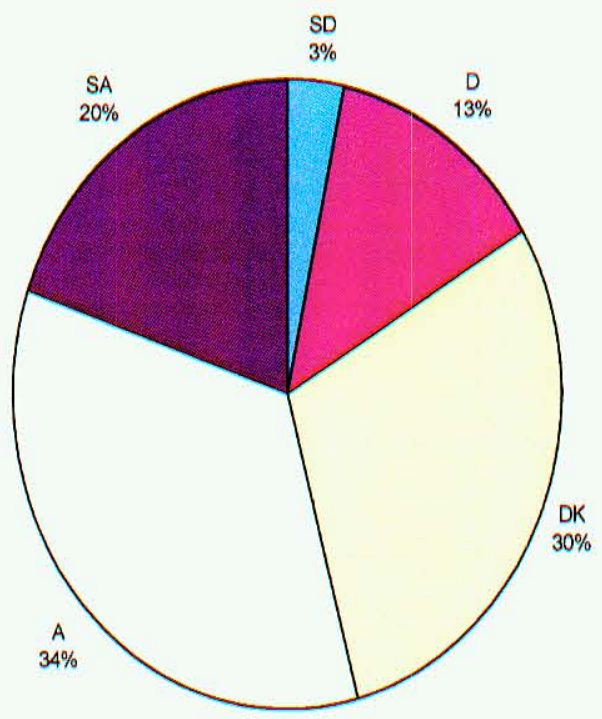

In Figure 11, WPAs report improvement in student relations due to use of technology. These responses point to the complex and often conflicting social functions that technology can play in daily lives of WPAs. 
Figure 11. Using technology has improved my interpersonal relations with students

Using technology has improved my inter-personal relations with students. ( $n=61)$

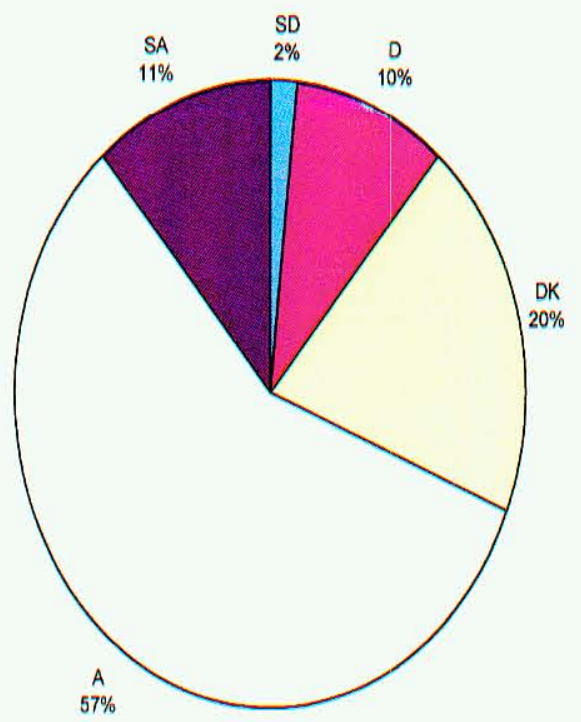

WPAs, graduate students, and technical support personnel confirm that students prefer instruction and instructors that utilize technology. Clearly, incoming students desire technology services and proficiency. This student trend counters sound pedagogical development when viewed in context to faculty who are on the "retirement track" and eschew edification in technology. Yet, to what degree should technology be "required" of any faculty? Data from the site visits find that acquiring technology skills beyond course management is still a laissez faire process for most faculty. At what point does technology literacy become as integral to the academic experience as numeracy and literacy both for faculty and students? 
One of the most significant responses to the survey was the overwhelming agreement $(82 \%)$ of respondents who stated that they were planning to increase the uses of technology in their department in Figure 12. Whether on a personal or a departmental level, these WPAs plan to incorporate more technology with writing. Exactly what this means in terms of critical and material choices would be an area we would like to study in the near future.

Figure 12. I plan to increase the uses of technology in my department/class

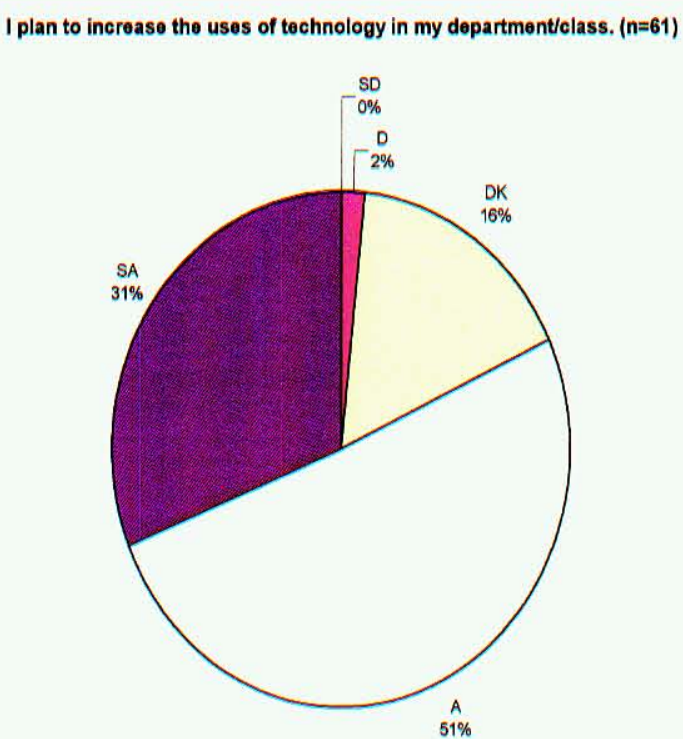

One surprise was the low number of WPAs reporting low participation in business, community or service projects related to writing and technology as seen in Figure 13. Seventy-six percent of respondents report minimal to no participation with such projects. Journal articles and sessions of the Conference 
on College Communication and Composition extol the virtues of service learning and community partnering, especially as it relates to technology and literacy. This is perhaps then, the area of social and critical import that has been neglected as WPAs attempt to keep up with labor costs, supplying and upgrading software and hardware, and satisfying upper-administrative efficiency demands.

Figure 13. Participating in business and community partnering, service projects related to writing and technology

Participating in business and community partnering, service projects related to writing and technology. ( $n=58$ )

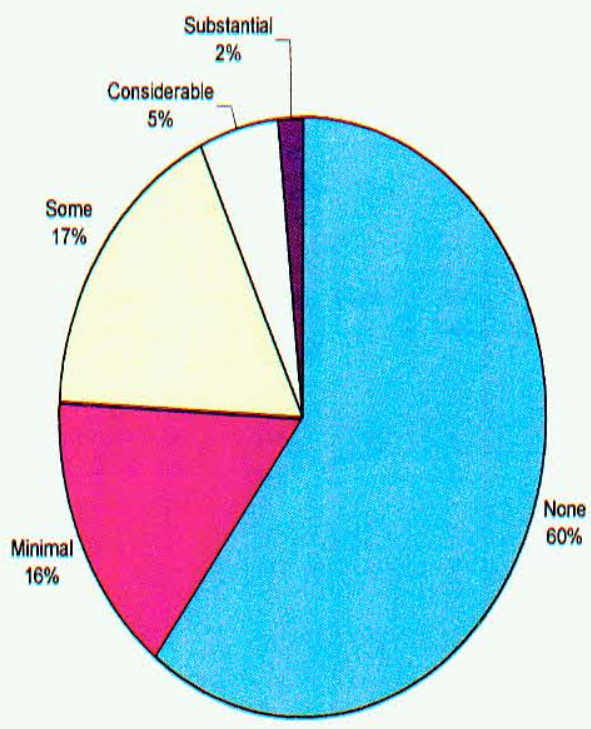

\section{Section Charts}

In Figure 14, WPAs report that much of their CAI effort time is taken up first by working with students (Q21) and second by changing pedagogy for better 
teaching and to accommodate technological components (Q20). This chart describes the average response to the quotations below in a six-point scale with $1=$ no effort and $6=$ major effort.

Figure 14. Effort put into technology-related initiatives EFFORT PUT INTO TECHNOLOGYRELATED INITLATIVS ( $n=60)$

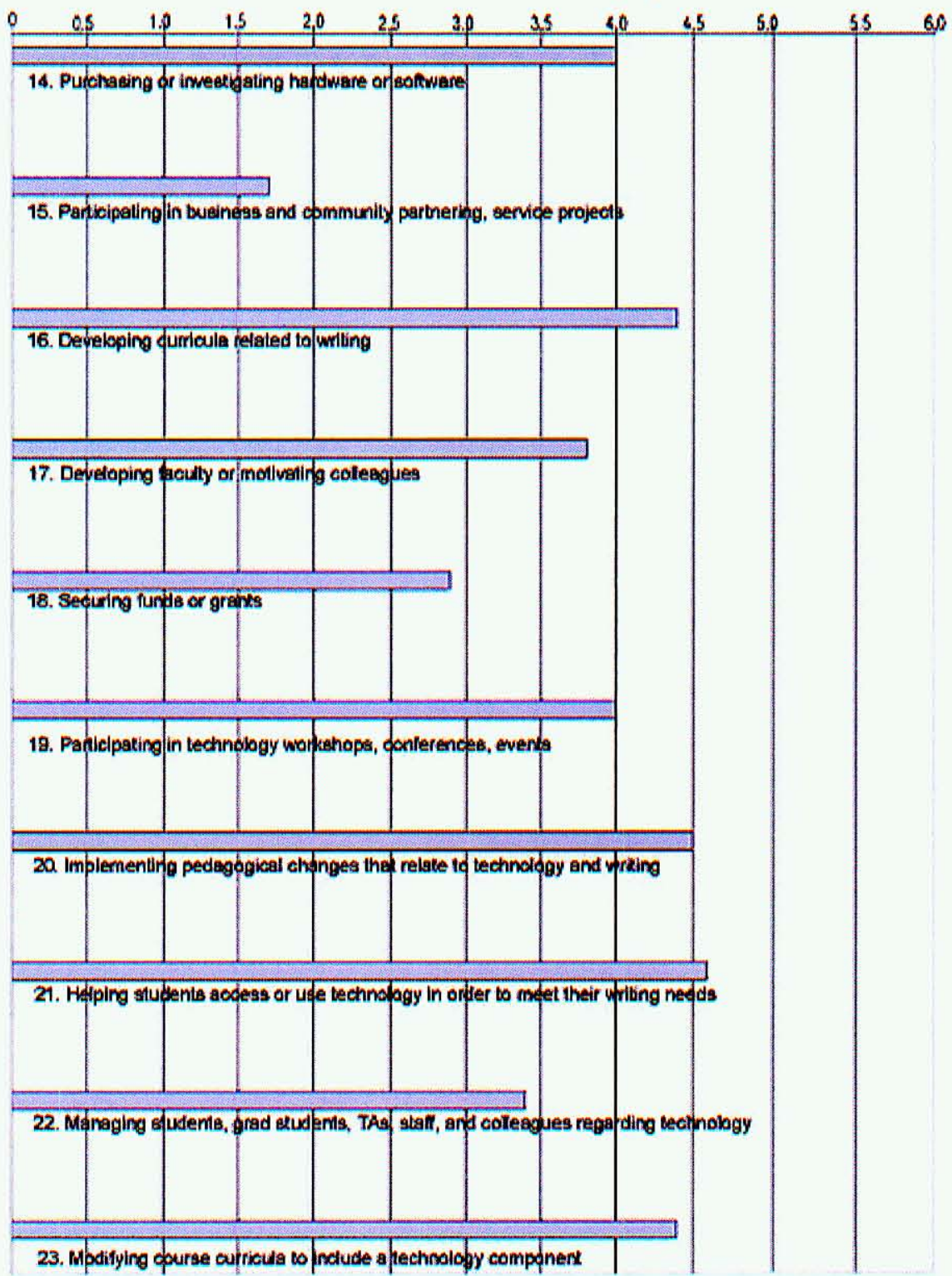

$1=$ no effort; $2=$ minimal effort; $3=$ some effort; $4=$ considerable effort; $5=$ substantial effort; $6=$ major effort 
Based on data from the site visits and the question on the social aspects of technology, respondents spend their effort and time on "managing" the technology might be predictable given that their students report high levels of appreciation $(31,32,38)$. If a WPA increases CAI (especially course management), then her appreciation from students and upper administration would seem to follow.

Figure 15. Social Effects of Teaching with Technology

SOCIAL EFFECTS OF TEACHING WIH TECHNOLOGY $(n=60)$

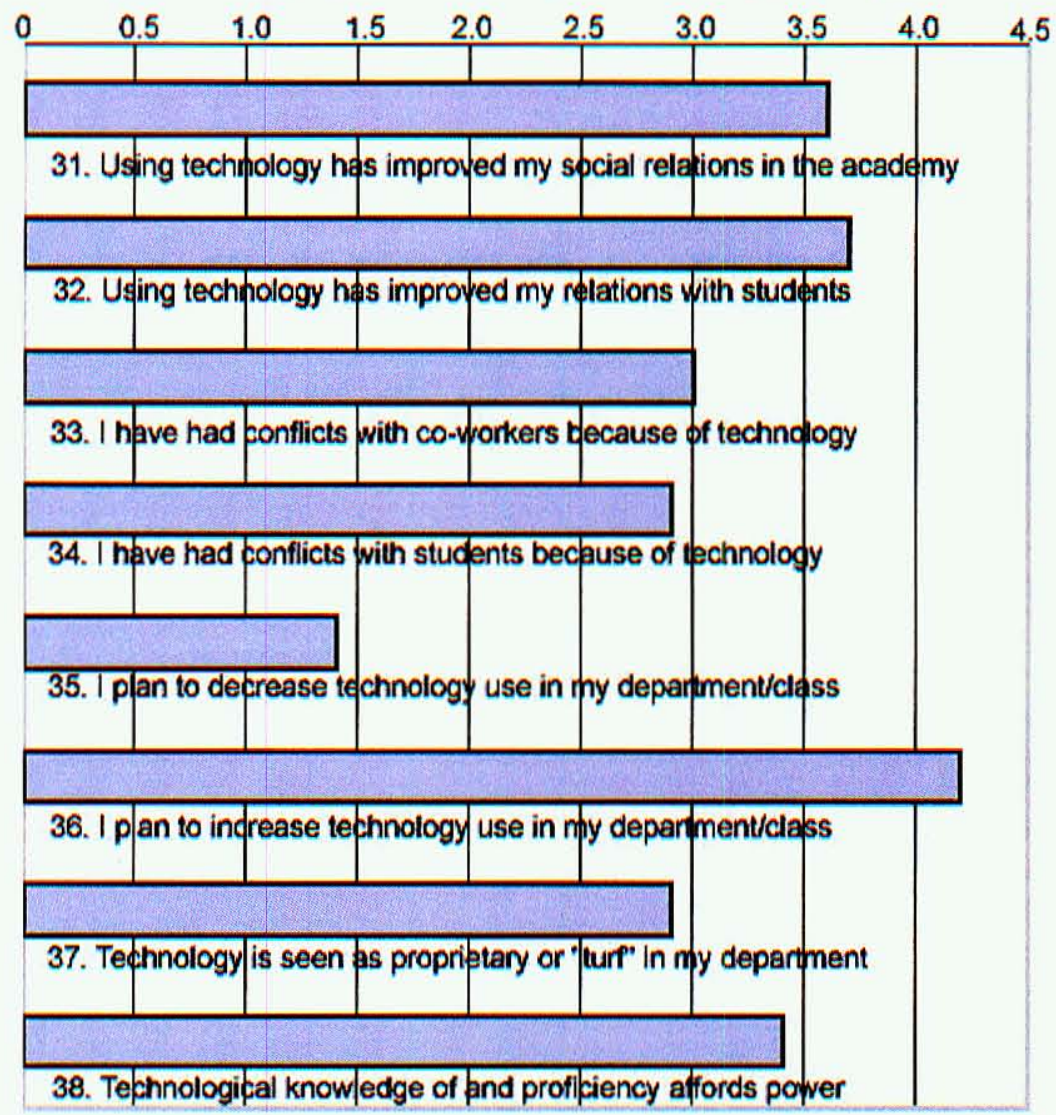

$1=$ strongly disagree; 2 = disagree; $3=$ don't know; $4=$ agree; $5=$ strongly agree 
Figure 16 covers the section Academic Labor and Technology. Respondents most strongly agree that using technology cuts into teaching of writing (41), people outside academia admire their work with technology (45), and that full- and part-time teachers possess similar skills. Respondents feel they spend less time on teaching: writing when they incorporate technology into their pedagogy (41). Respondents report little concern for their colleagues' performance $(45,46)$. They report noticeable appreciation for their technological expertise by non-academics. Overall, the data seem to indicate respondents are satisfied with their labor that other than wanting more time and money (40).

Figure 16. Academic Labor and Technology

ACADEMIC LABOR AND TECHNOLOGY $(n=60)$

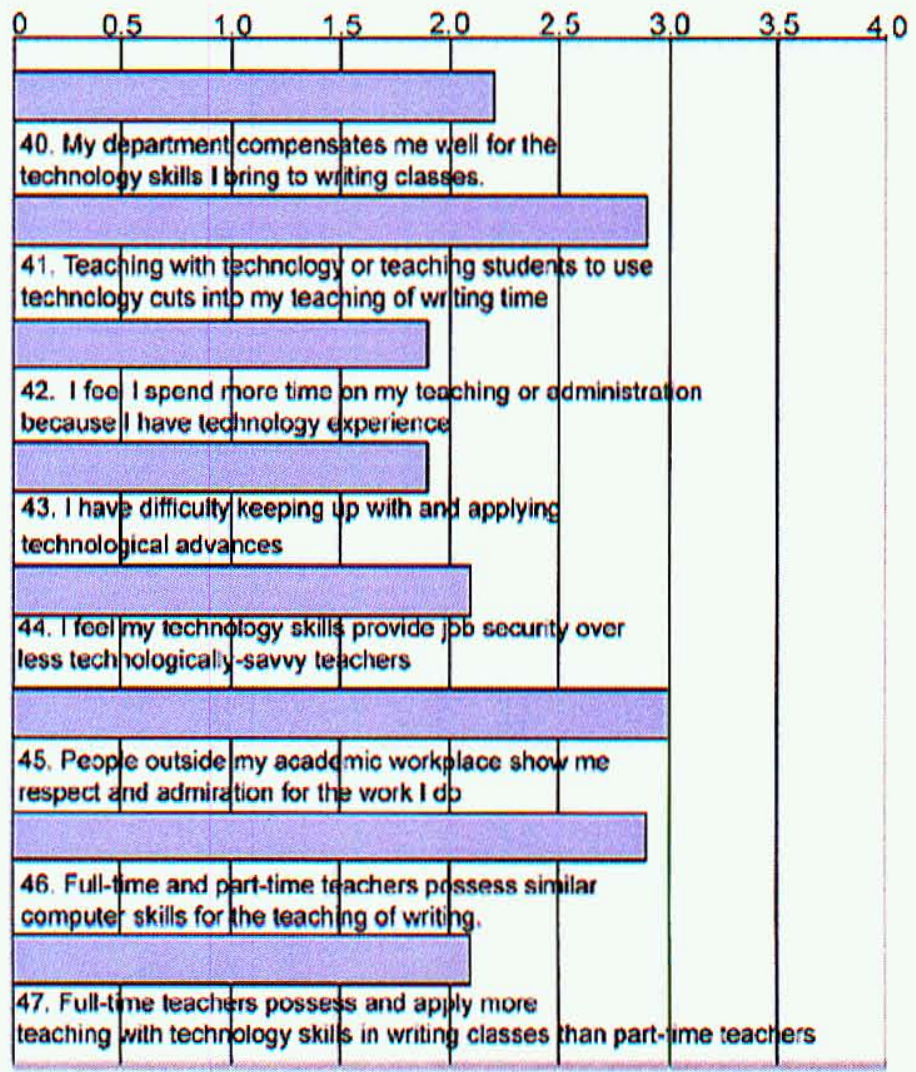

$1=$ strongly tisagree: 2 = somewhat cisagree;

3" somevihat agree: 4 " strongly agree 
The respondents in Figure 17, Students and Writing with Technology, reveal that they feel their students want technology (50) as much as they do (54). Overall, the respondents also reveal that they conceptualize technology and writing as inseparable in today's composition classes (53). This is contrast to the text box comments I discuss on page 108-109 (Q55: Any comments on students and writing with technology?). The respondents make a clear distinction between real writing and using technology.

Figure 17. Students and writing with technology

STUDENTS AND WRITING WITH TECHNOLOGY $(n=60)$

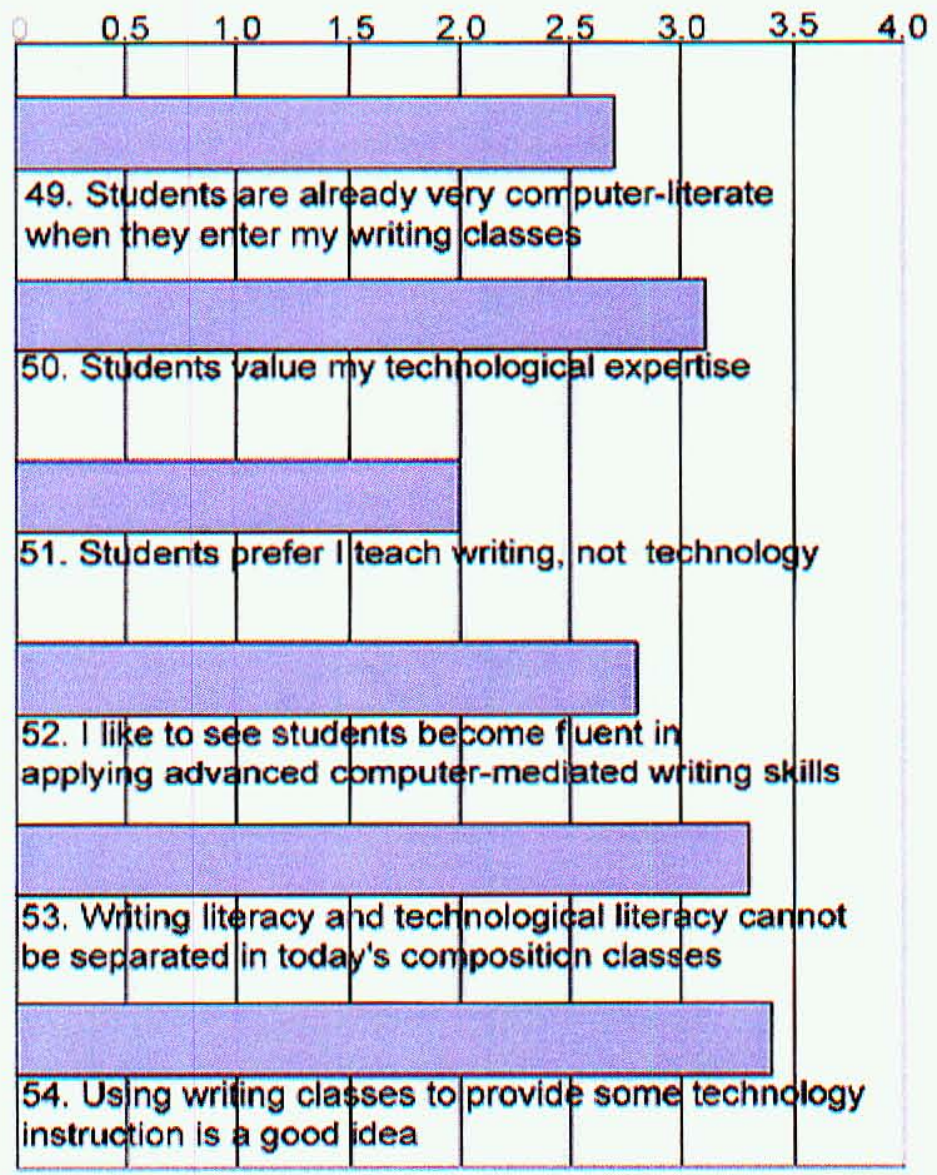

$1=$ strongly disagree; $2=$ somewhat disagree:

$3=$ somewhat agree; $4=$ strongly agree 
A comparison of the site visit data to the survey data finds similar trends among WPAs using CAI. WPAs voice the primacy of student-driven demand for technology as a motivating force for pedagogical innovation. Data from both sources report all WPAs strong commitment to meeting the perceived needs and wants of their students. The specific technological practices these needs take varies with instructors.

Across all sections, respondents report that their concern for student learning drives CAI pedagogy, even if that effort takes more time, is less compensated, and may cause difficulties in their academic workplace. Up to this point, the data in this study focus on WPAs' agency. The results in the online survey sections point to the motivation behind the WPAs decisions to use technology. The data suggest that WPAs are motivated by their inveterate belief that CAI will prepare students better than non-computer-mediated instruction and that students are more receptive to writing with technology than not writing with computers.

Chapter V will summarize the results of this study and explore recommendations for future study. 


\section{CHAPTER V \\ SUMMARY AND RECOMMENDATIONS}

\section{$\underline{\text { Summary }}$}

Increasingly, writing program administrators face mandates to incorporate writing technologies into their curriculum. Even without the bureaucratic push to consider writing technologies, however, writing program administrators responsive to the shape of writing practices and the needs of writers in an information economy are thinking critically about the impact of writing technologies into the writing curriculum. Deborah Brandt suggests the importance of such thinking when she writes, "literate ability at the end of the twentieth century may be best measured as a person's capacity to amalgamate new reading and writing practices in response to rapid social change" (651). Certainly, computers have been located at the heart of new reading and writing practices as well as some of the most profound social change experienced in America.

Writing programs, which structure education in college-level literate practices, seem a likely institutional location to examine when trying to understand how colleges and universities have addressed the increasing impact of writing technologies on college writing. At conferences, in the hallways, on 
listservs, writing program administrators ruminate over these changes to literacy practices, speculate on ways to account for them, and seek the guidance of others facing similar pressures to address these changes in writing learning and instruction. Andrea Lunsford, for example, turned to the WPA-L listserv group: >> lunsford@STANFORD.EDU 12/18/02 07:54PM $\gg>$ I'm writing to ask for information:

Since I've been at Stanford, we've developed three fabulous technologically-enhanced rooms in which to teach writing. They have wireless laptops, plasma screens for group work, Websters for presentations, equipment for teleconferencing, etc.

I am arguing that the University provide two additional such classrooms devoted solely to writing classes and, as might be expected, my bosses are asking me how I know that such classrooms are good for writers and writing instruction. We've been monitoring/evaluating our own classrooms for a year and so have good data from our own teachers and students. And I have made the case that it is a mistake ever to assume that any technology will somehow automatically improve writing; pencils don't; typewriters don't; laptops don't directly improve writing.

So, first, I'm interested in any studies that have been done evaluating the teaching of writing in such classrooms. In addition, I'd love to know how 
many research universities teach writing in computer-enhanced classrooms.

I have Transitions: Teaching Writing in Traditional and ComputerSupported Classrooms.

Anyone have any good leads?

Across the country, writing programs and writing instructors are increasingly pressured by administration (which is in turn pressured by students and accrediting agencies among other groups) to integrate technologies into our curricula. Many WPAs, like Lunsford, have found themselves asked to explain (or, in some cases, defend) how writing technologies support/fit within/are necessary for writing instruction. Takayoshi and my work as administrators of an English department computer writing instruction program, we understand first hand the need for knowledge and guidance from a broader community about the impact of writing technologies on the teaching of writing. Like Lunsford, we searched printed scholarship and wanted more information on the actual shape of practices in computer classrooms to guide our administrative work. What we found, though, was dismaying. While many WPAs are concerned about the smart integration of writing technologies into writing programs, there is little printed scholarship to guide them in making complex programmatic decisions and no 
studies that indicate how many research universities teach writing in computerenhanced classrooms.

It was nearly ten years ago (1995) when Charles Schuster asserted, "No WPA can work effectively without knowing the theories and practices that underlie ... computer classrooms ..." (ix). Schuster includes computer classrooms as one of many things WPAs must know the theories and practices of: "basic writing, invention, pedagogy, collaborative learning, writing across the curriculum, assessment, portfolios, computer classrooms, radical pedagogy - the list could go on indefinitely" (ix). There has been remarkably little written in writing program administration scholarship about writing technologies. While composition scholarship suggests that teaching writing with technology is increasingly becoming common (Faigley; Hawisher and Selfe; Hawisher, LeBlanc, Moran, and Selfe) and that writing programs are increasingly faced with mandates from administrative agencies that more technology be infused into existing curricula (Selfe), WPAs do not have very much information about how writing programs accomplish these goals.

Writing in 1995, Faigley and Romano argue that "writing instruction using networked computers has the potential to overturn the privileging of the essay in a writing classroom because teaching practices that we advocate and that have gone largely unquestioned are exposed as unsuited to the task" (48). Faigley and Romano do not focus on the particular ways writing program administration is affected by the advent of writing technologies, but instead relate how the emergence and development of writing technologies in one writing program 
called for revised meanings of writing, the flattening of hierarchies among teachers and students, and disrupted the program's priority of essayist writing. Faigley and Romano suggest that because "computer technologies are the intrinsically disruptive of traditional literacy practices" (49), WPAs will have to negotiate new meanings of writing instruction and their work with programs of writing. McAllister and Selfe, in 2002, approach the conjunction of writing program administration and writing technologies more pragmatically in order to "lay a foundation for planning and reflection that will help WPAs discover some new ways of imagining the problems and possibilities of instructional computing, and of transforming those imaginings into workable strategies for writing and literacy programs" (342). The foundation McAllister and Selfe is, indeed, sturdy ground on which to build local responses. The authors provide a wonderful beginning point for WPAs to think about writing technologies and writing program administration as a "hermeneutic relationship among practice, theory, reflection, and praxis" (345). In their chapter, they provide an overview of issues at the intersection of writing technologies and writing programs, texts WPAs might find informative, connections between theoretical rationales for writing instruction and writing technologies, and scenarios for thinking through administrative responses to computer use challenges and issues. They ask, "Recognizing the variety of intellectual and pedagogical issues at play in the landscape of technology-use issues, how are WPAs to decide where to begin?" (344). As our overview of the scholarship indicates, WPAs wanting to address writing technologies in a systematic, systemic way are still in need of models. 
McAllister and Selfe suggest that "A pragmatic assessment of one's current situation vis-à-vis instructional computing is usually a helpful place to start"' (344). I hypothesize further, that comparing this local benchmark assessment with the situation of other similar institutions would provide WPAs with both valuable information for developing our own programs and a rich picture of instructional computing at a cross-section of the nation's institutions.

The findings of this study provide one snapshot of the current status of technologically mediated writing instruction across the country. The study shows that WPAs' agency is often complicated by numerous factors. WPAs must integrate technologies at a breakneck pace that leave little time for critical and reflective practices. WPAs might often feel that they must rally disinterested colleagues in support of CAI the writing program. Then, WPAs must define technological literacy as course management and online course development for upper administration with little to no time left for innovative, critical, or reflective practices. Like McAllister and Selfe, we believe that "the development of a critical consciousness about the relationship between technology and literacy often begins with the example and initiatives established by careful, thoughtful WPAs" (345).

WPAs in the survey express sincere concern for all academic workers and state that labor is their primary workplace concern. Technology, however, is often pitted against labor when it comes to allocating time and resources. In other words, WPAs position technology (extras) in opposition to time spent on labor (people). WPAs (and other faculty) express their resistance to technology in 
multiple and often subtle ways. They may pay lip service to the grand narrative that technology is inevitable (is it?) and then actively resist implementing anything other than the minimal administrative requirements. For example, WPAs set up computer facilities and relegate their maintenance and pedagogy to interested instructors. Faculty passively resist CAI by arguing that they to close to retirement to pursue technological professional development. Graduate students, a few junior faculty, and part-timers show the most enthusiasm for technology and writing with English literature faculty show the least. The enthusiasm by graduate students may be fueled in part by job requirements that explicitly, though often implicitly, expect technological literacy skills: e-mail, web pages, and familiarity with a variety of software.

WPAs describe technology as a divisive or unifying force that acts upon them and their departments. WPAs describe their experiences with technology as out of their control. They are pushed and pulled in a variety of directions, sometimes pleasant, sometimes not. The WPAs we talked to were frustrated because they could not anticipate the results of technology implementation on their department and users. Technology seems to be less predictable than issues of labor, curriculum, or other administrative systems.

As stated in Chapter I, the central objective of this study was to examine the ways in which WPAs act as administrative agents when implementing technology. The study uses two methods to get to this information; first, interviews and observations at site visits of benchmark programs; and second, an online survey to WPAs and technology users. The respondents show discernable 
patterns in their responses about their agency in the application of technology to writing programs. While it is possible that the trends may have been an artifact of the researchers themselves or the research methods, we took care to use multiple methods.

Technology implementation spawns narratives of success. As with the rhetoric of the Agenda for Action discussed in Chapter II, students are imagined to be automatically more proficient and prolific writers especially by technophilic upper administrators outside of English and writing programs who may have not taught writing. WPAs are left with the reality after the romance is gone:

Fig. 18. The Romance and the Reality of CAI

\begin{tabular}{|l|l|}
\hline Romance & $\begin{array}{l}\text { Teaching is rarely easier and unusually } \\
\text { more time-consuming }\end{array}$ \\
\hline Teaching will be easier & Learning styles determine if CAI is \\
Learning for students will be easier for students
\end{tabular}


If overstating the benefits of technology is one part of the narrative process, then the demonization of technology is the mirror image of that process. We find that computer use was an easy target for an anecdotal rise in plagiarism. One WPA attributed technology as causing an increase in plagiarism cases with students who use the Internet to procure essays for writing assignments. Technology use easily becomes the target for programmatic problems that might be rooted in social or pedagogical practices. The following recommendations stemming from the this research study will hopefully aid in the management, implementation, and inquiry into CAI.

\section{$\underline{\text { Recommendations }}$}

The primary recommendations I make in light of this study are as follows:

- Recognize and be wary of situations that frame discussions as CAI as Technology vs. X. CAI or technology often is often portrayed as a false dilemma against other conditions within programs and departments. Either we can spend time on technology or we can teach writing. Either we can spend time with labor issues or we can spend time with new technologies. Either we can spend our budget for more teachers or we can spend it for computers. These binaries do not integrate possibilities. Some WPAs in the study expressed that they were more interested in people and students than technology. I suggest that technology need not be oppositional to other learning. The teaching of writing and the application of technology can go hand in hand in curricula and pedagogy. Technology might be a 
tool for assisting faculty (labor) who seek alternative teaching methods, times, venues.

- Appreciate the effect the motives of others have on WPAs' success at incorporating CAI. For example, WPAs might benefit by being more aware of what I call the "retirement track" rationale that many faculty across disciplines adopt in regards to learning or teaching with technology after many years of service. Literature faculty or composition faculty, fulltime or part-time, both in the site survey interviews and in the online data report resistance to technology by those who want to wait out having to learn something new. Ironically, many college students must prove their technological proficiency in order to graduate.

- Build in critical technological literacy at the beginning of any technologic project, whether mandated externally or initiated personally. WPAs who conscientiously follow step-by-step procedures to implement technology may not ever get to the point where the end-users see the relationship between their writing and their writing context. WPAs find themselves filling and maintaining labs in an enervated and piecemeal fashion. By the time WPAs have the support and stability to innovate or incorporate critical practices with technology, they may not be able to accomplish their goals because they must move on to another administrative initiative. 
Imagine way to incorporate critical technological literacy tht examines social and material contexts of technology when compelled to institute online courses and course management. Design with an eye towards sustainability.

- Recognize that many WPAs express their agency in subtle and almost invisible ways. Agency may take the form of passive resistance to technology implementation or administrative mandates. Chapters I and II review literature that questions whether WPAs have real agency at all (Bousquet). WPAs (and others) in our study have power and use their agency. However, agency need not be expressed in bold, political, and public moves; it can be expressed by doing only the minimum required by upper administration regarding technology and focusing on other administrative imperatives. For example, our study found that some WPAs provide the basic two technologies writing labs opens to interested staff and faculty and then move on to other administrative priorities. These actions, too, are expressions of agency. Several times the point was made that WPAs are constrained by administrators and budgets. I hope to avoid reductionist conclusions that WPAs have power only to the degree that they are given funds or obey mandates. The kinds and uses of agency mentioned above highlight that that WPAs influence the administrative process in many ways. 
- Challenge commonly held narratives about technology. Instantiated narratives similar to those that use the rhetoric of the Agenda for Action, can hinder critical inquiry. How does technology support democracy? How are access and democracy related? Is a technological application more efficient than previous technology? For whom? Toward what outcomes? When is efficiency being confused with homogeneity? Id efficiency always a fiscal and educational good? In any conversion narrative, ask what has been gained and what has been lost.

- Recognize that the term "technological literacy" takes on many different meanings for different audiences. And recognize that critical technological literacy includes a social and activist component that many teachers of writing do not advocate. Try to answer for oneself how student learning can be improved with a critical technological literacy?

- Build alliances with Literature and disciplines that promote writing, especially writing with technology. Literature-based studies continue to control a large segment of writing instruction nationally and within the benchmarks of this study. The relationship between Literature faculty and Composition faculty in regard to technology cannot be ignored. WPAs can partner with faculty who show an interest in alternative literacy (e.g. hypertext and visual argumentation, electronics poetry, business and technical applications, web authoring). 
- Clarify those issues that are caused by technology and those that are embedded in the learning process. Confusing causative, subordinate, and ancillary technology issues can sidetrack learning. For example, plagiarism and technology are increasingly referenced together when discussing CAI. Plagiarism existed long before digital technology. And in some world cultures today, the skill of accurately copying great works is consider a legitimate and laudable objective of learning. Technology is said to "make students lazy." These kinds of statements need to be challenged.

Margaret Himley, in "Writing Programs and Pedagogies in a Globalized Landscape," offers an example of how responding to a variety of pressures "[n]ew composition theories, university and college committees, mostly anecdotal student complaints (though serious ones), learning outcomes, major institutional reevaluation and redefinition from disciplinary shifts, administrative mandates, and student evaluations" (53) can lead to productive intellectual growth in a writing program.

Himley's narrative of change reassures us that writing program administrators are thinking critically about the effects of writing technologies, digital production processes, and new economies of knowledge on existing writing programs. This study of writing program administration print scholarship, however, found very little indication of these kinds of engagements. As the administrators in our study suggest to us over and over, more published accounts and explorations of writing 
technologies and writing program administration could serve as desired and needed guideposts for negotiating the complex and densely woven meanings of writing (through/with) technologies. Without a strongly articulated vision of "larger and more complex contexts (other courses, professional sites, civic arenas) and ... the processes and material realities and effects of textual economies" (Himley 57), writing program administrators are likely to be easily frustrated. Such a situation dampens the enthusiasm necessary for carrying out programmatic work with writing technologies.

The responses of teachers and writing program administrators to pressures to use or not to use technology reveal a fundamental shift in their thinking, Himley reports: "we locate students (and our courses) within larger and more complex contexts (other courses, professional sites, civic arenas) and within more of the processes and material realities and effects of textual economies .... [O]ur new curriculum plops students immediately into the broader complexities of the production, distribution, and circulation of texts to a greater degree than before, as a result of theory and technology ... and ... globalization" (57). Technology and writing are inextricably linked in and outside of the academy. WPAs can better serve their students' learning by recognizing and dealing with this social trend.

Because there is still so little written scholarship and research about the impact of writing technologies on writing programs and the administration of them, I feel as if I leave readers with more questions than answers: How might these findings differ for other groupings of benchmark institutions? Others might model similar investigations on our model of using benchmark institutions as a 
ready-made comparison group. What concrete forms and modes of expression forms do agency and power take in CAI and writing programs? How can WPAs apply critical technological literacy in the face of mandates and overwork? Through more studies, WPAs might develop a richer understanding of their own program's practices and policies and how their program compares to related institutions. These different findings might reveal a lot about the ways we've thought about writing program administration and technological facilities. These findings could be used by WPAs to collect data about issues such as teacher training, program review, and assessment to enact informed material and theoretical change in their programs, ultimately in the service of better quality writing and critical thought for all. 


\section{REFERENCES}

Agenda for Action. National Information Infrastructure Agenda for Action. Information Infrastructure Task Force. U.S. Department of Commerce. 15 September 1993. Accessed 10/18.03. < http://www.ibiblio.org/nii/NIIAgenda-for-Action.html>.

Allyn and Bacon Sourcebook for Writing Program Administrators. Eds. Irene Ward and William J. Carpenter. New York: Longman, 2002. 228-251.

Anson, Chris. "Distant Voices: Teaching and Writing in a Culture of Technology." College English 61 (1999): 261-280.

Althusser, Louis. "Ideology and Ideological State Apparatuses." Lenin and Philosophy. London: New Left Books, 1971.

Apple, Michael. "The New Technology: Is It Part of the Solution or Part of the Problem in Education?" Computers in the Schools 8. 1-3. 59-77.

Bakhtin, Mikhail M. The Dialogic Imagination. Trans., Caryl Emerson and Michael Holquist. Ed. Michael Holquist. Austin, TX: Texas UP, 1981.

---. Speech Genres and Other Late Essays. Trans. Vern W. McGee Ed. Caryl Emerson and Michael Holoquist. $7^{\text {th }}$ Ed. Austin, TX: Texas UP, 1999.

Barton, Ellen L. “Literacy in (Inter)Action.” College English 59.4 (April 1997).

Barker, Thomas and Fred O. Kemp "Network Theory: A Post-Modern Pedagogy for Writing Classrooms." Computers in Society: Teaching Composition in the Twenty-First Century. Upper Montclair, NJ: Boynton/Cook, 1990.

Baudrillard, Jean. Simulacra and Simulation. Trans. Sheila Faria Glaser. Ann Arbor: U. of Michigan P, 1994.

Bazerman, Charles. The Languages of Edison's Electric Light. Boston: MIT, 1999. 
---. "Systems of Genres and the Enactment of Social Intentions." Eds. A. Freeman and P. Medway. Genre and the New Rhetoric. London: Taylor and Francis, 1994. 79-101.

---, and James Paradis. Textual Dynamics of the Professions. Madison: Wisconsin UP, 1991.

Berkenkotter, Carol, and Thomas Huckin. Genre Knowledge in Disciplinary Communication: Cognition, Culture and Power. Hillsdale, NJ: Erlbaum, 1995.

---, "Rethinking Genre From a Socio-Cognitive Perspective." Written Communication 10.4 (1993). 475-509.

Berlin, James. "Post-structuralism, Cultural Studies and the Composition Classroom: Postmodern Theory in Practice.” Rhetoric Review 11.1 (1992): 16-33.

---. "Rhetoric and Ideology in the Writing Class. College English 50.5 (1988): 187-214.

--. Rhetoric and Reality: Writing Instruction in American Colleges, 1900-1985. Carbondale, IL: SIU, 1987.

Bolter, J. David. Turing's Man: Western Culture in the Computer Age. Chapel Hill: U of Carolina P, 1984.

Bourdieu, Pierre. Outline of a Theory of Practice. Cambridge: Cambridge UP, 1977, 4.

Bousquet, Marc. "Composition as Management Science: Toward a University Without a WPA." Journal of Advance Composition 22:3 (Summer 2002): 493-526.

Brandt, Deborah. "Sponsors of Literacy." College Composition and Communication 9.2 (1998).

---. "Accumulating Literacy: Writing and Learning to Write in the Twentieth Century.” College English 57:6 (1995): 649-668.

Brereton, John C., ed. The Origins of Composition Studies in the American College, 1975-1925." Pittsburgh: U of Pittsburgh P, 1995.

Bridwell, Lillian S., and Donald Ross. "Integrating Computers Into a Writing 
Curriculum; or, Buying, Begging, and Building.” Ed. William Wresch. The Computer in Composition Instruction: A Writer's Tool. Urbana, IL: NCTE, 1984. 107-119.

Brown, Stuart C., and Theresa Enos. The Writing Program Administrator's

Resource: A Guide to Reflective Institutional Practice. Mahwah, N.J.:

Erlbaum, 2002.

Cain, Mary Ann, and George Kalamaras. "(Re)presenting the Work of Writing Program Administrators.” Writing Program Administration 23.1.2 (1999): 24-58.

Campbell, Scott, and Susan Fainstein, eds. Readings in Planning Theory. Malden, MA: Blackwell, 1996.

Carr, Sarah. "Army Picks Consulting Group to Run Distance Education Effort." The Chronicle of Higher Education. January 5, 2001. A46.

Carspecken, Phil Francis. Critical Ethnography in Educational Research: A Theoretical and Practical Guide. New York: Routledge, 1996.

---, and Phil Francis, and Michael Apple. "Critical Qualitative Research: Theory, Methodology, and Practice.” Eds. Margaret LeCompte, Wendy L. Millroy, and Judith Preissle. The Handbook of Qualitative Research in Education. San Diego: Academic Press, 1992. 507-553.

Castells, Manuel. The Power of Identity: The Information Age of Economy, Society, and Culture. Vol. II. Oxford, UK: Blackwell, 1997.

---. Critical Education in the New Information Age. New York: Rowman and Littlefield, 1999.

Christie, Frances. "Curriculum Genres: Planning for Effective Teaching." Eds. B. Cope and M. Kalantzis. The Powers of Literacy: The Power Approach to Teaching Writing. London: Falmer, 1993.

Connors, Robert J. Composition Rhetoric: Backgrounds, Theory, and Pedagogy. Pittsburgh: U of Pittsburgh P, 1997.

---. "Writing the History of Our Discipline." An Introduction to Composition Studies. Eds. Erika Lindemann and Gary Tate. New York: Oxford UP, 1991. 49-71.

---. "Composition History and Disciplinarity" Eds. Mary Rosner, Beth Boehm, and Debra Journet. History, Reflection and Narrative: The 
Professionalization of Composition: 1963-1983. Stamford: Ablex, 1999. Series 3. 17.

Cooper, Marilyn M. and Cynthia L. Selfe. "Computer Conferences and Learning: Authority, Resistance, and Internally Persuasive Discourse. College English 52 (1990): 847-869.

Council of Writing Program Administrators. "Evaluating the Intellectual Work of Writing Administration." Writing Program Administration 22.1/2 (1998): 85-104.

Crowley, Sharon. “A Personal Essay on Freshman English.” Pre/text 12 (1991): 156-76.

---. Composition in the University: Historical \& Polemical Essays. Pittsburgh: Pittsburgh UP, 187-214.

Cushman, Ellen. "Rhetorician as Agent of Social Change." College Composition and Communication 47 (1996): 7-28.

Daniell, Beth. "Envisioning Literacy: Establishing E-Mail in a First-Year Program." Kitchen Cooks, Plate Twirlers, and Troubadours: Writing Program Administrators Tell Their Stories . Ed. Diana George. Portsmouth, NH: Boynton/Cook, 1999, 150-161.

Derrida, Jacques. "The Laws of Genres." On Narrative. Ed. J.T. Mitchell. Chicago: Chicago UP, 1981.

Dias, Patrick. "Writing Classrooms as Activity Systems." Transitions: Writing in the Academic and Workplace Settings. Creskill, NY: Hampton, 2000. 1130 .

Digest of Educational Statistics 1996/ November 1996. National Center for Educational Statistics. Office of Educational Research and Improvement, U.S. Department of Education, NCES 96-133.

Duffelmeyer, Barbara Blakely. "Critical Computer Literacy: Computers in FirstYear Composition as Topic and Environment." Computers and Composition 17 (2000): 289-307.

Duffey, Suellynn, Ben Feigert, Vic Mortimer, Jennifer Phegley, and Melinda Turnley. "Conflict, Collaboration and Authority: Graduate Students and Writing Program Administration.” Rhetoric Review 21.1 (2002): 79-87.

Dunn, Thomas F. "The Principles and Practices of the Communication Course." College Composition and Communication 6 (1955): 31-38. 
Eldred, J. M. "Computers, Composition Pedagogy, and the Social View." In Hawisher and Selfe. Eds. Critical Perspectives on Computers and Composition Instruction. New York: Teachers College Press, 1989. 201218.

Engestrom, Yrjo, ed. Perspectives on Activity Theory. Cambridge: Cambridge UP, 1999. 1-37, 317-376.

Engestrom, Yrjo, Michael Cole, and Olga Vasquez, eds. "Interobjectivity, Ideality, and Dialectics." Mind, Culture and Activity Seminal Papers from the Laboratory of Comparative Human Cognition. Cambridge: Cambridge UP, 1997. 259-265.

Faigley, Lester. Fragments of Rationality. Pittsburgh: U of Pittsburgh P, 1992.

---. "Literacy After the Revolution." College Composition and Communication. 48.1 (1996): 30-43.

-.-. "Veteran's Stories on the Porch." Eds. Mary Rosner, Beth Boehm, and Debra Journet. History, Reflection and Narrative: The Professionalization of Composition, 1963-1983. Stamford: Ablex, 1999. Series 3.34.

---, and Susan Romano. "Going Electronic: Creating Multiple Sites for Innovation in a Writing Program." See Janangelo and Hansen 1995.

Favorin, Marjo, and Kari Kuutti. "Supporting Learning at Work by Making Work Activities Visible Through Information Technology." Machine-Mediated Learning. 5.2 (1996): 109-18.

Feenberg, Andrew. Critical Theory of Technology. Oxford: Oxford UP, 1991.

---, and Alastair Hannay, eds. Technology and the Politics of Knowledge. Bloomington, IN: Indiana UP, 1995.

Fisher, John A. "The Problem of Freshman English: What Are Its Dimension?" College Composition and Communication 6 (1955): 75-78.

Forester, John. Planning in the Face of Power. Berkeley: U of C Press, 1989.

Foucault, Michel. Discipline and Punishment: The Birth of the Prison. Trans. Alan Sheridan. New York: Vantage Books, 1979.

---. The Foucault Reader. New York: Pantheon, 1984.

Friere, Paulo. Pedagogy of the Oppressed. New York: Herder, 1971. 
Gale, Irene. "Conflicting Paradigms: Theoretical and Administrative Tensions in Writing Program Administration. Writing Program Administration 14:1/2 (1990): 41-50.

Gerrard, Lisa. "Computers and Composition: Re-Thinking Our Values." Computers and Composition 10 (April 1993): 23-34.

Geisler, Cheryl. "Textual Objects: Accounting for the Roles of Texts in the Everyday Life of Complex Systems." Written Communication 18:3 (July 2001) 296-325.

---, Charles Bazerman, Stephen Doheny-Farina, Laura Gurak, Christina Haas, Johndan Johnson-Eilola, David S. Kaufer, Andrea Lunsford, Carolyn R.Miller, and Dorothy Winsor, JoAnne Yates. "Itext: Future Directions on the Relationship Between Information Technology and Writing. "Journal of Business and Technical Communication 15.3 (2001): 269-308.

Global Information Infrastructure Agenda for Cooperation. 1995. Issued by Al Gore, Vice President of the United State and Ronald H. Brown, secretary of commerce. Information Infrastructure Task Force. U.S. Department of Commerce. 31 January. Washington D.C. U.S. Government Printing Office.

Giroux, Henry. Ideology, Culture and the Process of Schooling. Philadelphia: Temple UP, 1981.

Goals 2000: Increasing Student Achievement Through State and Local Initiatives. 3 April. $<$ http://www.ed.gov/G2K/GoalsRpt $>$.

Goodwin, Irwin. Clinton's Hands-On Economic Plan: Technology Gains, Big Science Loses." Physics Today 46.4 (Apr 1993): 43-47.

Gresham, Sallie Morgan. "Feminist Dialectics: Mapping the landscape of Computer-Mediated Conversation." Diss. Univ. of Louisville, 2000.

Goree, Cathryn T., and John F. Marszalek. "Electronic Surveys: Ethical Issues for Researchers." College Student Affairs Journal. 15.1 (Fall 1995): 75-79.

Gunner, Jeanne. "Among the Composition People: The WPA as English Department Agent." Journal of Advanced Composition 18.1 (1998): $153-65$.

--.. "Decentering the WPA." Writing Program Administration 18.1 (1994): 8-15. 
Handa, Carolyn. Computers and Community: Teaching Composition in the Twenty-First Century. Portsmouth, NJ: Boynton/Cook, 1990.

Haraway, Donna. "A Manifesto for Cyborgs: Science, Technology, and Socialist Feminism in the 1980s." Feminism/Postmodernism. Ed. Linda J. Nicholson. New York: Routledge, 1990.

Harralson, Dave. "We've Barely Started-and We've Already Done it Wrong: How Not to Start a Computer-Assisted Writing Classroom." Computers and Composition 9.3 (1992) 71-78.

Harrington, Susanmarie, Rebecca Rickly, Michael Day, eds. The Online Writing Classroom. Creskill, NY: Hampton, 2000.

Harris, Jeanette, Diane George, Christine Hult, and M. Jimie Killingsworth. "Computers in the Composition Curriculum: Looking Ahead." Writing Program Administration 13.1/2 (1989): 35-43.

Harris, Joseph. "Meet the New Boss, Same as the Old Boss: Class Consciousness In Composition." College Composition and Communication 52.1 (2000): 44-64.

Hawisher, Gail E. "Blinding Insights: Classification Schemes and Software for Literacy Instruction." In Selfe and Hilligoss, 37-55.

Hawisher, Gail E., and Ericsson Patricia. "Stasis and Change: Role of Independent Composition Programs and the Dynamic Nature of Literacy." A Field of Dreams: Independent Writing Programs and the Future of Composition Studies Eds. O'Neill, Peggy, Angela Crow, and Larry W. Burton. Logan, Utah: Utah State UP, 268-278.

---, and Cynthia L. Selfe, eds. Critical Perspectives on Computers and Composition Instruction. New York: Teachers College Press, 1989. 201218.

---, and Cynthia L. Selfe, eds. Passions, Pedagogies, and $21^{\text {st }}$ Century Technologies. Urbana, IL: NCTE Press, 1999.

---, and Paul LeBlanc. Re-imagining Computers and Composition: Teaching and Research in the Virtual Age. Portsmouth: Boynton/Cook. Heinemann, 1992.

---, and Paul LeBlanc, Charles Moran, and Cynthia Selfe. Computers and the Teaching of Writing in Higher Education, 1979-1994: A History. Norwood, NJ: Ablex, 1996. 
Hayles, N. Katherine. How We Became Posthuman: Virtual Bodies in

Cybernetics, Literature, and Informatics. Chicago: UC Press, 1999.

Heidegger, Martin. The Question Concerning Technology. Trans. Martin Lovitt. New York: Harper Row, 1982.

Heyda, John. "Fighting Over Freshman English: CCCC's Early Years and the Turf Wars of the 1950s." College Composition and Communication 50.4 (1999): 663-681.

Himley, Margaret. "Writing Programs and Pedagogies in Globalized Landscape." Writing Program Administration 26 (2003): 49-66.

Holdstein, Deborah H. "A Politics of Composition and Technology: Institutions and the Hazards of Making New." Writing Program Administration. 20.1/2 (1995): 44-52.

---. "The Politics of CAI and Word-Processing: Some Issues for Faculty and Administrators." Writing at Century's End: Essays on Computer-Assisted Composition. Ed. Lisa Gerrard. New York: Random House, 1985, 122130.

---. "Power, Genre, and Technology." College Composition and Technology 47 (1996): 279-284.

Holt, Richard G., and Anthony W. Morris. "Activity Theory and the Analysis of Organizations.” Human Organization 52.1 (1993): 97-110.

Hult, Christine. "Politics Redux: The Organization and Administration of Writing Programs." Writing Program Administration 18.3 (1995): 44-52.

---. "The Scholarship of Administration." In Janangelo and Hansen. 119-31.

Huot, Brian. "Computers and Assessment: Understanding Two Technologies." Computers and Composition 13 (1996): 231-243.

---, and Kathleen Yancey, eds. Assessing Writing Across the Curriculum: Diverse Approaches and Practices. Greenwich, CT: Ablex, 1997.

Improving America's School Act 1996 of 1994 (Public Law 103-382). Kentucky Conference on Building A Scholarly Structure in Teaching. Hebron, KY 2000.

Janangelo, Joseph, and Kristine Hansen, eds. Resituating Writing: Constructing 
and Administering Writing Programs. Portsmouth, NH: Boynton/CookHeinemann, 1995.

Kemp, Fred. "Surviving in English Departments the Stealth Computer-Based Writing Program." In Harrington et al., 267-284.

Kling, Rob. "What is Social Informatics and Why Does it Matter?" D-Lib Magazine: 5:1 (January 1999). Accessed 6/1/03. http://www.dlib.org/dlib/january99/kling/01kling.html

---. Power in Knowledge Management in Late Modern Times." Academy of Management Conference. Seattle, WA: August 2003. Accessed 6/1/03. $<\mathrm{http}: / /$ www.slis.indiana.edu/CSI/WP/WP03-02B.html $>$.

Kinneavy, James L. "A Pluralistic Synthesis of Four Contemporary Models for Teaching Composition." Reinventing the Rhetorical Tradition. Eds. Aviva Freedman and Ian Pringle. Ottawa: Canadian Council of Teachers of English, 1980. 37-52.

Kitzhaber, Albert R. "The University of Kansas Courses in the College Teaching of English." College Composition and Communication 6 (1955): 194-200.

Knoblauch, C.H. "Intentionality and the Writing Process." College Composition and Communication 31 (1980): 153-59.

Kolb, David. Socrates in the Labyrinth: Hypertext, Argument, Philosophy. Watertown: Eastgate, 1994.

Kress, Gunther. "'English' at the Crossroads: Rethinking Curricula of Communication in the context of the Turn to the Visual." In Hawisher and Selfe Passions and Pedagogies. 66-88.

Landow, George. The Convergence of Contemporary Critical Theory and Technology. Baltimore: Johns Hopkins UP, 1992.

Langston, Diane and Trent Batson. "The Social Shifts Invited by Working Collaboratively on Computer Networks: The ENFI Project." In Handa 160- 184.

Lanham, Richard. The Electronic Word: Democracy, Technology, and the Arts. Chicago: U of Chicago P, 1993.

---. "Digital Literacy." Scientific American (September 1995): 198-200. Lucky, Robert W. "What Technology Alone Cannot Do." $\underline{\text { Scientific }}$ American (September 1995): 204-205. 
Latour, Bruno. Science in Action: How to Follow Scientists and Engineers Through Society. Milton Keynes, UK: Open UP, 1987.

Lauer, Janice M., and J. William Asher. Composition Research: Empirical Designs. Oxford: Oxford UP, 1988.

Layer, Edith E. "Motivation of Freshman Composition on the University Level." College Composition and Communication 3 (1952): 3-16.

Leontiev, Aleksie A. Activity, Consciousness, and Personality. Englewood Cliffs, NJ: Prentice-Hall, 1978.

Levitan, Sar A. Old Wars Remain Unfinished: The Veteran Benefits System. Baltimore: Johns Hopkins UP, 1973.

---, and Joyce K. Zickler. Swords Into Plowshares: Our GI Bill. Olympus: Salt Lake City, 1973.

MacNealy, Mary Sue. Strategies for Empirical Research in Writing. Needham Heights, MA: Allyn Bacon, 1999.

Means, Barbara, ed. Technology and the Education Reform: The Reality Behind the Promises. San Francisco, Jossey-Bass, 1994.

Miles, Mathew B., and Michael Huberman. Qualitative Data Analysis: An Expanded Sourcebook. $2^{\text {nd }}$ Ed. New York: Sage, 1994.

Miller, J. Millie and John S. Allen. Veterans Challenge the Colleges: The New York Program. New York: King's Crown Press, 1947.

Miller, Richard. "From Intellectual Wasteland to Resource-Rich Colony: Capitalizing on the Role of Writing Instruction in Higher Education." Writing Program Administration 24.3 (2001): 25-40.

---. As if Learning Mattered: Reforming Higher Education. Ithaca, NY: Cornell UP, 1998.

Miller, Susan. Textual Carnival: Politics of Composition. Carbondale: SIU Press: 1993.

Moll, Luis C. Vygotsky and Education: Instructional Implications and Applications of Socio-historical Psychology. Cambridge: Cambridge UP, 1992. 1-110.

Mosch, Theodore R. The GI Bill: A Breakthrough in Educational and Social Policy in the United States. Hicksville, NY: Exposition Press, 1975. 
Myers, Linda, ed. Approaches to Computer Writing Classrooms: Learning From Practical Experience. Albany: SUNY, 1993.

Nardi, Bonnie A., ed. Context and Consciousness: Activity Theory and HumanComputer Interaction. Cambridge, MA: MIT P, 1996. 1-15, 69-82, 125145.

National Center for Educational Statistics. 1987 Digest of Education Statistics Washington D.C. Government Printing Office.

National Information Infrastructure Agenda for Action. Information Infrastructure Task Force. U.S. Department of Commerce. 15 September 1993. Accessed 10/18.03. <http://www.ibiblio.org/nii/toc.html>.

Negroponte, Nicholas. "Selected Bits." Being Digital. New York: Knopf, 1995.

North, Stephen M. The Making of Knowledge in Composition: Portrait of an Emerging Field. Upper Montclair, NJ: Boynton/Cook, 1987.

Ohmann, Richard. English in America: A Radical View of the Profession. New York: Oxford UP, 1976.

---. "Literacy, Technology, and Monopoly Capital." College English 47.7 (1985): 675-89.

Olson, Gary A., and Joseph M. Moxley. "Directing Freshman Composition: The Limits of Authority." College Composition and Communication 40 (1989): 51-59.

Peterson, Marvin W., David D. Dills, and Lisa A. Mets. Planning and Management for a Changing Environment. Higher Education Series. San Francisco: Jossey-Bass, 1997.

Petraglia, Joseph. Reconceiving Writing, Rethinking Writing Instruction. Hillsdale, NJ: Erlbaum, 1995. 52-77.

Popham, Susan, Michael Neal, Ellen Schendel and Brian Huot. "Breaking Hierarchies: Using Reflective Practice to Re-Construct the Role of the Writing Program Administrator. "The Writing Program Administrator as Theorist. Ed. Shirley K. Rose and Irwin Weiser. Westport,CT: Heinemann Boynton/Cook, 2002. 19-28.

Porter, James E., Patricia Sullivan, Stuart Blythe, Jeffrey T. Grabill, and Libby Miles. "Institutional Critique: A Rhetorical Methodology for Change." College Composition and Communication 51.4 (2000): 610-642. 
"Portland Resolution: Guidelines for Writing Program Administration Positions." Writing Program Administration 16.1/2 (1992): 88-94.

Poster, Mark. The Mode of Information. Chicago: Chicago UP, 1990.

Postman, Neil. "Conscientious Objections: Stirring Up Trouble About Language." Technology and Education. New York: Knopf, 1988.

---. Technopoly: The Surrender of Culture to Technology. Vintage Books, 1993.

Pratt, Mary Louise. “Arts of the Contact Zone." Profession 91. New York: MLA, 1991. 33-40.

Pytlik, Betty P. "Teaching the Teacher of Writing: Whence and Whither?" Paper presented at the Conference on College Composition and Communication, San Diego, Mar. 31- Apr. 3, 1993.

Rajput, Sanjays. "High-tech Military Items Devour Budget." The Daily Beacon. 14 Mar. <http://beacon-ww.asa.utk.edu/issues/v71/n44/rajput.44v.html>.

Rose, Mike. Lives On the Boundary. Boston: Penguin, 1989.

--- Possible Lives: The Promise of Public Education in America. New York: Houghton, 1995.

Rose, Shirley K. and Irwin Weiser, eds. The Writing Program Administrator as Theorist: Making Knowledge Work. Portsmouth: Boynton/Cook, 2002.

Rose, Shirley K. and Irwin Weiser. Eds. The Writing Program Researcher: Inquiry in Action and Reflection. Portsmouth: Boynton/Cook, 1999.

Russell, David R. “Activity Theory and Its Implications for Writing Instruction. Ed. J. Petraglia. Reconceiving Writing, Rethinking Writing Instruction. Hillsdale NJ: Erlbaum, (1995): 52-77.

--.. "Rethinking Genre and School and Society: An Activity Theory Analysis." Written Communication 14.4 (1997): 504-554.

Salpeter, Judy. "Accountability: Meeting the Challenge with Technology." Technology and Learning 20.6 (2002): 20-32.

Schiller, Dan. Digital Capitalism: Networking the Global Market System. Cambridge, MA: MIT, 1999.

Scholes, Robert. The Rise and Fall of English. New Haven: Yale UP, 1998. 
Schon, Donald. The Reflective Practitioner. Basic Books: New York, 1982.

Schwartz, Helen and Lillian S. Bridwell. "A Selected Bibliography on Computers in Composition" College Composition and Communication 35.1 (1984): 71-77.

Shaughnessey, Mina P. Errors and Expectation. New York: Oxford UP, 1977.

Sirc, Geoffrey. " 'What is Composition ...?' After Duchamp: Notes Toward a General Teleintertext." In Gail E. Hawisher and Cynthia L. Selfe. Passions and Pedagogies. 178-204.

Selfe, Cynthia L. "Computers in English Departments: The Rhetoric of Techno/Power. Eds. Deborah H. Holdstein and Cynthia L. Self. Computers and Writing: Theory, Research, Practice. New York: MLA, 1990. 95-103.

---. Creating a Computer-Supported Writing Facility: A Blueprint for Action. Houghton, MI: Computers and Composition Press, 1989.

---. "English Teachers and the Humanization of Computers: Networking Communities of Readers and Writers." On Literacy and Its Teaching: Issues in Education. Eds. Gail E. Hawisher and Anna O. Soter. Albany NY: State U of New York P, 1990.

--.. "The Humanization of Computers: Forget Technology, Remember Literacy." English Journal 7.6 (1988b): 69-71.

---. Literacy, Technology, and Society: Confronting the Issues. Upper Saddle River, NJ: Prentice-Hall, 1997.

---. Technology and Literacy: A Story about the Perils of Not Paying Attention. College Composition and Communication.50.3 (February 1999).

---. "Preparing English Teachers for the Virtual Age: The Case for Technology Critics." in Hawisher and LeBlanc 24-4.

--- "Redefining Literacy: The Multi-Layered Grammars of Computers." Critical Perspectives on Computers and Composition Instruction. New York: Teacher's College Press, 1989.

---. Technology and Literacy in the Twenty-First Century: The Importance of Paying Attention. Carbondale, IL: SIU Press, 1999.

---, and Richard Selfe. "The Politics of the Interface." College Composition and 
Communication 45.5 (1994): 480-504.

---, Hawisher, Gail E., and Ericsson Patricia. "Stasis and Change: Role of Independent Composition Programs and the Dynamic Nature of Literacy." A Field of Dreams: Independent Writing Programs and the Future of Composition Studies. Eds. O'Neill, Peggy, Angela Crow, and Larry W. Burton. Logan, Utah: Utah State UP, 2002, 268-278.

---, and Susan Hilligoss. Literacy and Computers: The Complications of Learning and Teaching With Technology. New York: MLA, 1994.

Selfe, Richard. "Survey and Discussion of Technology-rich Facilities in English Studies Departments." Diss. Michigan Tech Univ. Houghton, MI:

Summer 1997. Accessed 1/5/02: 1-24.

http://www.hu.mtu.edu/ rselfe/diss/report.html.

---, and Hugh Stilley. "Surveying the Electronic Landscape In the Online Writing Classroom." 285-309. In Harrington et al.

Schell, Eileen E. "Whose the Boss?: The Possibilities and Pitfalls of Collaborative Administration for Untenured WPAs." Writing Program Administration 21 (1998): 56-80.

Simon, Julian L. Basic Research Methods in Social Sciences. New York: Random House, 1969. 58.

Sproull, Lee and Sara Kiesler. Connections: New Ways of Working Within the Networked Organization. Cambridge, MIT, 1991.

Sullivan, Patricia, and Jennie Dautermann. Electronic Literacies in the Workplace: Technologies of Writing. NCTE: Urbana, 1996.

Sullivan, Patricia and James E. Porter. Opening Spaces: Writing Technologies and Critical Research Practices. Greenwich, CT: Ablex, 1997.

Swales, John. Genre Analysis. Cambridge UK: Cambridge UP, 1990.

Takayoshi, Pamela D. "Building New Networks from the Old: Women's Experiences with Electronic Communications." Computers and Composition 11 (1994): 221-35.

---. "Resigned Acceptance: Construction of Technology and Agency." Talk given at Clemson University as an invited speaker. April 18, 2002. 
---. "The Shaping of Electronic Writing: Evaluating and Assessing ComputerAssisted Writing Processes and Products." Computers and Composition 13 (1996): 245-258.

Taylor, Mark C. The Moment of Complexity: Emerging Network Culture. Chicago: U of Chicago P: 2001.

Taylor, Todd. "Computers in the Composition Curriculum: An Update." Writing Program Administration 20.1/2 (1996): 7-18.

---. The Persistence of Difference in Networked Classroom: Non-Negotiable Difference and the African American Student Body. Computers and Composition 14 (1997): 169-178.

--.. "Ten Commandments for Computers and Composition." See Allyn and Bacon Sourcebook pp. 228-242.

---, and Irene Ward, eds. Literacy Theory in the Age of the Internet. New York: Columbia UP, 1998.

Toulmin, Stephen. Cosmopolis: The Hidden Agenda of Modernity. Chicago: The UP, 1992.

---. Human Understanding. Cambridge: The UP, 1972.

---. The Uses of Argument. Cambridge: The UP, 1958.

Van Nostrand, A.D. Fundable Knowledge: The Marketing of Defense Technology. Mahwah, NJ: Erlbaum, 1997.

Villanueva, Victor., Jr. "Considerations for American Freireistas." The Politics of Writing Instruction: Postsecondary. Eds. Richard Bullock and John Trimbur. Portsmouth, NH: Heinemann, 1991

---. Ed. Cross Talk in Comp Theory. Urbana, IL: NCTE, 1997.

Vygotsky, Lev S. Mind in Society: The Development of Higher Psychological Processes. Ed. Vera John-Steiner. Boston: Harvard UP, 1980.

White, Edward M. "Use It or Lose It: Power and WPA." Writing Program Administration 15 (1991): 3-12.

Williams, Sean, WPA Listerv. Online Survey and Study. October 2001. 
Wilson, Greg. "Technical Communication and Late Capitalism: Considering a Postmodern Technical Communication Pedagogy." Journal of

Business and Technical Communication 15:1 (January 2001) 72-99.

Winner, Langdon. 1986. "Mythinformation" The Whale in the Reactor: A Search For Limits in an Age of High Technology. Chicago: Chicago UP, 89-117.

Winsor, Dorothy. "Genre and Activity Theory." Written Communication 16.2 (1999): 200-24.

Walvoord, Barbara E., and Anna K. Carey, Hoke L. Smith, Suzanne W. Solded. Phillip K. Way, and Debbie Zorn. Academic Departments: How They Work, How They Change. ASHE-ERIC Higher Education Report 27.8. San Francisco: Jossey-Bass, 2000.

WPA Board of Consultant Evaluators "Writing Program Evaluation: An Outline for Self-Study." Writing Program Administration 4 (1980): 23-28.

Zimmerman, Ray and Ellen Strenski. "Using the World Wide Web for Instructional Development: Writing Program Homepages, On-line Course Manuals, and Archived Staff Listservs." Writing Program Administration 20.3 (1997): 91-101.

Zuboff, Soshana. In the Age of the Smart Machine: The Future of Work and Power. New York: Basic, 1951, 385. 


\title{
APPENDICES A-E APPENDIX A \\ Study of the Administration of Computer-Supported Writing Spaces WPA Human Subjects Consents
}

\author{
Subject Informed Consent
}

Invitation

You are being invited to participate in a research study. The study is being conducted by Dr. Pamela Takayoshi and Katherine V. Wills and is sponsored by the Department of English at the University of Louisville.

\section{Purpose}

The purpose of this study is to gather essential information about how other writing programs have structured their use of computers to teach writing. Armed with a picture of programmatic responses to the integration of technology into writing curricula, Writing Program Administrators (WPAs) can contextualize and assess their own uses of technology, measuring approaches against those at comparable institutions. Benchmark institutions are commonly defined as institutions that share similar missions and demographics. In our study, we focus on benchmark institutions as a way of giving WPAs a method for examining their implementation of technology into writing courses relative to peer institutions that share similar missions and resources. Additionally, focusing on benchmark institutions lessens the number of variables which might conflict with making accurate comparisons about a writing program's uses of technology.

\section{Procedures}

In this study you will either be asked to either fill out a questionnaire or to be interviewed you about writing program structure. The survey should take approximately 15 minutes to complete. The interviews should take approximately 30 minutes to complete. Your completed survey or interview will be stored at the University of Louisville office of Dr. Pamela Takayoshi. Individuals from the Department of English and the University Human Studies Committee may inspect these records. Although absolute confidentiality cannot be guaranteed, the data will be held in confidence to the extent permitted by law.

\section{Compensation}

There is no payment for your participation.

Voluntary Participation

Your participation is voluntary. You may decline to answer any question. There are no risks or benefits to you for your participation; however, the knowledge gained may benefit others.

Research Subject's Rights and Contacts

All your present questions have been answered in language you can understand. All future questions will be answered in a similar manner. You may call Katherine Wills at 812.988 .4250 for answers to questions you have related to the project. 
You may call the Human Studies Committee office (502.852.5188) and will be given an opportunity to discuss any questions about your rights as a research subject, in confidence, with a member of the committee. The Committee has reviewed this study.

\section{Consent}

You have discussed and understood the above information and hereby consent to voluntary participate in this study. You will be given a copy of the signed consent.

$\overline{\text { Signature of Subject/ Legal Representative }}$

Signature of Investigator
Date Signed

Date Signed 


\section{APPENDIX B}

\section{Council of Writing Program Administration 2001 Research Grant Proposal}

To:

Research Grant Committee

Date: January 2, 2001

Title: $\quad$ Building a Methodology for Studying the Intersection of Writing Program Administration and Computer-Aided Instruction in First-Year Curriculum

Investigators:

Dr. Pamela Takayoshi

Associate Professor

Director, Computer-Assisted Instruction

English Department

University of Louisville 40692

Phone

502.852 .0510

Fax

502.852 .4182

E-mail_pamt@louisville.edu

Katherine Wills

Assistant Director, Computer-Assisted Instruction

English Department

University of Louisville 40692

Phone $\quad 502.852 .8106$

Fax $\quad 502.852 .4182$

E-mail katherine.wills@louisville.edu

WPA Proposal

Writing programs do not exist in isolation. An institution's writing program exists within a larger context of writing programs across the country, reflecting not only local needs and concerns but also the body of knowledge arrived at by the profession as a whole. Writing programs benefit from both local and national knowledge. As administrators of our English Department's computer writing program, we have learned that local and national knowledge are necessary for writing program directors in shaping, running, and assessing a program incorporating technology as well as in articulating to the 
administration the need for resources. Increasingly, writing program administrators face mandates to incorporate writing technologies into their curriculum. For example, in a December 2000 discussion, members of WPA-L discussed the varied formats of institutional computer-assisted instruction (CAI) classes or labs. This discussion raised various questions: How do WPAs meet the demands of diverse educational stakeholders? How are different universities incorporating technology into their curriculum? How are classrooms configured? How are instructors prepared? Are program directors allocated reasonable funds and support for successful integration of technology in the classroom? Are WPAs provided a context of success? Are stakeholders' expectations in line with benchmark institutions? Answers to questions such as these provide heuristics and comparative information for individual programs and for the field, contributing to a snapshot of the current status of technology instruction across the country. Currently, this type of information is not readily available. The need for information about how other institutions handle the demands of computer-oriented instruction often permeates formal and informal discussions among WPAs. However, discussing one's program with colleagues from other institutions can have limited comparative value if the institutions differ in mission and resources.

In preliminary, informal investigations about technology and writing program administration, we have found that while composition scholarship suggests that teaching writing with technology is increasingly becoming common (Faigley; Hawisher and Selfe; Hawisher, LeBlanc, Moran, and Selfe) and that writing programs are increasingly faced with mandates from administrative agencies that more technology be infused into existing curricula (Selfe), WPAs do not have very much information about how writing programs accomplish these goals. Thus, WPAs are often left to reinvent the wheel. Knowing how other WPAs have accomplished similar goals in similar contexts can be valuable and time-saving to achieving an institution's own goals.

In this study we create a methodology for WPAs to gather essential information about how other writing programs have structured their use of computers to teach writing. Armed with a picture of programmatic responses to the integration of technology into writing curricula, WPAs can contextualize and assess their own uses of technology, measuring approaches against those at comparable institutions. Benchmark institutions are commonly defined as institutions that share similar missions and demographics. In our study, we focus on benchmark institutions as a way of giving WPAs a method for examining their implementation of technology into writing courses relative to peer institutions that share similar missions and resources. Additionally, focusing on benchmark institutions lessens the number of variables which might conflict with making accurate comparisons about a writing program's uses of technology.

Our method begins with contacting the WPA at each of our university's fifteen benchmark institutions (Appendix A) and interviewing her about the uses of technology in first year writing. Our interview questions (Appendix B) range from the pragmatic (how many sections of first year writing are taught each semester? who are the instructors? what do the computer facilities look like?) to the programmatic (what training do teachers receive? who manages the computer facilities?) to the theoretical (what are the beliefs and assumptions that inform writing program administrators decisions?). We plan to interview by phone (and tape record the interview) or send e-mail surveys. By focusing on benchmark institutions and questions that get at information which can be compared by institution, we have limited the scope and focus of the study to ensure an efficient way to collect valuable information. As such, our study becomes a 
model for other WPAs who can apply it to their own institutional concerns and develop a richer understanding of their own program's practices and policies and how their program compares to related institutions.

Once the interviews have been transcribed and reviewed, we will conduct on-site visits and follow-up interviews at four to five institutions selected as representative or exemplar models of technology and writing instruction. Three of our benchmark institutions are within an easy drive; two of the remaining on-site visits will require air travel. These onsite observations will give us a different kind of data to develop our understanding of the institution's integration of technology; observing the everyday life of these institution's uses of technology can provide valuable information which the interviewees and the researchers might not have considered significant during the initial interviews. Follow-up visits will be opportunities for us to interview other participants in the writing program and to collect additional perspectives on the integration of technology. We will then have a rich body of data (interview transcripts, observation notes, follow-up interview transcripts) which can provide a timely, detailed account for three different constituencies: 1) a comparative assessment of our institution's approach to integrating technology into writing instruction for our local needs; 2) a picture of the daily lives and practices of a cross-section of the nation's writing programs addressing an increasingly ubiquitous trend for composition scholars and theorists; and 3) a methodology for WPAs to gather information relevant to their own programs. Our study focuses on CAI, but this model can be shaped to the individual needs of each institution. We do not propose a "one-size-fits-all" methodology. Rather, because the methodology focuses on programmatic change and concerns, we seek to create a model that is amenable to the needs of each institution. This methodology could be used by WPAs to collect data about issues such as teacher training, program review, and assessment to enact informed material and theoretical change in their programs.

The project we propose needs support for: 1) the purchase of recording equipment and for the transcription of interview tapes; and 2) for travel to four to five institutions. This project has no other monetary supplements. As our timeline (Appendix C) demonstrates, this project is practical in its scope and focus. We envision the data collection process (including interviews and follow-up visits) to be completed by September 2001. After data analysis, we will write about the methodology and our findings in at least two articles for WPA and Computers and Composition. Our results will have significance for audiences of these two journals, and further, a review of both journals shows that neither has explicitly addressed the intersection of writing program administration and writing technologies. WPA, for example, has published $\mathrm{xx}$ articles on technology; none were empirically based examinations of the intersection of writing technologies and writing program administration. Computers and Composition has published $\mathrm{xx}$ articles focused on WPAs integrating writing technologies; none have developed an empirical understanding of the scale of the proposed study.

Universities are increasingly facing mandates from a number of factions (students, Boards of Regents, accrediting agencies) that technology be incorporated into the college curriculum. This often translates directly to the work that WPAs do, but without a picture of the broader context of writing instruction and writing technologies, WPAs are expected to produce results without access to methods or data about how to proceed. WPAs need more information about how to integrate technology into writing programs, including actual practices of other WPAs. Our study provides a methodology for gathering this valuable information. 


\section{Works Cited}

Faigley, Lester. "Literacy After the Revolution: 1996 CCC Chair's Address."

Hawisher, Gail, Paul LeBlanc, Charles Moran, and Cynthia Selfe. Computers and the Teaching of Writing in American Higher Education, 1979 - 1994. Norwood, NJ: Ablex Press, 1996.

Hawisher, Gail, and Cynthia Selfe. Passions, Pedagogies, and $21^{\text {st }}$ Century Technologies. Urbana, IL: NCTE Press, 1999.

Holdstein, Deborah H. "A Politics of Composition and Technology: Institutions and the Hazards of Making New." WPA v2 n1 (1996). 19-31.

Selfe, Cynthia L. Technology and Literacy in the Twenty-First Century: The Importance of Paying Attention. SIU Press, 1999.

Taylor, Todd. "Computers in the Composition Curriculum: An Update." WPA. V20 n1/2 (1996). 7-18.

Taylor, Todd and Irene Ward. Eds. Literacy Theory in the Age of the Internet. New York: Columbia UP, 1998.

University of Louisville's Benchmark Institutions

University of South Carolina at Columbia

University of South Florida

University of Pittsburgh

University of Missouri at Kansas City

University of Missouri at Columbia

University of Nevada at Reno

University of Illinois at Chicago

University of Cincinnati

Indiana University and Purdue University at Indianapolis

Temple University

State University of New York at Buffalo

State University of New York at Stoneybrook

University of Alabama at Birmingham

Virginia Commonwealth University

Wayne State University

Interview Questions

These questions are meant to give a sense of the types of information we want to gather in our study; the actual questions may be revised as we interview actual writing program administrators.

1. Does your program or department have access to a computer classroom in which to teach writing classes? If yes, please describe the classroom(s). How up-to-date is the hardward and software? 
2. Does your program or department have access to technological support within traditional classrooms (i.e., computer displays, laptop hook-ups)? If yes, please describe the arrangement and the technologies used.

3. If your program or department has a facility, who manages it? In what department is the administrator housed? How is the administrator compensated for her work? How is the facility related to the institution's writing program?

4. Does your program or department have a technical support person? Is that person faculty or staff? What is her job description? How is the technical support person compensated for her work?

5. How many sections of first year composition are taught on your campus? How many of these are taught partially in computer classrooms (i.e., scheduled occasionally in computer classrooms)? How many are taught full time in computer classrooms?

6. Who are the teachers?

7. How do teachers get access to technology? How do teachers get scheduled in computer classrooms? What technological training or orientation do they receive?

8. Has your program articulated pedagogical goals regarding writing technologies?

9. Has your program or department articulated a technology plan? If yes, what is the plan?

10. Has your program or department been mandated (by higher administration or accrediting agencies) to incorporate technology into your curriculum? If yes, how has your program or department answered the mandates?

11.Describe the administrative chain of command for implementing technology into your curriculum. From what offices (President, Dean, Chair) did the decision to incorporate technology come?

12. Who are the decision-makers that decide to add/increase computer-aided instruction? Whose (person, agency, office) decision was it to incorporate technology in your curriculum?

13. What is the decision-making process for incorporating computer curriculum in your department?

14 Are you aware of any public or governmental initiative, grant agency, or call to action that stimulated the addition of CAI curriculum to your department (i.e. NEH, NII, GII, ARPA)? What are these initiatives?

15. What factors influenced the decision-makers to add technology to the curriculum? This may include institutional, social, political, and other factors.

16. Can you name any intra-institutional policies or documents that were instrumental in developing your CAI curriculum? Are copies of these available to the public?

17. Can you name any extra-institutional policies or documents that were instrumental 
in developing your CAI curriculum? Are copies of these available to the public?

18. Have you been required to write or direct a study of your computer-assisted curriculum to date? If yes, what is the rationale for the study? If no, do you anticipate you will have to conduct a study in the future? 


\section{APPENDIX C \\ Sample Site Survey Transcript \\ VCU - Site visit Transcript Sample \\ Tape One 5/29/03 \\ Transcriber: Betty Christian}

001 I: How long have you been here?

002 MK: I've been here since 1986. I came as a graduate student in ' 86 in the 003 lab then.

004 I: Would you say that you are one of the main technology people and how did you get into that role?

007 MK: Okay. Yeah, I am one of the people. In fact that's my job. That is in my

008 job description as computer coordinator. When I came as a grad student in

009 ' 86 there was a lab here. I was actually teaching as a first year TA. I didn’t

010 know anything about computers other than having had a little Bic20 you know

011 what that was. It was not much of a computer. And I guess I got interested in

012 using computer for my own writing. I very quicly knew more about this system

013 just through my own work and self-study than the TAs working the lab did.

014 Because there was no one really training the TAs on how to do support and 
015 they often would either not get help or didn't know what the answer to the

016 question or they were giving the wrong answers. They were causing students

017 to lose data and that may be more complicated than we want to go into here

018 with what the problems were in the system and beyond but - so I asked in my

019 the second year of my TA because I felt very burnt out on teaching after I

020 high school for a year than taught here one year as a TA to be moved to the

021 lab and I was advised by one faculty member that was a real mistake. That

022 was a backward move.

023 I: Why was it?

024 MK They thought that since I came in teaching in a TA I should continue

025 teaching. That I needed the teaching experience, not to move back to work

026 in the computer lab, this is a lab but I really asked for that and got it and then

027 by the third year I was asked to actually administrate the lab for ten hours a

028 week so I had sort of a split assignment where I was working in the lab ten 029 hours and then I was doing scheduling, doing some administration. I then 030 applied for an instructorship after graduation. It was not an instructorship that

031 included any technology responsibilities. I did not get the instructorship but

032 then suddenly two others opened up and I was hired for one of those and 
033 asked if I would run the lab for a course release. So I had 3 and 3 and then

034 half. That - when I got toward the end of my term limit, my chair approached

035 me and said that it's clear to us that we're going to have to hire somebody to

036 do what you're doing. I've talked to the dean and we're going to see if we

037 can't work out some way to make this a continuing position, not tenure track

038 but a continuing collatiral faculty position and they made me a lecturerer to

039 avoid the issue of a term limit and created a position computer coordinator

040 and the chair's original idea was that there would be a position that would do

041 some computer support and some general work in the composition program

042 and I told em, and this was just the year before the office were networked that

043 once the offices are networked you need somebody just doing computer

044 support without that being a split position and he really trusted me on that and

045 I think it was the right call because then as soon as those offices were

046 networked people really needed a lot of my time and so that's how that came

047 that came about. That's a long answer 


\title{
APPENDIX D
}

\author{
Agenda for Action
}

\section{The Administration's Agenda for Action}

\section{The Promise of the NII}

http://www.ibiblio.org/nii/NII-Agenda-for-Action.html

Imagine you had a device that combined a telephone, a TV, a camcorder, and a personal computer. No matter where you went or what time it was, your child could see you and talk to you, you could watch a replay of your team's last game, you could browse the latest additions to the library, or you could find the best prices in town on groceries, furniture, clothes -- whatever you needed.

Imagine further the dramatic changes in your life if:

- The best schools, teachers, and courses were available to all students, without regard to geography, distance, resources, or disability;

- The vast resources of art, literature, and science were available everywhere, not just in large institutions or big-city libraries and museums;

- Services that improve America's health care system and respond to other important social needs were available on-line, without waiting in line, when and where you needed them;

- You could live in many places without foregoing opportunities for useful and fulfilling employment, by "telecommuting" to your office through an electronic highway instead of by automobile, bus or train;

- Small manufacturers could get orders from all over the world electronically -with detailed specifications -- in a form that the machines could use to produce the necessary items;

- You could see the latest movies, play the hottest video games, or bank and shop from the comfort of your home whenever you chose; 
- You could obtain government information directly or through local organizations like libraries, apply for and receive government benefits electronically, and get in touch with government officials easily; and

- Individual government agencies, businesses and other entities all could exchange information electronically -- reducing paperwork and improving service.

Information is one of the nation's most critical economic resources, for service industries as well as manufacturing, for economic as well as national security. By one estimate, two- thirds of U.S. workers are in information-related jobs, and the rest are in industries that rely heavily on information. In an era of global markets and global competition, the technologies to create, manipulate, manage and use information are of strategic importance for the United States. Those technologies will help U.S. businesses remain competitive and create challenging, high- paying jobs. They also will fuel economic growth which, in turn, will generate a steadilyincreasing standard of living for all Americans.

That is why the Administration has launched the National Information Infrastructure initiative. We are committed to working with business, labor, academia, public interest groups, Congress, and state and local government to ensure the development of a national information infrastructure (NII) that enables all Americans to access information and communicate with each other using voice, data, image or video at anytime, anywhere. By encouraging private sector investment in the NII's development, and through government programs to improve access to essential services, we will promote U.S. competitiveness, job creation and solutions to pressing social problems.

\section{What Is the NII?}

The phrase "information infrastructure" has an expansive meaning. The NII includes more than just the physical facilities used to transmit, store, process, and display voice, data, and images. It encompasses:

- A wide range and ever-expanding range of equipment including cameras, scanners, keyboards, telephones, fax machines, computers, switches, compact disks, video and audio tape, cable, wire, satellites, optical fiber transmission lines, microwave nets, switches, televisions, monitors, printers, and much more.

The NII will integrate and interconnect these physical components in a technologically neutral manner so that no one industry will be favored over any other. Most importantly, the NII requires building foundations for living in the Information Age and for making these technological advances useful to the public, business, libraries, and other nongovernmental entities. That is why, beyond the physical components of the infrastructure, the value of the National Information Infrastructure to users and the nation will depend in large part on the quality of its other elements: 
- The information itself, which may be in the form of video programming, scientific or business databases, images, sound recordings, library archives, and other media. Vast quantities of that information exist today in government agencies and even more valuable information is produced every day in our laboratories, studios, publishing houses, and elsewhere.

- Applications and software that allow users to access, manipulate, organize, and digest the proliferating mass of information that the NII's facilities will put at their fingertips.

- The network standards and transmission codes that facilitate interconnection and interoperation between networks, and ensure the privacy of persons and the security of the information carried, as well as the security and reliability of the networks .

- The people -- largely in the private sector -- who create the information, develop applications and services, construct the facilities, and train others to tap its potential. Many of these people will be vendors, operators, and service providers working for private industry.

Every component of the information infrastructure must be developed and integrated if America is to capture the promise of the Information Age.

The Administration's NII initiative will promote and support full development of each component. Regulatory and economic policies will be adopted that encourage private firms to create jobs and invest in the applications and physical facilities that comprise the infrastructure. The Federal government will assist industry, labor, academia, and state and local governments in developing the information resources and applications needed to maximize the potential of those underlying facilities. Moreover, and perhaps most importantly, the NII initiative will help educate and train our people so that they are prepared not only to contribute to the further growth of the NII, but also to understand and enjoy fully the services and capabilities that it will make available.

\section{Need for Government Action To Complement Private Sector Leadership}

The foregoing discussion of the transforming potential of the NII should not obscure a fundamental fact -- the private sector is already developing and deploying such an infrastructure today. The United States communications system -- the conduit through which most information is accessed or distributed -- is second to none in speed, capacity, and reliability. Each year the information resources, both hardware and software, available to most Americans are substantially more extensive and more powerful than the previous year.

The private sector will lead the deployment of the NII. In recent years, U.S. companies have invested more than $\$ 50$ billion annually in telecommunications infrastructure -- and that figure does not account for the vast investments made by firms in related industries, such as computers. In contrast, the Administration's ambitious agenda for investment in critical NII projects (including computing) 
amounts to \$1-2 billion annually. Nonetheless, while the private sector role in NII development will predominate, the government has an essential role to play. In particular, carefully crafted government action can complement and enhance the benefits of these private sector initiatives. Accordingly, the Administration's NII initiative will be guided by the following nine principles and goals, which are discussed in more detail below:

- 1) Promote private sector investment, through tax and regulatory policies that encourage innovation and promote long- term investment, as well as wise procurement of services.

- 2) Extend the "universal service" concept to ensure that information resources are available to all at affordable prices. Because information means empowerment, the government has a duty to ensure that all Americans have access to the resources of the Information Age.

- 3) Act as catalyst to promote technological innovation and new applications. Commit important government research programs and grants to help the private sector develop and demonstrate technologies needed for the NII.

- 4) Promote seamless, interactive, user-driven operation of the NII. As the NII evolves into a "network of networks," government will ensure that users can transfer information across networks easily and efficiently.

- 5) Ensure information security and network reliability. The NII must be trustworthy and secure, protecting the privacy of its users. Government action will also aim to ensure that the overall system remains reliable, quickly repairable in the event of a failure and, perhaps most importantly, easy to use.

- 6) Improve management of the radio frequency spectrum, an increasingly critical resource.

- 7) Protect intellectual property rights. The Administration will investigate how to strengthen domestic copyright laws and international intellectual property treaties to prevent piracy and to protect the integrity of intellectual property.

- 8) Coordinate with other levels of government and with other nations. Because information crosses state, regional, and national boundaries, coordination is important to avoid unnecessary obstacles and to prevent unfair policies that handicap U.S. industry.

- 9) Provide access to government information and improve government procurement. As described in the National Performance Review, the Administration will seek to ensure that Federal agencies, in concert with state and local governments, use the NII to expand the information available to the public, so that the immense reservoir of government information is available to the public easily and equitably. Additionally, Federal procurement policies for telecommunications and information services and equipment will be designed to promote important technical developments for the NII and to provide attractive incentives for the private sector to contribute to NII development.

- The time for action is now. Every day brings news of change: new technologies, like hand-held computerized assistants; new ventures and mergers combining businesses that not long ago seemed discrete and insular; new legal decisions that challenge the separation of computer, cable and telephones. These changes 
promise substantial benefits for the American people, but only if government understands fully the implications of these changes and to work with the private sector and other interested parties to shape the evolution of the communications infrastructure.

\section{Managing Change/ Forging Partnerships}

We will help to build a partnership of business, labor, academia, the public, and government that is committed to deployment of an advanced, rapid, powerful infrastructure accessible and accountable to all Americans.

Forging this partnership will require extensive inter-governmental coordination to ensure that Administration, Congressional, state and local government policy regarding the NII is consistent, coherent, and timely. It also requires the development of strong working alliances among industry groups and between government and the businesses responsible for creating and operating the NII. Finally, close cooperation will be needed between government, users, service providers, and public interest groups to ensure that the NII develops in a way that benefits the American people.

Specifically, the Administration will:

- (1) Establish an interagency Information Infrastructure Task Force

The President has convened a Federal inter-agency "Information Infrastructure Task Force" (IITF) that will work with Congress and the private sector to propose the policies and initiatives needed to accelerate deployment of a National Information Infrastructure. Activities of the IITF include coordinating government efforts in NII applications, linking government applications to the private sector, resolving outstanding disputes, and implementing Administration policies. Chaired by Secretary of Commerce Ron Brown and composed of highlevel Federal agency representatives, the IITF's three committees focus on telecommunications policy, information policy, and applications.

- (2) Establish a private sector Advisory Council on the National Information Infrastructure

To facilitate meaningful private sector participation in the IITF's deliberations, the President will sign an Executive Order creating the "United States Advisory Council on the National Information Infrastructure" to advise the IITF on matters relating to the development of the NII. The Council will consist of 25 members, who will be named by the Secretary of Commerce by December 1993. Nominations will be solicited from a variety of NII constituencies and interested parties. The IITF and its committees also will use other mechanisms to solicit public comment to ensure that it hears the views of all interested parties. 
- (3) Strengthen and streamline Federal communications and information policymaking agencies

In order to implement the ambitious agenda outlined in this document, the federal agencies most directly responsible for the evolution of the NII (such as NTIA, the Office of Information and Regulatory Affairs at OMB, and the FCC) must be properly structured and adequately staffed to address many new and difficult policy issues. The Administration intends to ensure that these agencies have the intellectual and material resources they need. In addition, in accord with the Vice President's National Performance Review, these agencies will make the organizational and procedural changes needed to most effectively contribute to the NII initiative.

\section{Principles and Goals for Government Action}

The Task Force currently is undertaking a wide-ranging examination of all issues relevant to the timely development and growth of the National Information Infrastructure. Specific principles and goals in areas where government action is warranted have already been identified and work has begun on the following matters:

\section{- 1. Promote Private Sector Investment}

One of the most effective ways to promote investments in our nation's information infrastructure is to introduce or further expand competition in communications and information markets. Vibrant competition in these markets will spur economic growth, create new businesses and benefit U.S. consumers.

To realize this vision, however, policy changes will be necessary:

Action: Passage of communications reform legislation. The Administration will work with Congress to pass legislation by the end of 1994 that will increase competition and ensure universal access in communications markets -particularly those, such as the cable television and local telephone markets, that have been dominated by monopolies. Such legislation will explicitly promote private sector infrastructure investment -- both by companies already in the market and those seeking entry.

Action: Revision of tax policies. Tax policies are important determinants of the amount of private sector investment in the NII. The President has signed into law tax incentives for private sector investment in R\&D and new business formation, including a three-year extension of the R\&D credit and a targeted capital gains reduction for investments in small businesses. Both of these tax incentives will help spur the private sector investment needed to develop the NII. 
- 2. Extend the "Universal Service" Concept to Ensure that Information Resources Are Available to All at Affordable Prices

The Communications Act of 1934 articulated in general terms a national goal of "Universal Service" for telephones -- widespread availability of a basic communications service at affordable rates. A major objective in developing the NII will be to extend the Universal Service concept to the information needs of the American people in the 21st Century. As a matter of fundamental fairness, this nation cannot accept a division of our people among telecommunications or information "haves" and "have- nots." The Administration is committed to developing a broad, modern concept of Universal Service -- one that would emphasize giving all Americans who desire it easy, affordable access to advanced communications and information services, regardless of income, disability, or location.

Devising and attaining a new goal for expanded Universal Service is consistent with efforts to spur infrastructure development by increasing competition in communications and information markets. As noted above, competition can make low cost, high quality services and equipment widely available. Policies promoting greater competition in combination with targeted support for disadvantaged users or especially high cost or rural areas would advance both rapid infrastructure modernization and expanded Universal Service.

Action: Develop a New Concept of Universal Service. To gather information on the best characteristics of an expanded concept of Universal Service, the Commerce Department's National Telecommunications and Information Administration (NTIA) will hold a series of public hearings on Universal Service and the NII, beginning by December 1993. The Administration will make a special effort to hear from public interest groups. Building on the knowledge gained from these activities, the IITF will work with the Advisory Council on the National Information Infrastructure, as well as with state regulatory commissions, to determine how the Universal Service concept should be applied in the 21 st Century.

\section{- 3. Promote Technological Innovation and New Applications}

Government regulatory, antitrust, tax, and intellectual property policies all affect the level and timing of new offerings in services and equipment -- including the technology base that generates innovations for the marketplace. But technological innovations ultimately depend upon purposeful investment in research and development, by both the private sector and government. R\&D investment helps firms to create better products and services at lower costs.

As noted in the Administration's February 22, 1993 technology policy statement: "We are moving to accelerate the development of technologies critical for longterm growth but not receiving adequate support from private firms, either because 
the returns are too distant or because the level of funding required is too great for individual firms to bear." Government research support already has helped create basic information technologies in computing, networking and electronics. We will support further NII-related research and technology development through research partnerships and other mechanisms to accelerate technologies where market mechanisms do not adequately reflect the nation's return on investment. In particular, these government research and funding programs will focus on the development of beneficial public applications in the fields of education, health care, manufacturing, and provision of government services.

Action: Continue the High-Performance Computing and Communications Program. Established by the High-Performance Computing Act of 1991, the HPCC Program funds R\&D designed to create more powerful computers, faster computer networks, and more sophisticated software. In addition, the HPCC Program is providing scientists and engineers with the tools and training they need to solve "Grand Challenges," research problems -- like designing new drugs -- that cannot be solved without the most powerful computers. The Administration has requested \$1 billion for the HPCC Program in fiscal year 1994, and is in the process of forming a "High-Performance Computing Advisory Committee," to provide private sector input on the Program.

We have also requested an additional \$96 million in the FY 1994 budget to create a new component of the HPCC Program -- Information Infrastructure

Technologies and Applications (IITA). The Administration is working with Congress to obtain authorization to fund this effort, which will develop and apply high-performance computing and high-speed networking technologies for use in the fields of health care, education, libraries, manufacturing, and provision of government information.

Action: Implement the NII Pilot Projects Program. In its FY 94 budget, the Administration has requested funding from the Congress for NII networking pilot and demonstration projects. Under NTIA's direction, this pilot program will provide matching grants to state and local governments, health care providers, school districts, libraries, universities, and other non-profit entities. The grants will be awarded after a competitive merit review process and will be used to fund projects to connect institutions to existing networks, enhance communications networks that are currently operational, and permit users to interconnect among different networks. Funded projects will demonstrate the potential of the NII and provide tangible benefits to their communities. Equally important, they will help leverage the resources and creativity of the private sector to devise new applications and uses of the NII. The successes of the these pilot projects will create an iterative process that will generate more innovative approaches each year.

Action: Inventory NII Applications Projects. Many insights can be gained by sharing information about how government can effectively use the NII. By the 
end of January 1994, the IITF will complete an inventory of current and planned government activities and will widely disseminate the results through electronic and printed means. An electronic forum is being established to encourage government and private sector contributions and comments about government applications projects.

\section{- 4. Promote Seamless, Interactive, User-Driven Operation}

Because the NII will be a network of networks, information must be transferable over the disparate networks easily, accurately, and without compromising the content of the messages. Moreover, the NII will be of maximum value to users if it is sufficiently "open" and interactive so that users can develop new services and applications or exchange information among themselves, without waiting for services to be offered by the firms that operate the NII. In this way, users will develop new "electronic communities" and share knowledge and experiences that can improve the way that they learn, work, play, and participate in the American democracy.

To assure interoperability and openness of the many components of an efficient, high-capacity NII, standards for voice, video, data, and multi-media services must be developed. Those standards also must be compatible with the large installed base of communications technologies, and flexible and adaptable enough to meet user needs at affordable costs. The United States has long relied on a consensusbased, voluntary standards-setting process in communications. Particularly in the area of information and communications technology, where product cycles are often measured in months, not years, the standards process is critical and has not always worked to speed technological innovation and serve end-users well. Government can catalyze this industry-driven process by participating more actively in private-sector standards-writing bodies and by working with industry to address strategic technical barriers to interoperability and adoption of new technologies.

To increase the likelihood that the NII will be both interactive and, to a large extent, user-driven, government also must reform regulations and policies that may inadvertently hamper the development of interactive applications. For example, government regulations concerning the lack of reimbursement of health care procedures may deter the growth of distance medicine applications.

Action: Review and clarify the standards process to speed NII applications. By October 15, 1993 the Commerce Department's National Institute for Standards and Technology (NIST) will establish a panel and work with other appropriate agencies to review the government's involvement in establishing network requirements and standards with domestic and international partners. The panel, with input from the private sector and other levels of government, will consider the role of the government in the standards process and will identify opportunities for accelerating the deployment of the NII. 
Action: Review and reform government regulations that impede development of interactive services and applications. The Administration will work closely with the private sector, as well as state and local governments, to identify government policies and regulations that may hinder the growth of interactive services and applications. The IITF will determine how those regulations should be changed.

\section{- 5. Ensure Information Security and Network Reliability}

The trustworthiness and security of communications channels and networks are essential to the success of the NII. Users must be assured that information transmitted over the infrastructure will go when and where it is intended to go. Electronic information systems can create new vulnerabilities. For example, electronic files can be broken into and copied from remote locations, and cellular phone conversations can be monitored easily. Yet these same systems, if properly designed, can offer greater security than less advanced communications channels.

Through the use of information systems, gathering, sending, and receiving a wide variety of personal information is now simple, quick, and relatively inexpensive. The use of information technologies to access, modify, revise, repackage, and resell information can benefit individuals, but unauthorized use can encroach on their privacy. While media reports often emphasize the role of modern information technology in invading privacy, technology advances and enhanced management oversight also offer the opportunity for privacy protection. This protection is especially important to businesses that increasingly transmit sensitive proprietary data through electronic means. In a climate of tough global competitiveness to gain market advantage, the confidentiality of this information can spell the difference between business success or failure.

In addition, it is essential that the Federal government work with the communications industry to reduce the vulnerability of the nation's information infrastructure. The NII must be designed and managed in a way that minimizes the impact of accident or sabotage. The system must also continue to function in the event of attack or catastrophic natural disaster.

Action: Review privacy concerns of the NII. The IITF has developed a work plan to investigate what policies are necessary to ensure individual privacy, while recognizing the legitimate societal needs for information, including those of law enforcement. The IITF has also developed a work plan to investigate how the government will ensure that the infrastructure's operations are compatible with the legitimate privacy interests of its users.

Action: Review of encryption technology. In April, the President announced a thorough review of Federal policies on encryption technology. In addition, Federal agencies are working with industry to develop new technologies that protect the privacy of citizens, while enabling law enforcement agencies to continue to use court-authorized wiretaps to fight terrorism, drug rings, organized 
crime, and corruption. Federal agencies are working with industry to develop encryption hardware and software that can be used for this application.

Action: Work with industry to increase network reliability. The National Communications System brings together 23 Federal agencies with industry to reduce the vulnerability of the nation's telecommunications systems to accident, sabotage, natural disaster, or military attack. And the Federal Communications Commission has an industry and user Network Reliability Council to advise it on ensuring the reliability of the nation's commercial telecommunications networks. These efforts are increasingly important as the threat posed by terrorism and computing hacking grows. The NCS will continue its work and will coordinate with the IITF. In addition, the National Security Telecommunications Advisory Committee, which advises the President in coordination with the NCS, as well as the FCC's Network Reliability Council, will coordinate with and complement the work of the Advisory Council on the National Information Infrastructure.

\section{- 6. Improve Management of the Radio Frequency Spectrum}

Many of the dramatic changes expected from the development of the information infrastructure will grow out of advances in wireless technologies. The ability to access the resources of the NII at any time, from anywhere in the country, will be constrained, however, if there is inadequate spectrum available. To ensure that spectrum scarcity does not impede the development of the NII, the Administration places a high priority on streamlining its procedures for the allocation and use of this valuable resource.

Action: Streamline allocation and use of spectrum. The Administration is working with Congress to fully implement the spectrum management provisions of the Omnibus Budget and Reconciliation Act of 1993, to streamline government use of spectrum and to get spectrum to the public efficiently. These provisions will provide greater flexibility in spectrum allocation, including increased sharing of spectrum between private sector and government users, increased flexibility in technical and service standards, and increased choices for licensees in employing their assigned spectrum.

Action: Promote market principles in spectrum distribution. Further, the Administration will continue to support policies that place a greater reliance on market principles in distributing spectrum, particularly in the assignment process, as a superior way to apportion this scarce resource among the widely differing wireless services that will be a part of the NII. At the same time, the Administration will develop policies to ensure that entrepreneurs and small, rural, minority- and women-owned businesses are able to participate in spectrum auctions.

- 7. Protect Intellectual Property Rights 
Development of an advanced information infrastructure will create unprecedented market opportunities and new challenges for our world-preeminent media and information industries. The broad public interest in promoting the dissemination of information to our citizens must be balanced with the need to ensure the integrity of intellectual property rights and copyrights in information and entertainment products. This protection is crucial if these products -- whether in the form of text, images, computer programs, databases, video or sound recordings, or multimedia formats -- are to move in commerce using the full capability of the NII.

Action: Examine the adequacy of copyright laws. The IITF will investigate how to strengthen domestic copyright laws and international intellectual property treaties to prevent piracy and to protect the integrity of intellectual property. To ensure broad access to information via the NII, the IITF will study how traditional concepts of fair use should apply with respect to new media and new works.

Action: Explore ways to identify and reimburse copyright owners. The IITF will explore the need for standards for the identification of copyright ownership of information products in electronic systems (e.g., electronic headers, labels or signature techniques). The Task Force will also evaluate the need to develop an efficient system for the identification, licensing, and use of work, and for the payment of royalties for copyrighted products delivered or made available over electronic information systems.

\section{- 8. Coordinate with Other Levels of Governmental and With Other Bodies}

Domestic: Many of the firms that will likely participate in the NII are now subject to regulation by Federal, state, and local government agencies. If the information infrastructure is to develop quickly and coherently, there must be close coordination among the various government entities, particularly with respect to regulatory policy. It is crucial that all government bodies -- particularly Congress, the FCC, the Administration, and state and local governments -- work cooperatively to forge regulatory principles that will promote deployment of the NII.

Action: Seek ways to improve coordination with state and local officials. The IITF will meet with state and local officials to discuss policy issues related to development of the NII. The Task Force will also seek input from the private sector and non-federal agencies as it devises proposals for regulatory reform. The Administration is committed to working closely with state and local governments in developing its telecommunications policies.

International: The NII also will develop in the context of evolving global networks. Because customers typically demand that U.S. communications providers offer services on a global basis, it is critical that the infrastructure within this country can meet international, as well as domestic, requirements. 
Action: Open up overseas markets. The Administration has shown its willingness to work directly on behalf of U.S. firms to ensure that they have an equal opportunity to export telecommunications-related goods and services to potential overseas customers. For example, the Commerce Department is developing new export control policies governing computers and telecommunications equipment manufactured by U.S. firms. These changes will remove export restrictions on many of these products and permit U.S. manufacturers to enter new markets not previously available to them. The Administration will continue to work to open overseas markets for U.S. services and products.

Action: Eliminate barriers caused by incompatible standards. Equally important is the need to avoid trade barriers raised by incompatible U.S. and foreign standards or -- more subtly -- between the methods used to test conformance to standards. Through its participation in international standards committees, the Administration is working to eliminate or avert such barriers.

Action: Examine international and U.S. trade regulations. The IITF will coordinate the Administration's examination of policy issues related to the delivery of telecommunications services to and from the U.S., including claims by some U.S. companies that regulatory practices in foreign countries -- including denial of market access for U.S. carriers and the imposition of excessive charges for completing calls from the United States -- are harming the competitiveness of the industry and the costs charged to U.S. customers for service. The IITF also will reexamine U.S. regulation of international telecommunications services.

- 9. Provide Access to Government Information and Improve Government Procurement

Thomas Jefferson said that information is the currency of democracy. Federal agencies are among the most prolific collectors and generators of information that is useful and valuable to citizens and business. Improvement of the nation's information infrastructure provides a tremendous opportunity to improve the delivery of government information to the taxpayers who paid for its collection; to provide it equitably, at a fair price, as efficiently as possible.

The Federal government is improving every step of the process of information collection, manipulation, and dissemination. The Administration is funding research programs that will improve the software used for browsing, searching, describing, organizing, and managing information. But it is committed as well to applying those tools to the distribution of information that can be useful to the public in their various roles as teachers, researchers, businesspeople, consumers, etc.

The key questions that must be addressed are: What information does the public want? What information is in electronic form? By what means can it be 
distributed? How can all Americans have access to it? A secondary question is: How can government itself improve through better information management?

Action: Improve the accessibility of government information. IITF working groups will carefully consider the problems associated with making government information broadly accessible to the public electronically. Additionally, several inter-agency efforts have been started to ensure that the right information is stored and available. Finally, to help the public find government information, an interagency project has been formed to develop a virtual card catalogue that will indicate the availability of government information in whatever form it takes.

Action: Upgrade the infrastructure for the delivery of government information. The Federal government has already taken a number of steps to promote wider distribution of its public reports. Legislation has been enacted to improve electronic dissemination of government documents by the Government Printing Office. A number of Federal agencies have moved aggressively to convert their public information into electronic form and disseminate it over the Internet, where it will be available to many more people than have previously had access to such information. In the future, substantial improvements will be made to "FedWorld," an electronic bulletin board established by the Department of Commerce's National Technical Information Service (NTIS), which links the public with more than 100 Federal bulletin boards and information centers. These improvements will enhance FedWorld's ability to distribute to the public scientific, technical, and business-related information generated by the U.S. Government and other sources. Finally, a conference will be held in the Fall of 1993 to begin teaching Federal employees how they can use these distribution mechanisms.

Action: Enhance citizen access to government information. In June 1993, OMB prescribed new polices pertaining to the acquisition, use, and distribution of government information by Federal agencies. Among other things, the policies mandate that, in distributing information to the public, Federal agencies should recoup only those costs associated with the dissemination of that information, not with its creation or collection. Moreover, a number of inter-agency efforts are under way to afford greater public access to government information. One project seeks to turn thousands of local and field offices of various Federal agencies into Interactive Citizen Participation Centers, at which citizens can communicate with the public affairs departments of all Federal agencies.

Action: Strengthen inter-agency coordination through the use of electronic mail. To implement the National Performance Review's recommendation on expanded use of electronic mail within the Federal government, an inter- agency coordinating body has been established to incorporate electronic mail into the daily work environment of Federal workers. The group is also sponsoring three pilot projects to expand connectivity that will build a body of experience that other Federal agencies can draw on when they begin to use electronic mail. 
Action: Reform the Federal procurement process to make government a leadingedge technology adopter. The Federal government is the largest single buyer of high technology products. The government has played a key role in developing emerging markets for advanced technologies of military significance; it can be similarly effective for civilian technologies. The Administration will implement the procurement policy reforms set forth in the National Performance Review report.

\section{America's Destiny is Linked to our Information Infrastructure}

The principles and goals outlined in this document provide a blueprint for government action on the NII. Applying them will ensure that government provides constructive assistance to U.S. industry, labor, academia and private citizens as they develop, deploy and use the infrastructure.

The potential benefits for the nation are immense. The NII will enable U.S. firms to compete and win in the global economy, generating good jobs for the American people and economic growth for the nation. As importantly, the NII promises to transform the lives of the American people. It can ameliorate the constraints of geography and economic status, and give all Americans a fair opportunity to go as far as their talents and ambitions will take them. 


\section{APPENDIX E}

Online Survey Data Sample

\section{WPAs, Teachers, and Technological Literacy Survey}

\section{Survey Key: ZS16159}

\section{WPAs, Teachers, and Technological Literacy Survey \\ What Teachers and Writing Program Administrators Say About Computer-Mediated Writing Environments}

The purpose of this study is to gather essential information about how writing program administrators and teachers implement, use, and feel about their use of computers to teach writing. Armed with a picture of responses to the integration of technology into writing curricula, Writing Program Administrators and teachers can contextualize and assess their own uses of technology. Your participation is voluntary and you will not be identified. There is no payment for your participation; however, the knowledge gained from this survey may benefit others. This study is being conducted by Dr. Pamela Takayoshi and doctoral student Katherine Wills and is sponsored by the Department of English at the University of Louisville, KY. If you have questions or comments, please contact me at katherine.wills@louisville.edu (812.348.7215) or my dissertation director, Pam Takayoshi at pamT@louisville.edu. This survey should take 10 minutes to fill out.

\section{PLEASE ANSWER ALL THE FOLLOWING QUESTIONS ACCURATELY.}

1.Institutional Demographics. Is your institution public or private?

[46] Public

[14] Private

[1] Mixed

[0] Other

2.In what geographic region is your institution located? 
[10] Northeast

[6] Southeast

[27] Midwest

[5] Southern

[4] Southwestern

[0] Northern Plains

[8] West Coast

[0] Non-contiguous

3.How would you classify your institution?

[4] 2-year or Community

[19] 4-year-Bachelor

[0] Technical

[29] Research I-Doctoral

[8] Research II-6 year

4.How long have you directed or participated in a computer-mediated teaching/writing facility?

[0] Under a year

[13] 1-3 years

[23] 4-10 years

[15] 11-20 years

[2] Over 20 years

[6] I am not currently in a computer-mediated facility

[2] I have never been in a computer-mediated writing facility

5.What is the student enrollment of your institution?

[5] 2000 or fewer

[9] 2001-5000

[8] 5001-10,000

[27] $10,001-35,000$

[11] More than 35,000

6. What is your position in the department?

[37] Full-time, tenure-track composition faculty

[6] Full-time, tenure-track, non-composition faculty

[9] Non-tenure track lecturer, full-time

[1] Adjunct, part-time

[2] Staff

[5] Graduate Student

[1] Other

7.What is your rank?

[10] Professor

[13] Associate Professor

[19] Assistant Professor 
[8] Instructor-fulltime

[1] Adjunct or part-time

[7] Administrator

[5] Student

[2] Staff

8.Please use this text box to clarify demographic information.

[I am WPA at a Jesuit university in the Pacific Northwest, a private school with roughly 4,000 students ( 900 students per year in composition).]

[I'm new here (as of 9/3/03), hired as an Asst. Prof. of English to help enhance a writing minor (adding professional writing \& creative non-fiction) and an upcoming MA in Writing.]

[I don't know how broadly you define "computer-mediated teaching/writing faciltily" so my answers may be misleading.]

[Our school is a four-year, $\mathrm{PhD}$-granting institution, but I don't think we're classified as Research-I. Our mission calls for us to provide the "best undergraduate education" in the state, and the doctoral programs are seen as helping to support that mission. We are not the land-grant institution in our state.]

[I'm a WPA in charge of a large 2-semester FYComp program. I'm not working in a computer-mediated facility, but I supervise 96 instructors and TAs who teach in computer labs at least once a week.] [I'm not sure if I answered \#6 accurately; I am a member of the English department (we don't have a comp. dept.), and all of my teaching is composition-related.]

[I am full-time, renewable term and considered an assistant professor, nopt a lecturer. I am also the director of the writing program.]

[large metropolitan suburban university, majority commuter students, $28 \%$ NNS]

[large metropolitan suburban university, majority commuter students, $28 \%$ NNS]

[My institution is a former normal school, now offering B.A., M.A. and $\mathrm{Ph}$.D. in English. It would probably fit the description of Research II but goes through Ph.D. in our program. I'm qualified to teach composition but nearly all of my work involves technical writing.] [We have approximately 13,500 students. We offer an AA, a BA, BS, BT, MS, MAT, MFA, MA and various specialist degrees.]

[Texas Tech University]

[I am not now directing a computer lab or other facility. That may affect my responses below.]

[You entirely failed to provide a check box for schools in the Northwest, which is where I am responding from.]

[Some consider Arkansas "Southern." Others consider it "Southwestern." There was no position for "Tenured full-time."] 
[The majority of the campus student population is female, non-tradtional as well as traditional, with varying degrees of computer technology literacy.]

[I guess I'm closest to comp faculty, but at my institution, we don't define it this way. Technically, my area is rhetoric and composition.]

[Columbia College Chicago is an Open-Admissions arts and communications

college. We're located in the South Loop of Chicago. We have about 10 thousand undergrads and 3 thousand graduate students]

[I am officially assistant professor of technical communication, although I teach quite a bit of comp. I just wanted you to know why I checked "non-composition."]

[Also the Director of Tech for School of Liberal Arts and Sciences....]

[My college has no rank. I have a $\mathrm{PhD}$.]

[Approximately $30 \%$ Hispanic population]

[I'm at a research I, but on a regional campus. The overall enrollment for the university is over 35,000, but my campus has an enrollment of under 2000. You decide what number to check!]

[State Institution in the MidWest (R1D1).]

[My position is program director which is an academic line, but largely administrative.]

[My position is administrative/professional]

HOW IS YOUR POSITION COMPENSATED?

TOTAL SHOULD BE $100 \%$.

$100 \% 80 \% 60 \% 40 \% 20 \% 0 \%$

9.Salary [38] [10] [6] [1] [0] [0]

10.Course Release [2] [1] [0] [4] [10] [8]

11.Consultation fees, hourly wages $[0][0][0][0][1][14]$

12.Department or university service workload [0] [0] [2] [0] [3] [13]

13.If you would like to clarify your method of compensation, please explain here. Include a percentage.

[I teach a $3 / 2$ load (rather than 3/3) and direct both the writing program and the writing lab.]

[For an additional, small stipend, I am the Asst. Director of the Honors Program.]

[I am Director of Composition, for which I receive one course release from a regular two-course load. Since research is an expectation, the course release amounts to $25 \%$ ]

[My position is $75 \%$ administrative, $25 \%$ instructional, so I don't technically have a "course release," but I teach only one course/semester although the standard load in our dept is $3 / 2$.] [I don't understand the above question; I receive a salary, teach fewer courses than my non-WPA colleagues, but, like them, am expected to do 
university service. However, there is a blur between WPA work and college service.]

[Courseload reduction for coordinating program]

[Additional tuition remission and portion of health insurance - 20\%]

[The figures above are not completely accurate since $100 \%$ of my salary

is paid by the college while I am granted course release for my

administrative duties. I am on a $66 \%$ teaching schedule and a $33 \%$

reassigned time as program director.]

[I'm compensated by salary, and I get a $2 / 2$ course reduction for working as WPA (out of $4 / 4$ load). My work ratios officially are supposed to break down to $50 \%$ teaching, $30 \%$ administrative, $10 \%$ research, and $10 \%$ service.]

[I teach adjunct in addition to my full time professional advising position at the university.]

[Normal faculty load is $4 / 4$; graduate faculty have a $3 / 3$. Directors of the writing program have a $2 / 2$. We also get course releases for teaching 2 grad courses back to back; for directing a dissertation; and for other administrative type activities.]

[I'm not sure how to answer. I don't get adn extra salary or course release, but my position has a reduced teaching load figured into it from the get go. And of course, I'm talking about my WPA position, since I don't direct a computer facility.]

[I am full-time faculty, not a WPA. I teach courses in addition to computer-mediated ones.]

[I was not sure how to answer this. I am Acting Director of Composition. Our teaching load is normally $4 / 4$. In this position it is a $1 / 2$. When I am not Acting Director, I am the Coordinator of Technology and Pedagogy for the English Department and the load is 3/3.] [I receive a full salary plus course release time.] [I assume you mean the WPA part of my position?] [I am supposed to receive a course release for the position. The position went uncompensated for 2 years and in the 3 rd year I received 1 course release when I was supposed to receive 2 . So far this year there are to be no course releases because we simply don't have the staff to cover it.]

[This question isn't quite clear to me. I don't receive any specific compensation for course release ... but I am released from 3 courses per semester: 1 as grad faculty, 2 as WPA.]

[I am a program coordinator and get one course release per academic year. Tenure track faculty teach 3 courses each semester.]

[I am reassigned $50 \%$ for administration.]

HOW MUCH EFFORT HAVE YOU PUT INTO THE FOLLOWING TECHNOLOGY-RELATED

INITIATIVES?

CHECK ALL THAT APPLY TO THE DEGREE THAT THEY APPLY. 
No Effort Minimal Effort Some Effort Considerable Substantial Effort Major Effort

14.Purchasing or investigating hardware or software related to writing and technology [10] [9] [20] [8] [8] [5]

15.Participating in business and community partnering, service projects related to writing and technology [35] [9] [10] [3] [1] [0]

16.Developing curricula related to writing and technology [2] [2] [12] [14] [14] [16]

17.Developing faculty or motivating colleagues regarding technology and writing [4] [6] [11] [18] [11] [9]

18.Securing funding or grants for technology-related projects or teaching related to technology [18] [7] [18] [6] [7] [5]

19.Participating in technology workshops, conferences, events at the institutional, local, or national level [3] [8] [14] [10] [11] [14]

20.Implementing pedagogical changes that relate to technology and writing [1] [6] [4] [12] [18] [18]

21.Helping students access or use technology in order to meet their writing needs [1] [4] [8] [14] [15] [19]

22.Managing students, grad students, TAs, staff, and colleagues regarding technology [13] [10] [9] [10] [12] [7]

23.Modifying course curricula so as to include a technology component [1] [7] [11] [13] [12] [17] 


\section{CURRICULUM VITA}

Katherine V. Tsiopos Wills was born in St. Louis, Missouri, on September 30, 1957 to Vasilios Tsiopos and Kalliope Stratos Tsiopos. She attended St. Louis University City Elementary School and graduated from Afton High School in St. Louis County in 1976. She completed a Bachelor of Arts degree with majors in English and Anthropology at Washington University, St. Louis, Missouri. She was then offered an allied health internship to study Histologic technique in Chicago, Illinois, at St. Joseph Hospital in Lincoln Park. From 1981 through 1986 she was employed as a biomedical research assistant at Chicago University and Northwestern University Medical Centers.

In 1987 Katherine and her spouse, Howard Wills moved to Brown County Indiana, adjacent to the Indiana University in Bloomington, Indiana, where they owned a nautical home décor boutique in the arts colony of Nashville, Indiana. Katherine completed her Masters degree in Writing at Indiana University in 1991. She wrote a poetry thesis titled "Lost Atlantis" under the tutelage of Yusef Komunyakaa.

In 1997 Katherine began work toward the Ph.D. in English (Rhetoric and Composition) at the University of Louisville, where she taught as a graduate 
teaching assistant and acted as both Assistant Coordinator of Computer Assistant Instruction and Writing Across the Curriculum. 